\title{
Nail to Nail Fingerprint Challenge Prize Analysis
}

\author{
Gregory Fiumara \\ Elham Tabassi \\ Patricia Flanagan \\ John Grantham \\ Kenneth Ko \\ Karen Marshall \\ Matthew Schwarz \\ Bryan Woodgate \\ Christopher Boehnen
}

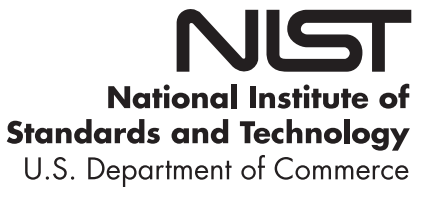


NISTIR 8210

\title{
Nail to Nail Fingerprint Challenge Prize Analysis
}

\author{
Gregory Fiumara \\ Elham Tabassi \\ Patricia Flanagan \\ Kenneth Ko \\ Karen Marshall \\ Bryan Woodgate \\ Information Access Division \\ Information Technology Laboratory \\ John Grantham \\ Systems Plus, Inc. \\ Matthew Schwarz \\ Schwarz Forensic Enterprises \\ Christopher Boehnen \\ Intelligence Advanced Research Projects Activity
}

This publication is available free of charge from:

https://doi.org/10.6028/NIST.IR.8210

April 2018

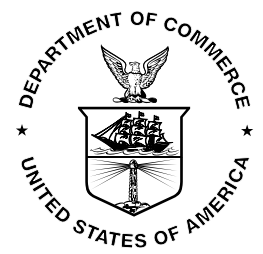

U.S. Department of Commerce Wilbur L. Ross, Jr., Secretary

National Institute of Standards and Technology Walter Copan, NIST Director and Under Secretary of Commerce for Standards and Technology 


\begin{abstract}
In September 2017, the Intelligence Advanced Research Projects Activity held a fingerprint data collection as part of the Nail to Nail Fingerprint Challenge. Participating Challengers deployed devices designed to collect an image of the full nail to nail surface area of a fingerprint - equivalent to a rolled fingerprint - from an unacclimated user without assistance from a trained device operator. Images captured from these devices were searched against a set of traditionally-captured operator-assisted rolled fingerprints. Thousands of latent fingerprints were also searched against the images.
\end{abstract}

\title{
Key words
}

acquisition; biometrics; capture devices; data; fingerprints; latent; prototypes; rolled; sensors.

\section{Published Images}

All friction ridge images depicted within this report come from study participants of the Nail to Nail Fingerprint Challenge. All study participants consented to the publication and release of images of their friction ridges and were compensated for their participation. Collection of these images was overseen by both the Johns Hopkins Medicine Institutional Review Board (IRB00138363) and the National Institute of Standards and Technology Institutional Review Board (ITL-17-0028b, ITL-17-0028c). Publication and use of the images in this report was overseen by the National Institute of Standards and Technology Human Subjects Protection Office (ITL-17-0013). Refer to Section 3.2 for more information.

\section{Disclaimer}

Certain commercial equipment, instruments, or materials are identified in this document in order to specify the development procedure adequately. Such identification is not intended to imply recommendation or endorsement by the National Institute of Standards and Technology, nor is it intended to imply that the materials or equipment identified are necessarily the best available for the purpose. 


\section{Table of Contents}

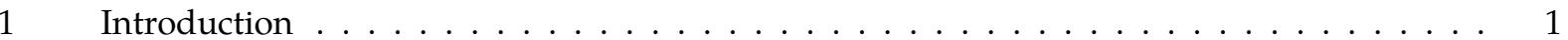

Nail to Nail Fingerprint Challenge . . . . . . . . . . . . . . . . . . . . . . 2

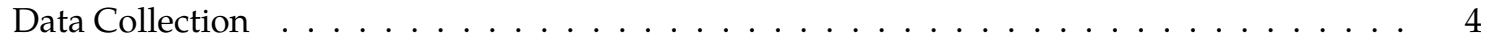

Data - Nail to Nail . . . . . . . . . . . . . . . . . . . . . 8

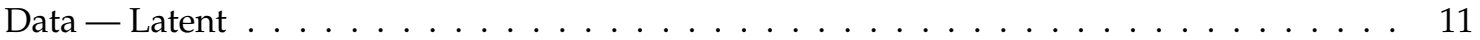

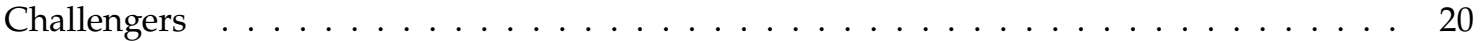

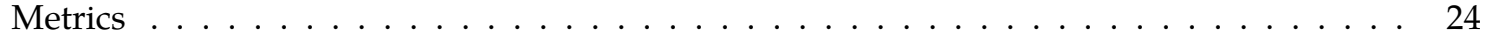

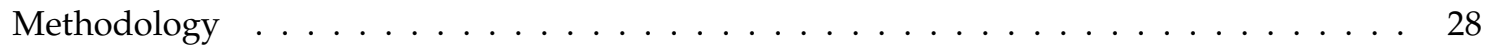

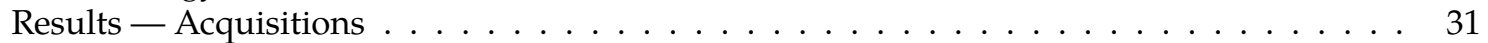

Results — Nail to Nail Identification . . . . . . . . . . . . . . . . . . . . . . . . 34

Results — Latent Identification . . . . . . . . . . . . . . . . . . . . . . . 37

References . . . . . . . . . . . . . . . . . . . . . . 42

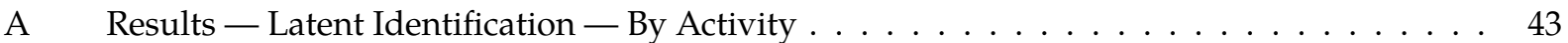

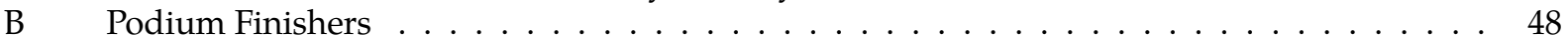

C Public Data . . . . . . . . . . . . . . . . . . . . . . . . . . . 49

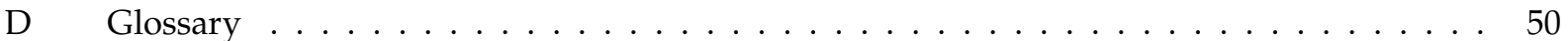

\section{List of Tables}

Nail to Nail Fingerprint Challenge Prizes . . . . . . . . . . . . . . . . . . 3

Study Participant Population $\ldots \ldots \ldots \ldots \ldots \ldots$

Auxiliary Capture Devices . . . . . . . . . . . . . . . . . . . . . . . . 6

Median Acquisition Time and Timing Metric . . . . . . . . . . . . . . . . . 33

5 Nail to Nail Identification - False Negative Identification Rate at a False Positive Identifi-

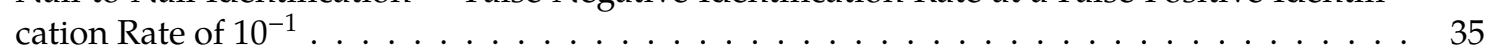

$6 \quad$ Nail to Nail Identification - Cumulative Match Characteristic - Rank $1 \ldots$. . . . . . . 36

7 Latent Identification - False Negative Identification Rate at a False Positive Identification

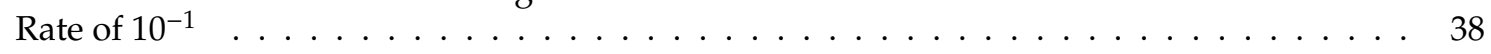

$8 \quad$ Latent Identification - Cumulative Match Characteristic - Ranks 1, 5, and 10 . . . . . 39

9 Latent Identification - False Negative Identification Rate at a False Positive Identification Rate of $10^{-1}$ - By Activity . . . . . . . . . . . . . . . . . . . . . 43

10 Latent Identification - Cumulative Match Characteristic - Rank 1 - By Activity _ . . . 45

11 Latent Identification — Data Breakdown . . . . . . . . . . . . . . . . . . 47

12 National Institute of Standards and Technology Fingerprint Image Quality 2.0 Values . . . . 48

\section{List of Figures}

Plain and Nail to Nail Impressions $\ldots \ldots \ldots \ldots \ldots \ldots \ldots$

Definition of Moderate . . . . . . . . . . . . . . . . . . . . . 2

Timeline of Nail to Nail Fingerprint Challenge Events . . . . . . . . . . . . . . . . . 3

Image Centering Example . . . . . . . . . . . . . . . . . . . . . . 9

Image Flopping Example . . . . . . . . . . . . . . . . . . . . . . . . . 9

Examples of Developed Latent Activities - Black Powder . . . . . . . . . . . . . . . . . . 14

Examples of Developed Latent Activities — Chemical . . . . . . . . . . . . . . . . . . . 15

Comparison of Digital Camera and FSIS Digitization . . . . . . . . . . . . . . . . . 17

Picture of Glass from Latent Collection . . . . . . . . . . . . . . . . . . . . . . . . . . . . . . 19

Examples of Challenger Captures . . . . . . . . . . . . . . . . . . . . . . . . 22

Examples of Challenger Captures with Minutia . . . . . . . . . . . . . . . . . . . 23

Example of Latent Print Cropped after Development with Minutia . . . . . . . . . . . . . 28

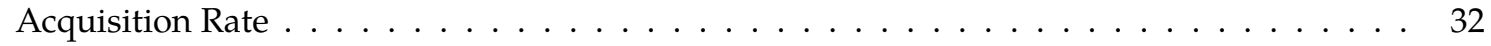

Acquisition Time . . . . . . . . . . . . . . . . . . . . . . . 33

15 Nail to Nail Identification - Detection Error Tradeoff $\ldots \ldots \ldots \ldots \ldots$ 
16 Nail to Nail Identification - Cumulative Match Characteristic . . . . . . . . . . . . 36

17 Latent Identification — Detection Error Tradeoff . . . . . . . . . . . . . . . . . . . . . . . . 38

18 Latent Identification - Cumulative Match Characteristic . . . . . . . . . . . . . . . . . . . . 39

19 Latent Identification — Detection Error Tradeoff — By Activity . . . . . . . . . . . . . . . . 44

20 Latent Identification - Cumulative Match Characteristic - By Activity . . . . . . . . 46 


\section{Executive Summary}

Overview The National Institute of Standards and Technology (NIST) conducted data analysis on fingerprint images acquired during the fingerprint data collection portion of the Nail to Nail Fingerprint Challenge ${ }^{1}$, an Intelligence Advanced Research Projects Activity (IARPA) Prize Challenge. The Challenge was conducted to assess the feasibility of creating a fingerprint sensor that produces high-quality rolledequivalent, or nail to nail (N2N), fingerprint images, without relying on a trained device operator. IARPA used the analysis presented in this report to award the winners of the Challenge.

Motivation Capturing a high-quality rolled fingerprint image is a difficult task that traditionally has always required the use of a trained device operator. The operator physically holds a subject's finger and repeatedly rolls it on a live scan platen until a high-quality image is produced. This can be an expensive and time consuming task, and may additionally make the subject feel uncomfortable. Because of this, many organizations that require fingerprinting resort to capturing plain fingerprint impressions. Compared to N2N impressions, plain impressions capture a limited region of the finger, resulting in less information being made available for searching with automated fingerprint identification algorithms. This lack of searchable information is especially detrimental in forensic applications, because latent fingerprints found at crime scenes are sometimes formed from areas of the finger not imaged by a plain impression. The development of an acquisition device that can quickly capture a high-quality and complete N2N representation of a finger will encourage use from organizations by promoting greater identification accuracy and a higher respect for the subject.

Challenge Eight organizations - comprised of both industry and academia - were selected as finalists, and invited to participate in a fingerprint data collection to exercise their devices. Fingerprint images from 331 study participants captured with the Challenger's devices during the fingerprint data collection were provided to NIST, along with traditionally-captured N2N exemplars. Tens of thousands of latent fingerprints were also developed from activities performed by the Challenge fingerprint data collection study participants. NIST searched Challenger fingerprint images and collected latent fingerprint images against an enrollment set of 29986091 rolled fingerprint images with an automated fingerprint identification algorithm and reported accuracy.

Winners Four prizes were awarded based on the data analysis performed by NIST. To be eligible for all prizes, Challengers had to capture fingerprint images from at least $90 \%$ of study participants within $8 \mathrm{~min}$.

\section{Speed Prize}

The Speed Prize was awarded to the Challenger achieving the fastest N2N acquisition time. This award was won by Advanced Optical Systems ${ }^{2}$. Second place was won by IDEMIA ${ }^{3}$ and third place was won by Touchless Biometric Systems ${ }^{4}$ (Section 9.3).

\section{Gallery Accuracy Prize}

The Gallery Accuracy Prize was awarded to the Challenger whose images were most accurately identified during the N2N identification portion of the Challenge. This award was won by Green Bit ${ }^{5}$. Second place was won by Jenetric ${ }^{6}$ and third place was won by IDEMIA ${ }^{3}$ (Section 10).

\section{Latent Accuracy Prize}

The Latent Accuracy Prize was awarded to the Challenger whose images resulted in the most accurate identifications during the latent identification portion of the Challenge. This award was won by Green

\footnotetext{
${ }^{1}$ https://challenge.gov/challenge/nail-to-nail-n2n-fingerprint-challenge

${ }^{2}$ https://aos-inc.com

${ }^{3}$ https://idemia.com

${ }^{4}$ https://tbs-biometrics.com

${ }^{5}$ http://greenbit.com

${ }^{6}$ https://jenetric.com
} 
Bit $^{5}$. Second place was won by Jenetric ${ }^{6}$ and third place was won by IDEMIA ${ }^{3}$ (Section 11). Results for second and third place relied on a tie-breaker (Appendix B).

\section{Grand Prize}

The Grand Prize was awarded to the Challenger with the best overall latent identification system. To qualify, Challengers had to capture images from $90 \%$ of study participants in under $3 \mathrm{~min}$ and achieve accuracy within $2 \%$ of the traditional N2N capture for both N2N and latent identification. Although Green Bit ${ }^{5}$ came the closest, their accuracy in N2N identification was not close enough to the traditional N2N capture's accuracy to qualify, and as such, this prize was not awarded (Appendix B).

Impact A goal of the Nail to Nail Fingerprint Challenge was to identify viable replacements for traditional operator-assisted rolled fingerprint capture by investigating acquisition speed and identification accuracy using fingerprint images captured on a device without an operator's physical intervention. In terms of speed, nearly all Challengers created a device capable of acquiring images as fast as or faster than a skilled device operator. However, in terms of accurate N2N identifications, only Green Bit performed similarly to the traditional capture method. The difference between first and second place in the Gallery Accuracy Prize was nearly ten percentage points. Although study participants had to perform the physical fingerprint capture themselves, Challengers were allowed to coach study participants and provide feedback and suggestions if the captured fingerprint was not of a good quality. For the purposes of the Nail to Nail Fingerprint Challenge, this technique is referred to as moderated capture.

Identification performance awarded in the Latent Accuracy Prize is inconclusive due to overall poor and unanticipated results (Section 11.1), including when latent prints are compared to images formed by the traditional operator-assisted capture method.

Additionally, there was no effort to quantify the difference in surface area between a fingerprint image captured with a Challenger device and a fingerprint image rolled by a skilled operator. The goal of the Nail to Nail Fingerprint Challenge was instead to produce a rolled-equivalent image - an image that performs as well as the traditional operator-assisted rolled image. By this definition, the only device that performed to the desired level was produced by Green Bit - a live scan device coupled with a "hands-off" operator that mimicked the rolling procedure and image quality checks of the traditional method. 


\section{Introduction}

In a traditional and controlled fingerprinting environment, there are primarily two representations in which a fingerprint impression can be captured. Using a plain or flat representation, a subject's finger is depressed straight down onto a flat surface, such as the platen of a live scan device or a fingerprint ink card, with the subject's fingernail facing up. Using the rolled representation, a subject's finger is oriented such that their fingernail is perpendicular to a flat surface. Their finger is slowly rolled on that flat surface until their fingernail is again perpendicular to the surface and facing the opposite direction. The rolled impression type is often called nail to nail (N2N) because it captures the surface area of a finger's distal phalanx from one edge of the fingernail to the other, ideally including the tip. Conversely, plain impressions can only capture the surface area on the palmar side of a finger's distal phalanx, omitting the sides and the tip. When searching fingerprints, the larger surface area of an $\mathrm{N} 2 \mathrm{~N}$ impression provides more information for the search than a plain impression. This is especially important when searching latent fingerprints, as the portion of the latent fingerprint being searched may be solely from an area not imaged by a plain impression. Fig. 1 shows the difference between a plain and $\mathrm{N} 2 \mathrm{~N}$ impression.
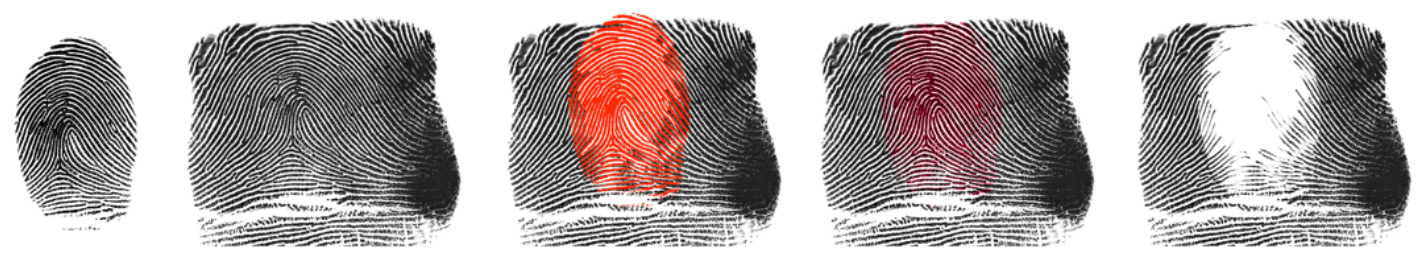

Fig. 1. An example of a plain (left) and rolled or N2N (second from left) impression of the same finger. In the middle, the plain impression is superimposed in red on the rolled impression. Areas of overlap in the rolled impression are highlighted in red in the image second from the right, and removed in the rightmost image. The N2N impression has more information available for searching.

Although they provide more detail, N2N fingerprints are more difficult to capture. A skilled operator is typically employed when capturing $\mathrm{N} 2 \mathrm{~N}$ impressions. The operator holds and controls the subject's finger throughout the capture process. Without an operator that knows how to examine a fingerprint for quality, it is common to produce motion blur (rolling too fast), smudges (non-uniform pressure), distortions (movement on the platen), or to simply not capture the entire desired finger surface area. Conversely, plain fingerprint impressions are often produced by subjects directly, achieving high quality plain representations without operator assistance.

Requiring a skilled operator in N2N fingerprint collection can constrain the feasibility, flexibility, and cost of collection in a number of scenarios, such as high-throughput environments like a port of entry. As such, many fingerprint collection environments forego collecting these more detailed fingerprints and instead opt for a simpler and more cost-effective plain impression.

\begin{tabular}{|c|c|c|c|c|c|c|c|c|c|}
\hline$\Omega$ & FBI Baseline & $\begin{array}{l}\mathrm{A} \\
\mathrm{E}\end{array}$ & $\begin{array}{l}\text { IDEMIA } \\
\text { Jenetric }\end{array}$ & $\begin{array}{l}\mathrm{B} \\
\mathrm{F}\end{array}$ & $\begin{array}{l}\text { Advanced Optical Systems } \\
\text { Touchless Biometric Systems }\end{array}$ & $\begin{array}{l}\mathrm{C} \\
\mathrm{G}\end{array}$ & $\begin{array}{l}\text { Green Bit } \\
\text { Crossmatch }\end{array}$ & $\begin{array}{l}\mathrm{D} \\
\mathrm{H}\end{array}$ & $\begin{array}{l}\text { Cornell University } \\
\text { Clarkson University }\end{array}$ \\
\hline $1 \mathrm{~A}$ & Peering Into Window & $1 \mathrm{~B}$ & Fist Banging on Glass & $1 \mathrm{C}$ & Fingertip Window Slide & 10 & Get-away Palm on Glass & $1 \mathrm{E}$ & “OK” Sign on Glass \\
\hline $1 \mathrm{~F}$ & Counter Vault on Glass & 16 & Cylinder Grab & $1 \mathrm{H}$ & Impatient Tapping on Glass & $2 \mathrm{~A}$ & Samsung Galaxy S5 & $2 \mathrm{~B}$ & Apple iPhone $5 \mathrm{~s}$ \\
\hline 3 & Check & $4 \mathrm{~A}$ & Lined Paper & $4 \mathrm{~B}$ & Low-quality Copy Paper & $4 \mathrm{C}$ & High-quality Copy Paper & $4 \mathrm{D}$ & Yellow Lined Paper \\
\hline $4 \mathrm{E}$ & Low-quality White Envelope & $4 \mathrm{~F}$ & Greeting Card and Envelope & $4 G$ & Manila Envelope & $5 \mathrm{~A}$ & Photo Paper & $5 B$ & Glossy Magazine \\
\hline $5 \mathrm{C}$ & U.S. Currency & $6 \mathrm{~A}$ & Stamp & $6 \mathrm{~B}$ & Address Label & $6 \mathrm{C}$ & Clear Packing Tape & $6 \mathrm{D}$ & Black Electrical Tape \\
\hline $6 \mathrm{E}$ & Duct Tape & $7 \mathrm{~A}$ & Circuit Board & $7 \mathrm{~B}$ & $\mathrm{CD} / \mathrm{DVD}$ & $7 \mathrm{C}$ & Clear Plastic Bag & $7 D$ & Black Plastic Bag \\
\hline
\end{tabular}




\section{Nail to Nail Fingerprint Challenge}

In an effort to reduce the burden of collecting N2N fingerprints and eliminate the fallback plan of solely collecting plain impressions, Intelligence Advanced Research Projects Activity (IARPA) held the first Nail to Nail Fingerprint Challenge in 2017. The Challenge aimed to identify N2N fingerprint capture solutions that could support high-quality live N2N capture without requiring the physical intervention of a human operator to roll a subject's finger. The participating solution could be newly-engineered fingerprint capture hardware, specialized software with existing fingerprint capture

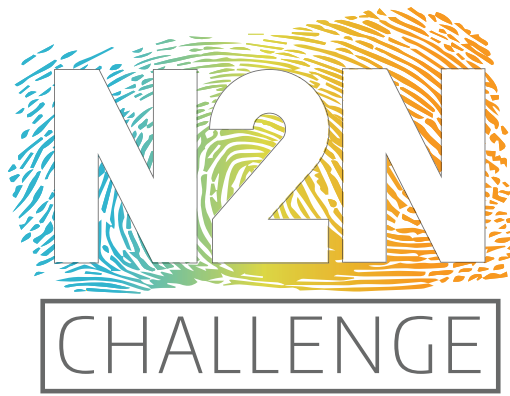
hardware, or anything else imaginable.

The Nail to Nail Fingerprint Challenge did not enforce complete autonomy for capture on the part of the subject. An operator could still be present to supervise, coach, and provide feedback to the subject towards them providing a high-quality N2N print, but could not physically touch the subject or instruct them to apply any sort of fingerprint matrix (e.g., lotion or natural oils from the forehead or ears). Per the definition in Fig. 2, the term moderated capture is used to define the level of capture assistance allowed.

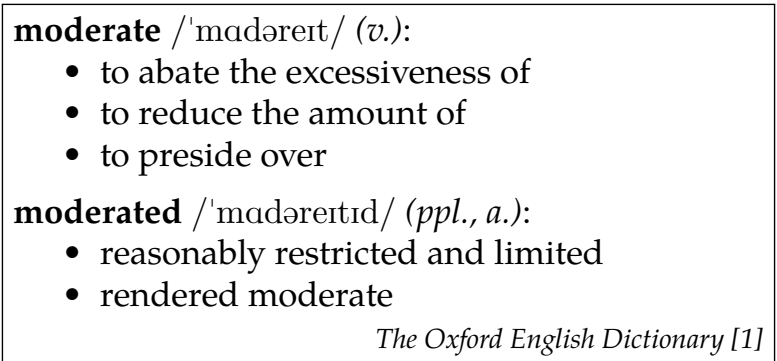

Fig. 2. The definition of moderate and moderated, according to The Oxford English Dictionary [1]. The term moderated capture is used to define the N2N capture technique allowed during the Nail to Nail Fingerprint Challenge. Challengers were allowed to provide instructions and feedback to study participants throughout the capture process, but were not permitted to touch them. This is a lesser version of a traditional N2N capture, where the study participant renders full control to an operator, but is not fully uncontrolled

The desired outcome of the Nail to Nail Fingerprint Challenge is for a collection device to be created that allows for better quality fingerprint data to be collected, while reducing the time and cost to operate a comparable rolled capture station. This outcome is a mutually beneficial scenario for fingerprint identification systems and organizations that require fingerprint capture.

\subsection{Participation}

Information about the Nail to Nail Fingerprint Challenge was made public in September 2016. In order to participate, potential Challengers needed to submit an abstract regarding their proposed N2N fingerprint capture solution. By July 2017, sample N2N fingerprint images captured by a Challenger's device were required to be submitted to a three-person United States Government (USG) judging panel, known as the $\mathrm{N} 2 \mathrm{~N}$ Judging Committee, along with a video recording of the device in operation. The N2N Judging Committee assessed the quality of the images and the content of the video, and used that information to select eight finalists. These finalists were invited to the Washington, D.C. metro area in September 2017 to participate in a live fingerprint data collection with their devices. Fingerprints captured from each of the Challenger's devices were compared to fingerprints captured with traditional operator-assisted methods. Latent fingerprints were also captured and searched against enrollment sets of Challenger-collected N2N images. A timeline of Nail to Nail Fingerprint Challenge events is presented in Fig. 3.

Throughout this report, Challengers are referred to by a letter code, A through H. A mapping for these codes can be found at the bottom of each page. The Greek letter Omega $(\Omega)$ represents the data captured using

\begin{tabular}{rlrl}
$\Omega$ & FBI Baseline & A & IDEMIA \\
& & Jenetric \\
\hline 1A & Peering Into Window & 1B & Fist Banging on Glass \\
1F & Counter Vault on Glass & 16 & Clinder Grab \\
3 & Check & 4A & Lined Paper \\
4E & Low-quality White Envelope & $4 \mathrm{~F}$ & Greeting Card and Envelope \\
$5 \mathrm{C}$ & U.S. Currency & 6A & Stamp \\
6E & Duct Tape & $7 \mathrm{~A}$ & Circuit Board
\end{tabular}

Advanced Optical Systems
Touchless Biometric Systems
Fingertip Window Slide
Impatient Tapping on Glass
Low-quality Copy Paper
Manila Envelope
Address Label
CD/DVD

Green Bit
Crossmatch
Get-away Palm on Glass
Samsung Galaxy S5
High-quality Copy Paper
Photo Paper
Clear Packing Tape
Clear Plastic Bag

Cornell University Clarkson University "OK" Sign on Glass Apple iPhone 5s Glossy Magazine Black Electrical Tap Black Plastic Bag 


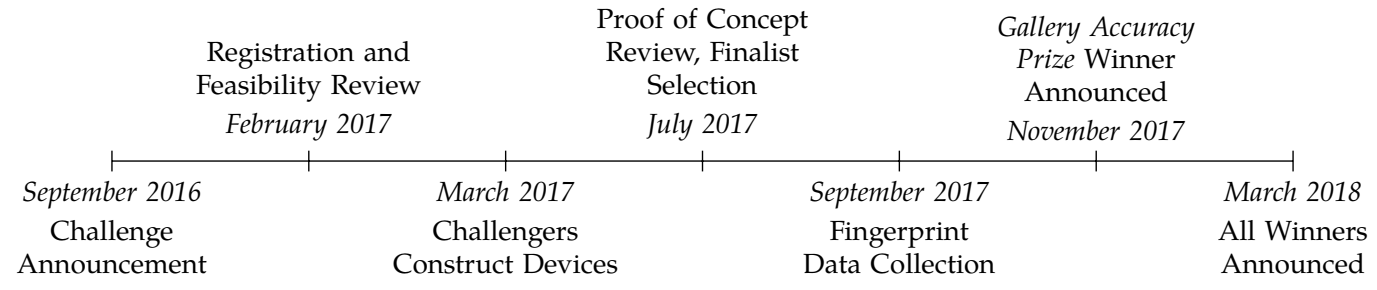

Fig. 3. Timeline of Nail to Nail Fingerprint Challenge events. Challengers worked on their devices for at most one year.

traditional operator-assisted techniques.

\subsection{Prizes}

There were several monetary prizes eligible to win in the Nail to Nail Fingerprint Challenge. For most prizes, the fingerprints captured by the Challenger's device had to perform comparably to the traditional operator-assisted fingerprints in various aspects, such as capture speed and identification accuracy. The complete list of prizes is recorded in Table 1. If there was no winner for a prize, at the discretion of the N2N Judging Committee, the award for that prize could be used to honor second and third place finishers for a different prize.

For an official list of winners, please refer to the official IARPA Nail to Nail Fingerprint Challenge website, https://challenge.gov/challenge/nail-to-nail-n2n-fingerprint-challenge.

\begin{tabular}{|c|c|c|}
\hline Prize & Criteria & Constraints \\
\hline $\begin{array}{l}\text { Grand Prize } \\
\$ 100000\end{array}$ & $\begin{array}{l}\text { Best latent } \\
\text { identification system }\end{array}$ & $\begin{array}{l}\text { - } \geq 90 \% \text { of data captured } \\
\text { - Acquisition time } \leq 120 \% \text { of } \Omega \\
\text { ( } \leq 172.8 \text { s, per Table } 4) \\
\text { - N2N matching FNIR within } 2 \% \text { of } \Omega \\
\text { - Latent matching FNIR within } 2 \% \text { of } \Omega\end{array}$ \\
\hline $\begin{array}{l}\text { Gallery Accuracy Prize } \\
\$ 25000\end{array}$ & $\begin{array}{l}\text { Best N2N } \\
\text { identification } \\
\text { performance }\end{array}$ & $\begin{array}{l}\text { - } \geq 90 \% \text { of data captured } \\
\text { - All data acquired in } \leq 8 \text { min }\end{array}$ \\
\hline $\begin{array}{l}\text { Latent Accuracy Prize } \\
\$ 25000\end{array}$ & $\begin{array}{l}\text { Best latent } \\
\text { identification } \\
\text { performance }\end{array}$ & $\begin{array}{l}\text { - } \geq 90 \% \text { of data captured } \\
\text { - All data acquired in } \leq 8 \mathrm{~min}\end{array}$ \\
\hline $\begin{array}{l}\text { Speed Prize } \\
\$ 25000\end{array}$ & $\begin{array}{l}\text { Fastest } \mathrm{N} 2 \mathrm{~N} \\
\text { acquisition }\end{array}$ & $\begin{array}{l}\text { - } \geq 90 \% \text { of data captured } \\
\text { - Latent matching FNIR within } 80 \% \text { of } \Omega\end{array}$ \\
\hline $\begin{array}{l}\text { Print Provider Prize }(\times 8) \\
\$ 8000\end{array}$ & $\begin{array}{l}\text { Providing data to } \\
\text { share with the public }\end{array}$ & $\begin{array}{l}\text { - Captured data from the live test must } \\
\text { be made public domain }\end{array}$ \\
\hline $\begin{array}{l}\text { Master Builder Prize }(\times 8) \\
\$ 2000\end{array}$ & $\begin{array}{l}\text { Invited to fingerprint } \\
\text { collection }\end{array}$ & $\begin{array}{l}\text { - Participation in September } 2017 \\
\text { fingerprint data collection }\end{array}$ \\
\hline
\end{tabular}

Table 1. A description of the eligibility criteria for prizes available to be awarded by IARPA in the Nail to Nail Fingerprint Challenge.

\begin{tabular}{|c|c|c|c|c|c|c|c|c|c|}
\hline$\Omega$ & FBI Baseline & $\begin{array}{l}A \\
E\end{array}$ & $\begin{array}{l}\text { IDEMIA } \\
\text { Jenetric }\end{array}$ & $\begin{array}{l}\text { B } \\
F\end{array}$ & $\begin{array}{l}\text { Advanced Optical Systems } \\
\text { Touchless Biometric Systems }\end{array}$ & $\begin{array}{l}\mathrm{C} \\
\mathrm{G}\end{array}$ & $\begin{array}{l}\text { Green Bit } \\
\text { Crossmatch }\end{array}$ & $\begin{array}{l}\mathrm{D} \\
\mathrm{H}\end{array}$ & $\begin{array}{l}\text { Cornell University } \\
\text { Clarkson University }\end{array}$ \\
\hline $1 \mathrm{~A}$ & Peering Into Window & $1 \mathrm{~B}$ & Fist Banging on Glass & 1C & Fingertip Window Slide & $1 \mathrm{D}$ & Get-away Palm on Glass & $1 \mathrm{E}$ & "OK" Sign on Glass \\
\hline $1 \mathrm{~F}$ & Counter Vault on Glass & 16 & Cylinder Grab & $1 \mathrm{H}$ & Impatient Tapping on Glass & $2 \mathrm{~A}$ & Samsung Galaxy S5 & $2 \mathrm{~B}$ & Apple iPhone $5 \mathrm{~s}$ \\
\hline 3 & Check & $4 \mathrm{~A}$ & Lined Paper & $4 \mathrm{~B}$ & Low-quality Copy Paper & $4 \mathrm{C}$ & High-quality Copy Paper & 4D & Yellow Lined Paper \\
\hline $4 \mathrm{E}$ & Low-quality White Envelope & $4 \mathrm{~F}$ & Greeting Card and Envelope & $4 G$ & Manila Envelope & $5 \mathrm{~A}$ & Photo Paper & $5 B$ & Glossy Magazine \\
\hline $5 \mathrm{C}$ & U.S. Currency & $6 \mathrm{~A}$ & Stamp & $6 \mathrm{~B}$ & Address Label & $6 \mathrm{C}$ & Clear Packing Tape & $6 \mathrm{D}$ & Black Electrical Tape \\
\hline $6 \mathrm{E}$ & Duct Tape & $7 \mathrm{~A}$ & Circuit Board & $7 \mathrm{~B}$ & CD/DVD & $7 \mathrm{C}$ & Clear Plastic Bag & $7 D$ & Black Plastic Bag \\
\hline
\end{tabular}




\section{Data Collection}

\subsection{Facility}

Johns Hopkins University Applied Physics Laboratory (JHU APL) was chosen by IARPA as the host facility for the Nail to Nail Fingerprint Challenge. From 18-21 September 2017, N2N test staff and Challengers transformed much of the Intelligent Systems Center at JHU APL into a secure area for performing a fingerprint data collection. The facility is a typical airport style environment, with climate control, high ceilings, and fluorescent lighting. There were no windows in the facility. All Challengers were located in the same room, and as such, environmental factors for all Challengers were uniform.

\subsection{Institutional Review Board}

Before any analysis of the performance of Challenger devices could be performed, fingerprint images from a number of human subjects needed to be collected. Such a collection of human subject data is bound by a rule of ethics known as the Common Rule. All data collected and distributed under the Nail to Nail Fingerprint Challenge has been approved separately by Institutional Review Boards (IRBs) associated with National Institute of Standards and Technology (NIST) and JHU APL. The analysis and public distribution of the coded data was approved by the NIST Human Subjects Protection Office. All study participants consented to reproduction of images of their friction ridges captured during the Nail to Nail Fingerprint Challenge.

\subsection{Study Participant Pool}

study participants were recruited by a third-party recruitment company on behalf of JHU APL. study participants were required to have all 10 fingers imaged. Those with any amputated or bandaged fingers when arriving for the fingerprint data collection were excluded. Study participants were required to be able to speak, read, and understand the English language, and have full mobility in their fingers, arms, and wrists. They also needed the ability to stand for the duration of the fingerprint data collection, though in practice, study participants were permitted to sit down between capture stations. Additionally, many Challengers preferred that the study participants sit down during fingerprint acquisition. Breakdowns of study participant self-reported ages, genders, races, and occupations can be found in Table 2.

\subsection{Baseline Data}

study participants needed to have their fingerprints captured using the traditional operator-assisted technique in order to quantify the performance of the Challenger devices. IARPA invited members of the Federal Bureau of Investigation (FBI) Biometric Training Team to the fingerprint data collection to perform this task. Each study participant had N2N fingerprint images captured using the traditional operator-assisted rolled technique twice, each by a different FBI expert. This resulted in two N2N baseline datasets, referred to as Baseline Data, that could be used as a comparison against the Challengers.

To ensure the veracity of recorded N2N finger positions for Baseline Data, as would be necessary in order to make accurate comparisons (Section 4.2), N2N test staff also captured plain fingerprint impressions in a 4-4-2 slap configuration. This capture method refers to simultaneously imaging the index, middle, ring, and little fingers on the right hand (4), then repeating the process on the left hand (4), and finishing with the simultaneous capture of the left and right thumbs (2). This technique is a best practice to ensure finger sequence order, since it is physically challenging for a study participant to change the ordering of fingers when imaging them simultaneously.

Operators at both N2N Baseline Data stations and the slap station were given at most 5 min with the study participant, totaling $15 \mathrm{~min}$ of collection time dedicated to establishing a baseline.

\begin{tabular}{|c|c|c|c|c|c|c|c|c|c|}
\hline$\Omega$ & FBI Baseline & $\begin{array}{l}A \\
E\end{array}$ & $\begin{array}{l}\text { IDEMIA } \\
\text { Jenetric }\end{array}$ & $\begin{array}{l}\mathrm{B} \\
\mathrm{F}\end{array}$ & $\begin{array}{l}\text { Advanced Optical Systems } \\
\text { Touchless Biometric Systems }\end{array}$ & $\begin{array}{l}c \\
G\end{array}$ & $\begin{array}{l}\text { Green Bit } \\
\text { Crossmatch }\end{array}$ & $\stackrel{D}{H}$ & $\begin{array}{l}\text { Cornell University } \\
\text { Clarkson University }\end{array}$ \\
\hline 1A & Peering Into Window & $1 \mathrm{~B}$ & Fist Banging on Glass & $1 \mathrm{c}$ & Fingertip Window Slide & 1D & Get-away Palm on Glass & $1 \mathrm{E}$ & “OK” Sign on Glass \\
\hline $1 \mathrm{~F}$ & Counter Vault on Glass & $1 \mathrm{G}$ & Cylinder Grab & $1 \mathrm{H}$ & Impatient Tapping on Glass & $2 \mathrm{~A}$ & Samsung Galaxy S5 & $2 \mathrm{~B}$ & Apple iPhone $5 \mathrm{~s}$ \\
\hline 3 & Check & $4 \mathrm{~A}$ & Lined Paper & $4 B$ & Low-quality Copy Paper & 4C & High-quality Copy Paper & 4D & Yellow Lined Paper \\
\hline $4 \mathrm{E}$ & Low-quality White Envelope & $4 \mathrm{~F}$ & Greeting Card and Envelope & 46 & Manila Envelope & $5 \mathrm{~A}$ & Photo Paper & $5 B$ & Glossy Magazine \\
\hline $5 c$ & U.S. Currency & $6 \mathrm{~A}$ & Stamp & $6 \mathrm{~B}$ & Address Label & $6 \mathrm{C}$ & Clear Packing Tape & $6 \mathrm{D}$ & Black Electrical Tape \\
\hline $6 \mathrm{E}$ & Duct Tape & $7 \mathrm{~A}$ & Circuit Board & $7 \mathrm{~B}$ & $\mathrm{CD} / \mathrm{DVD}$ & 7c & Clear Plastic Bag & $7 \mathrm{D}$ & Black Plastic Bag \\
\hline
\end{tabular}




\begin{tabular}{|c|c|c|c|c|c|c|}
\hline Age Range & Percentage & \multirow[b]{3}{*}{ Gender } & & \multirow[b]{2}{*}{ Race } & \multirow{2}{*}{\multicolumn{2}{|c|}{ Percentage }} \\
\hline \multirow{8}{*}{$\begin{array}{l}18 \text { to } 24 \\
25 \text { to } 29 \\
30 \text { to } 39 \\
40 \text { to } 49 \\
50 \text { to } 59 \\
60 \text { to } 69 \\
70 \text { to } 79 \\
80 \text { to } 89\end{array}$} & $11.8 \%$ & & \multirow[b]{2}{*}{ Percentage } & & & \\
\hline & $14.2 \%$ & & & \multirow{3}{*}{\multicolumn{2}{|c|}{$\begin{array}{l}\text { Asian } \\
\text { Pacific Islander }\end{array}$}} & $19.3 \%$ \\
\hline & $23.0 \%$ & \multirow{4}{*}{$\begin{array}{l}\text { Female } \\
\text { Male } \\
\text { No Answer } \\
\end{array}$} & \multirow{4}{*}{$\begin{array}{r}64.7 \% \\
35.0 \% \\
0.3 \% \\
\end{array}$} & & & $7.6 \%$ \\
\hline & $24.2 \%$ & & & & & $0.6 \%$ \\
\hline & $22.3 \%$ & & & \multicolumn{2}{|c|}{ White } & $65.0 \%$ \\
\hline & $3.6 \%$ & & & \multirow{2}{*}{\multicolumn{2}{|c|}{$\begin{array}{l}\text { Other } \\
\text { No Answer }\end{array}$}} & $6.0 \%$ \\
\hline & $0.6 \%$ & & & & & $1.5 \%$ \\
\hline & $0.3 \%$ & & & \multicolumn{2}{|c|}{ No Answer } & \\
\hline & Employment Status & s Percentage & & & & \\
\hline & Disabled & $1.2 \%$ & & Employment Type & Percentage & \\
\hline & $\begin{array}{l}\text { Full-time } \\
\text { Homemaker }\end{array}$ & $\begin{array}{r}54.4 \% \\
8.2 \%\end{array}$ & & Manual Labor & $5.1 \%$ & \\
\hline & Part-time & $18.4 \%$ & & Office Work & $49.2 \%$ & \\
\hline & Retired & $3.9 \%$ & \multicolumn{2}{|c|}{ Other } & $37.5 \%$ & \\
\hline & Unemployed & $4.8 \%$ & \multirow{2}{*}{\multicolumn{2}{|c|}{ No Answer }} & $8.2 \%$ & \\
\hline & Other & $7.6 \%$ & & & & \\
\hline & No Answer & $1.5 \%$ & & & & \\
\hline
\end{tabular}

Table 2. Ages, genders, races, and occupations represented in the Nail to Nail Fingerprint Challenge study participant population, as reported by study participants.

\subsection{Challengers}

Each of the eight Challengers were supplied with a table, chairs, and an electrical power strip. Challenger tables were separated by sound-dampening panels. Challengers brought their fingerprint capture devices and any computer hardware and software necessary to perform fingerprint capture. All software, including any necessary to interact with the JHU APL facility Application Programming Interface (API) (Section 3.8), were written or procured by the Challenger.

Each Challenger was given at most $5 \mathrm{~min}$ with a study participant, totaling $40 \mathrm{~min}$ of collection time dedicated to Challengers. Challengers were allowed to process the data they captured after the study participant had left their station, but were required to finish processing all data by the time the facility closed for the evening.

For each study participant, Challengers were to submit an individual image for each finger usable with a commercial off-the-shelf (COTS) fingerprint identification system. Challengers could capture more than one finger at a time, but all images submitted through the JHU APL facility API had to depict a single finger per image only (Section 3.8).

All devices used in the fingerprint data collection underwent a safety review. JHU APL's device safety committee reviewed each device, examining the physical construction, mechanical operation, electrical systems, optical components, and other aspects with the potential to cause harm.

\subsection{Latent Fingerprints}

NIST partnered with the FBI and Schwarz Forensic Enterprises (SFE) to design activity scenarios in which subjects would likely leave latent fingerprints on different objects. The activities and associated objects described in Section 5.1 - were chosen in order to use a number of latent print development techniques and simulate the types of objects often found in real law enforcement case work.

SFE additionally conducted the latent print data collection for the Nail to Nail Fingerprint Challenge. Members of SFE instructed study participants to interact naturally with a variety of objects. SFE had $10 \mathrm{~min}$

\begin{tabular}{|c|c|c|c|c|c|c|c|c|c|}
\hline$\Omega$ & FBI Baseline & $\begin{array}{l}\text { A } \\
E\end{array}$ & $\begin{array}{l}\text { IDEMIA } \\
\text { Jenetric }\end{array}$ & $\begin{array}{l}\mathrm{B} \\
\mathrm{F}\end{array}$ & $\begin{array}{l}\text { Advanced Optical Systems } \\
\text { Touchless Biometric Systems }\end{array}$ & $\begin{array}{l}c \\
G\end{array}$ & $\begin{array}{l}\text { Green Bit } \\
\text { Crossmatch }\end{array}$ & $\begin{array}{l}\mathrm{D} \\
\mathrm{H}\end{array}$ & $\begin{array}{l}\text { Cornell University } \\
\text { Clarkson University }\end{array}$ \\
\hline $1 \mathrm{~A}$ & Peering Into Window & $1 \mathrm{~B}$ & Fist Banging on Glass & $1 \mathrm{C}$ & Fingertip Window Slide & 10 & Get-away Palm on Glass & $1 \mathrm{E}$ & "OK" Sign on Glass \\
\hline $1 \mathrm{~F}$ & Counter Vault on Glass & 16 & Cylinder Grab & $1 \mathrm{H}$ & Impatient Tapping on Glass & $2 \mathrm{~A}$ & Samsung Galaxy S5 & $2 \mathrm{~B}$ & Apple iPhone 5s \\
\hline 3 & Check & $4 \mathrm{~A}$ & Lined Paper & $4 \mathrm{~B}$ & Low-quality Copy Paper & $4 \mathrm{C}$ & High-quality Copy Paper & $4 \mathrm{D}$ & Yellow Lined Paper \\
\hline $4 \mathrm{E}$ & Low-quality White Envelope & $4 \mathrm{~F}$ & Greeting Card and Envelope & $4 \mathrm{G}$ & Manila Envelope & $5 \mathrm{~A}$ & Photo Paper & $5 \mathrm{~B}$ & Glossy Magazine \\
\hline $5 \mathrm{C}$ & U.S. Currency & $6 \mathrm{~A}$ & Stamp & $6 \mathrm{~B}$ & Address Label & $6 \mathrm{C}$ & Clear Packing Tape & $6 \mathrm{D}$ & Black Electrical Tape \\
\hline $6 \mathrm{E}$ & Duct Tape & $7 \mathrm{~A}$ & Circuit Board & $7 \mathrm{~B}$ & CD/DVD & $7 \mathrm{C}$ & Clear Plastic Bag & $7 D$ & Black Plastic Bag \\
\hline
\end{tabular}




\begin{tabular}{llll}
\hline Manufacturer & Model & Impression & Capture \\
\hline Crossmatch & Guardian USB & Plain & 4-4-2 slap \\
Crossmatch & L Scan 1000 & Plain & Upper, lower, and writer's palm \\
DigitalPersona & EikonTouch 710 & Plain & 10 individual fingers \\
Futronic & FS88 & Plain & 10 individual fingers \\
Green Bit & MultiScan 527g & Plain & Upper, lower, and writer's palm \\
MorphoTrust & TouchPrint 5300 & Plain & Upper, lower, and writer's palm \\
Michigan State University & RaspiReader & Plain & 10 individual fingers \\
\hline
\end{tabular}

Table 3. A list of auxiliary capture devices deployed during the Nail to Nail Fingerprint Challenge. The Make and Model columns show the make and model of the devices used. The Impression and Capture columns show what types of images were captured using the devices. Not all devices were deployed for all five days of the data collection. The Crossmatch L Scan 1000, MorphoTrust TouchPrint 5300, and Michigan State University RaspiReader were provided to IARPA without cost and returned after the Nail to Nail Fingerprint Challenge. All other devices were procured at market price by IARPA, JHU APL, or NIST. All auxiliary capture devices were operated by $\mathrm{N} 2 \mathrm{~N}$ test staff.

to interact with each study participant. Not every study participant performed every activity, but the activities were distributed such that each study participant performed activities with similar characteristics. There were three stations available for performing latent collection, with only two in use by study participants at any given time. The third station remained empty for $5 \mathrm{~min}$ while SFE staff completed black powder development and preparing for the next study participant.

\subsection{Other}

The facility at JHU APL was large enough to comfortably allow three latent collection stations, eight Challengers, and additional capture devices. Since the participants were already consented and paid for their time, additional friction ridge capture devices were deployed and operated by the N2N test staff. This allowed for additional traditionally-captured data to be made available to the public. A list of all additional devices is shown in Table 3.

An especially important auxiliary collection device provided for the capture of palm friction ridge data. During the latent collection activities, it was likely that palm prints would be left behind on objects. Capturing baseline exemplar palm data from all study participants added to the usefulness of the data collection.

\subsection{Application Programming Interface}

JHU APL developed an API, referred to as the JHU APL facility API, for Challengers to unify and simplify the process of transmitting fingerprint images from Challenger devices to the N2N backend server for later analysis by NIST. The JHU APL facility API allowed Challengers to send image data and associated metadata, including finger position, to the N2N backend server.

The JHU APL facility API also introduced a scheme for associating study participants with a Challenger device and their captured fingerprint images. Each study participant was given a wristband printed with a unique Quick Response (QR) code. Upon entering each station, a member of the N2N test staff would scan the study participant's wristband QR code, followed by a QR code identifying the Challenger. This triggered a unique identifier to be sent from the N2N backend server to the Challenger's fingerprint capture software and start their five min capture timer. Fingerprint acquisition times used to award the Speed Prize were calculated by subtracting the time of the QR code scan from the time of the final submission of fingerprint images for a given identifier/device combination.

Challengers were responsible for implementing the JHU APL facility API themselves, but JHU APL provided ample documentation and technical assistance. N2N test staff implemented the JHU APL facility API for baseline and other non-Challenger biometric devices.

\begin{tabular}{|c|c|c|c|c|c|c|c|c|c|}
\hline$\Omega$ & FBI Baseline & $\begin{array}{l}A \\
E\end{array}$ & $\begin{array}{l}\text { IDEMIA } \\
\text { Jenetric }\end{array}$ & $\begin{array}{l}\text { B } \\
F\end{array}$ & $\begin{array}{l}\text { Advanced Optical Systems } \\
\text { Touchless Biometric Systems }\end{array}$ & $\begin{array}{l}\mathrm{C} \\
\mathrm{G}\end{array}$ & $\begin{array}{l}\text { Green Bit } \\
\text { Crossmatch }\end{array}$ & $\begin{array}{l}\mathrm{D} \\
\mathrm{H}\end{array}$ & $\begin{array}{l}\text { Cornell University } \\
\text { Clarkson University }\end{array}$ \\
\hline $1 \mathrm{~A}$ & Peering Into Window & $1 \mathrm{~B}$ & Fist Banging on Glass & 1C & Fingertip Window Slide & $1 \mathrm{D}$ & Get-away Palm on Glass & $1 \mathrm{E}$ & "OK" Sign on Glass \\
\hline $1 \mathrm{~F}$ & Counter Vault on Glass & 16 & Cylinder Grab & $1 \mathrm{H}$ & Impatient Tapping on Glass & $2 \mathrm{~A}$ & Samsung Galaxy S5 & $2 \mathrm{~B}$ & Apple iPhone $5 \mathrm{~s}$ \\
\hline 3 & Check & $4 \mathrm{~A}$ & Lined Paper & $4 \mathrm{~B}$ & Low-quality Copy Paper & $4 \mathrm{C}$ & High-quality Copy Paper & 4D & Yellow Lined Paper \\
\hline $4 \mathrm{E}$ & Low-quality White Envelope & $4 \mathrm{~F}$ & Greeting Card and Envelope & $4 G$ & Manila Envelope & $5 \mathrm{~A}$ & Photo Paper & $5 B$ & Glossy Magazine \\
\hline $5 \mathrm{C}$ & U.S. Currency & $6 \mathrm{~A}$ & Stamp & $6 \mathrm{~B}$ & Address Label & $6 \mathrm{C}$ & Clear Packing Tape & $6 \mathrm{D}$ & Black Electrical Tape \\
\hline $6 \mathrm{E}$ & Duct Tape & $7 \mathrm{~A}$ & Circuit Board & $7 \mathrm{~B}$ & CD/DVD & $7 \mathrm{C}$ & Clear Plastic Bag & $7 D$ & Black Plastic Bag \\
\hline
\end{tabular}




\subsection{Flow}

Much care went into designing the way study participants flowed through the many fingerprint data acquisition stations. In total, study participants needed to make their way around to 16 stations (8 Challengers, 2 Baseline Data, 1 baseline slap, 1 latent, and 4 auxiliary) before they could leave.

study participants arrived at JHU APL in groups of 17 - one more subject than there were stations, to account for the duration of latent collection. In a separate room, a JHU APL IRB representative guided study participants through the informed consent process required before providing their friction ridge data. After all participants in a group were consented, they were escorted into the fingerprint data collection room. Inside, $\mathrm{N} 2 \mathrm{~N}$ test staff members would pair with each study participant and accompany them to their specified starting station. An announcement was made to begin QR code scanning, which started a five min timer. After five min, study participants had $30 \mathrm{~s}$ to move to the next station, where the process would repeat. study participants at the latent collection stations stayed in place for two consecutive rotations. When each 93 min round of fingerprint data collection had completed (15 fingerprint stations with $5 \mathrm{~min}$ durations, 1 latent station with a 10 min duration, and 15 transitions with $30 \mathrm{~s}$ durations), subjects were paid for their time and signed out of the facility.

On each day, (3 to 5) groups of 17 study participants would make their rounds in the facility. Each day, $\mathrm{N} 2 \mathrm{~N}$ test staff reversed the direction in which a study participant would move to the adjacent station, to reduce the affects of habituation formed by preceding devices. Additionally, half-way through the week, Challengers physically changed location of their stations. Where possible, care was taken to avoid putting devices that operated in a similar manner adjacent to each other.

\begin{tabular}{|c|c|c|c|c|c|c|c|c|c|}
\hline$\Omega$ & FBI Baseline & $\begin{array}{l}A \\
E\end{array}$ & $\begin{array}{l}\text { IDEMIA } \\
\text { Jenetric }\end{array}$ & $\begin{array}{l}\mathrm{B} \\
\mathrm{F}\end{array}$ & $\begin{array}{l}\text { Advanced Optical Systems } \\
\text { Touchless Biometric Systems }\end{array}$ & $\begin{array}{l}c \\
G\end{array}$ & $\begin{array}{l}\text { Green Bit } \\
\text { Crossmatch }\end{array}$ & $\begin{array}{l}\mathrm{D} \\
\mathrm{H}\end{array}$ & $\begin{array}{l}\text { Cornell University } \\
\text { Clarkson University }\end{array}$ \\
\hline $1 \mathrm{~A}$ & Peering Into Window & $1 \mathrm{~B}$ & Fist Banging on Glass & $1 \mathrm{C}$ & Fingertip Window Slide & 1D & Get-away Palm on Glass & $1 \mathrm{E}$ & “OK" Sign on Glass \\
\hline $1 \mathrm{~F}$ & Counter Vault on Glass & 16 & Cylinder Grab & $1 \mathrm{H}$ & Impatient Tapping on Glass & $2 \mathrm{~A}$ & Samsung Galaxy S5 & $2 \mathrm{~B}$ & Apple iPhone $5 \mathrm{~s}$ \\
\hline 3 & Check & $4 \mathrm{~A}$ & Lined Paper & $4 \mathrm{~B}$ & Low-quality Copy Paper & $4 \mathrm{C}$ & High-quality Copy Paper & $4 \mathrm{D}$ & Yellow Lined Paper \\
\hline $4 \mathrm{E}$ & Low-quality White Envelope & $4 \mathrm{~F}$ & Greeting Card and Envelope & $4 \mathrm{G}$ & Manila Envelope & $5 \mathrm{~A}$ & Photo Paper & $5 B$ & Glossy Magazine \\
\hline $5 c$ & U.S. Currency & $6 \mathrm{~A}$ & Stamp & $6 \mathrm{~B}$ & Address Label & 6c & Clear Packing Tape & $6 \mathrm{D}$ & Black Electrical Tape \\
\hline $6 \mathrm{E}$ & Duct Tape & $7 \mathrm{~A}$ & Circuit Board & $7 \mathrm{~B}$ & CD/DVD & $7 \mathrm{C}$ & Clear Plastic Bag & 70 & Black Plastic Bag \\
\hline
\end{tabular}




\section{Data - Nail to Nail}

\subsection{Image Format}

For each study participant, Challengers submitted up to 10 individual fingerprint images captured from their devices to the N2N backend server via the JHU APL facility API. All images were required to:

- be encoded in the Portable Network Graphics (PNG) format,

- contain 8 bits or 16 bits per channel,

- contain $\geq 196.85$ Pixels Per Centimeter (PPCM) (500 Pixels Per Inch or PPI),

- not make use of ancillary PNG features that change color display,

- be sized at least 128 pixels $\times 128$ pixels at 196.85 PPCM (500 PPI),

- be encoded in the grayscale colorspace, using black to represent friction ridges and white to represent ridge valleys,

- be usable as-is with existing COTS template generation and template identification algorithms, including being approximately upright and oriented equivalent to an inked impression.

\subsection{Traditional Collection}

The FBI staff operating the traditional Baseline Data capture stations used Crossmatch L Scan 1000 live scan capture devices. These devices captured baseline N2N, 4-4-2 slap, and palm data at 393.7 PPCM (1000 PPI). Each device platen was equipped with a Crossmatch silicone membrane.

The Crossmatch device was chosen due to the staff's familiarity with the device, as well as its wide deployment at numerous United States Government biometric enrollment settings, such as ports of entry. It was operated at 393.7 PPCM (1000 PPI) in order to capture the highest amount of detail and to enable future research on high-resolution fingerprint images. Crossmatch devices used for capturing Baseline Data were procured independently at market price by NIST and JHU APL prior to learning that Crossmatch would be participating in the Nail to Nail Fingerprint Challenge.

\subsubsection{Groundtruth}

Mistakes that affect the integrity of a fingerprint data collection are often inevitable. For instance, the capture of a right index finger might accidentally be coded as a left index finger, or a software alert indicating that an image wasn't sent to the N2N backend server could be accidentally ignored. Such technical issues would impede on the integrity of this or any other fingerprint data collection.

In the N2N identification portion of the Nail to Nail Fingerprint Challenge, all Challenger data was compared to the Baseline Data, so it was imperative that the Baseline Data be $100 \%$ accurate. The process of ensuring the veracity of the data - checking that fingers were sequenced in order and associated with the correct study participant identifier - is known as groundtruthing.

Each baseline N2N image was matched with segmented versions of the 4-4-2 baseline slap imagery using both the NIST-provided Fingerprint Identification Algorithm (the MATCHER) and other COTS fingerprint identification algorithms. Low-scoring mated and high-scoring non-mated pairs were examined by visual inspection and labeling was corrected as necessary. As an added check, the Matcher was used to compare both sets of baseline $\mathrm{N} 2 \mathrm{~N}$ images to each other. Low-scoring mated and high-scoring non-mated pairs were examined by visual inspection and labeling was corrected as necessary.

\begin{tabular}{|c|c|c|c|c|c|c|c|c|c|}
\hline$\Omega$ & FBI Baseline & $\begin{array}{l}A \\
E\end{array}$ & $\begin{array}{l}\text { IDEMIA } \\
\text { Jenetric }\end{array}$ & $\begin{array}{l}\mathrm{B} \\
\mathrm{F}\end{array}$ & $\begin{array}{l}\text { Advanced Optical Systems } \\
\text { Touchless Biometric Systems }\end{array}$ & $\begin{array}{l}c \\
G\end{array}$ & $\begin{array}{l}\text { Green Bit } \\
\text { Crossmatch }\end{array}$ & $\stackrel{D}{\mathrm{D}}$ & $\begin{array}{l}\text { Cornell University } \\
\text { Clarkson University }\end{array}$ \\
\hline $1 \mathrm{~A}$ & Peering Into Window & $1 \mathrm{~B}$ & Fist Banging on Glass & $1 \mathrm{C}$ & Fingertip Window Slide & 10 & Get-away Palm on Glass & $1 \mathrm{E}$ & "OK" Sign on Glass \\
\hline $1 \mathrm{~F}$ & Counter Vault on Glass & $1 \mathrm{G}$ & Cylinder Grab & $1 \mathrm{H}$ & Impatient Tapping on Glass & $2 \mathrm{~A}$ & Samsung Galaxy S5 & $2 \mathrm{~B}$ & Apple iPhone $5 \mathrm{~s}$ \\
\hline 3 & Check & $4 \mathrm{~A}$ & Lined Paper & $4 B$ & Low-quality Copy Paper & $4 \mathrm{C}$ & High-quality Copy Paper & $4 \mathrm{D}$ & Yellow Lined Paper \\
\hline $4 \mathrm{E}$ & Low-quality White Envelope & $4 \mathrm{~F}$ & Greeting Card and Envelope & $4 G$ & Manila Envelope & $5 \mathrm{~A}$ & Photo Paper & $5 \mathrm{~B}$ & Glossy Magazine \\
\hline $5 \mathrm{C}$ & U.S. Currency & $6 \mathrm{~A}$ & Stamp & $6 \mathrm{~B}$ & Address Label & $6 \mathrm{C}$ & Clear Packing Tape & $6 \mathrm{D}$ & Black Electrical Tape \\
\hline $6 \mathrm{E}$ & Duct Tape & $7 \mathrm{~A}$ & Circuit Board & $7 \mathrm{~B}$ & CD/DVD & $7 \mathrm{C}$ & Clear Plastic Bag & $7 \mathrm{D}$ & Black Plastic Bag \\
\hline
\end{tabular}




\subsection{Challengers}

Challengers were required to submit images to the N2N backend server via the JHU APL facility API in the format specified in Section 4.1. Challengers were ultimately responsible for finger sequence checking with their own devices, and as such, there was no groundtruthing of Challenger data performed. The JHU APL facility API allowed for multiple images per finger to be submitted for each study participant, but only the most recently submitted image was considered during analysis.

\subsubsection{Errors}

Several Challengers deviated from the image specifications outlined in Section 4.1 for a large quantity of submitted images. NIST determined that the images from these Challengers would be unusable by the MATCHER if they remained as submitted, and would be detrimental to the Challenger's overall results. With permission granted from the N2N Judging Committee, NIST performed the following minimal modifications to Challenger images.

Some Challengers submitted several images that were sized under 128 pixels $\times 128$ pixels at $196.85 \mathrm{PPCM}$ (500 PPI). To correct this situation, NIST centered the image on a white background of at least 128 pixels $\times$ 128 pixels at 196.85 PPCM (500 PPI), as demonstrated in Fig. 4. Other Challengers incorrectly recorded the resolution in their submitted images. After consulting with the Challenger to determine the correct resolution, NIST updated the recorded resolution. Neither operation was destructive to the image data.

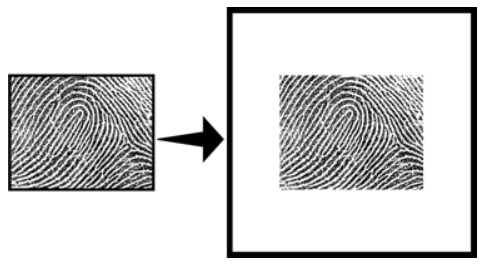

Fig. 4. An example of correcting a fingerprint image whose dimensions were smaller than that required by the N2N image specifications, outlined in Section 4.1. A larger image with a white background was created, and the smaller image was centered inside. This operation was not destructive to the image data.

One Challenger's device recorded different horizontal and vertical capture resolutions in their submitted images. Although not inherently incorrect, varying horizontal and vertical capture resolutions could cause issues with some COTS fingerprint identification algorithms. With permission from the N2N Judging Committee and the Challenger, NIST resampled these images to the smaller resolution using the Lanczos-2 interpolation kernel, as provided by MATLAB [2].

Finally, it was observed that one Challenger's images were mirrored along the vertical axis, otherwise known as being flopped. A COTS fingerprint identification algorithm would fail to find a mate for such fingerprint images. All images from this Challenger were flopped to allow potential for successful identification, as shown in Fig. 5.

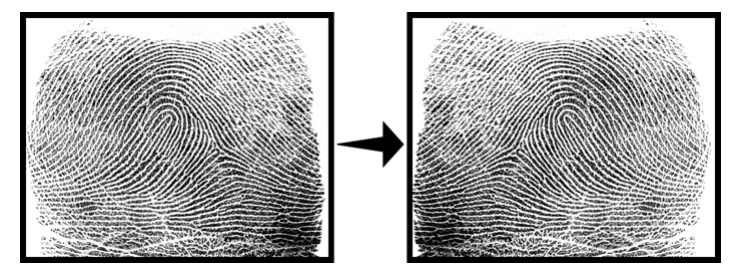

Fig. 5. An example of correcting a fingerprint image by flopping, or reversing the columns of the image to mirror it over the vertical axis. This operation was not destructive to image data.

All changes to Challenger images made by NIST were permitted by unanimous affirmative decisions by the N2N Judging Committee and the Challengers in question.

\begin{tabular}{|c|c|c|c|c|c|c|c|c|c|}
\hline$\Omega$ & FBI Baseline & $\begin{array}{l}A \\
E\end{array}$ & $\begin{array}{l}\text { IDEMIA } \\
\text { Jenetric }\end{array}$ & $\begin{array}{l}\mathrm{B} \\
\mathrm{F}\end{array}$ & $\begin{array}{l}\text { Advanced Optical Systems } \\
\text { Touchless Biometric Systems }\end{array}$ & $\begin{array}{l}c \\
G\end{array}$ & $\begin{array}{l}\text { Green Bit } \\
\text { Crossmatch }\end{array}$ & $\stackrel{D}{\mathrm{D}}$ & $\begin{array}{l}\text { Cornell University } \\
\text { Clarkson University }\end{array}$ \\
\hline $1 \mathrm{~A}$ & Peering Into Window & $1 \mathrm{~B}$ & Fist Banging on Glass & $1 \mathrm{C}$ & Fingertip Window Slide & 10 & Get-away Palm on Glass & $1 \mathrm{E}$ & "OK" Sign on Glass \\
\hline $1 \mathrm{~F}$ & Counter Vault on Glass & $1 \mathrm{G}$ & Cylinder Grab & $1 \mathrm{H}$ & Impatient Tapping on Glass & $2 \mathrm{~A}$ & Samsung Galaxy S5 & $2 \mathrm{~B}$ & Apple iPhone $5 \mathrm{~s}$ \\
\hline 3 & Check & $4 \mathrm{~A}$ & Lined Paper & $4 B$ & Low-quality Copy Paper & $4 \mathrm{C}$ & High-quality Copy Paper & $4 \mathrm{D}$ & Yellow Lined Paper \\
\hline $4 \mathrm{E}$ & Low-quality White Envelope & $4 \mathrm{~F}$ & Greeting Card and Envelope & $4 G$ & Manila Envelope & $5 \mathrm{~A}$ & Photo Paper & $5 \mathrm{~B}$ & Glossy Magazine \\
\hline $5 \mathrm{C}$ & U.S. Currency & $6 \mathrm{~A}$ & Stamp & $6 \mathrm{~B}$ & Address Label & $6 \mathrm{C}$ & Clear Packing Tape & $6 \mathrm{D}$ & Black Electrical Tape \\
\hline $6 \mathrm{E}$ & Duct Tape & $7 \mathrm{~A}$ & Circuit Board & $7 \mathrm{~B}$ & CD/DVD & $7 \mathrm{C}$ & Clear Plastic Bag & $7 \mathrm{D}$ & Black Plastic Bag \\
\hline
\end{tabular}




\subsection{Omitted Data}

For fairness, study participants were omitted:

- whose Baseline Data was not fully acquired,

- who were removed from the test floor by N2N test staff for any reason,

- who did not have a QR code scan at all required stations,

- whose baseline images resulted in low mated comparison scores and could not be verified as accurate after visual inspection,

- whose baseline images resulted in high comparison scores for other N2N participants for all 10 fingers when searching (i.e., N2N backend server labeling error).

\subsection{Public Data}

IARPA is pleased to be able to provide much of the Challenger N2N data to biometric researchers. Refer to Appendix $\mathrm{C}$ for details.

\begin{tabular}{|c|c|c|c|c|c|c|c|c|c|}
\hline$\Omega$ & FBI Baseline & $\begin{array}{l}A \\
E\end{array}$ & $\begin{array}{l}\text { IDEMIA } \\
\text { Jenetric }\end{array}$ & $\begin{array}{l}\mathrm{B} \\
\mathrm{F}\end{array}$ & $\begin{array}{l}\text { Advanced Optical Systems } \\
\text { Touchless Biometric Systems }\end{array}$ & $\begin{array}{l}C \\
G\end{array}$ & $\begin{array}{l}\text { Green Bit } \\
\text { Crossmatch }\end{array}$ & $\begin{array}{l}\mathrm{D} \\
\mathrm{H}\end{array}$ & $\begin{array}{l}\text { Cornell University } \\
\text { Clarkson University }\end{array}$ \\
\hline $1 \mathrm{~A}$ & o Window & $1 \mathrm{~B}$ & Fist Bang & $1 \mathrm{C}$ & Fingertip Window Slide & 10 & Get-away Palm on Glass & $1 \mathrm{E}$ & "OK" Sign on Glass \\
\hline $1 \mathrm{~F}$ & Counter Vault on Glass & $1 \mathrm{G}$ & Cylinder Grab & $1 \mathrm{H}$ & Impatient Tapping on Glass & $2 \mathrm{~A}$ & Samsung Galaxy S5 & $2 \mathrm{~B}$ & Apple iPhone 5s \\
\hline 3 & Check & $4 \mathrm{~A}$ & Lined Paper & $4 B$ & Low-quality Copy Paper & $4 \mathrm{C}$ & High-quality Copy Paper & $4 \mathrm{D}$ & Yellow Lined Paper \\
\hline $4 \mathrm{E}$ & Low-quality White Envelope & $4 \mathrm{~F}$ & Greeting Card and Envelope & $4 \mathrm{G}$ & Manila Envelope & $5 \mathrm{~A}$ & Photo Paper & $5 B$ & Glossy Magazine \\
\hline $5 c$ & U.S. Currency & $6 \mathrm{~A}$ & Stamp & $6 \mathrm{~B}$ & Address Label & $6 \mathrm{C}$ & Clear Packing Tape & $6 \mathrm{D}$ & Black Electrical Tape \\
\hline $6 \mathrm{E}$ & Duct Tape & $7 \mathrm{~A}$ & Circuit Board & $7 \mathrm{~B}$ & $\mathrm{CD} / \mathrm{DVD}$ & $7 \mathrm{C}$ & Clear Plastic Bag & 70 & Black Plastic Bag \\
\hline
\end{tabular}




\section{Data - Latent}

Traces of an individual's fingerprints have the potential to be left behind on nearly every surface they touch, primarily due to glands present in human skin. At a crime scene, these impressions are collected by an investigator for later analysis and automated identification. To that end, it was important that the latent fingerprints collected during the Nail to Nail Fingerprint Challenge mimicked the type of data that is typically seen in criminal investigations.

A set of thirty activities were created to cause study participants to leave latent fingerprints on a variety of objects in a natural manner. The activities, described in Section 5.1, were chosen such that different development techniques would be required, and were designed in consultation with the FBI to resemble the most common types of substrates latent prints are found on at crime scenes.

When collecting data, there were little to no instructions provided to study participants related to fingerprint deposition on the substrates. For example, nothing was said about the amount of pressure that should be applied, the location of touches, or what fingers should be used. Instead, the activities and instructions created were common enough daily occurrences that the study participants were left to their own devices to complete the task they were presented with. There was no wrong way to perform a task. As a result, the data collected from performing these activities were as close to real-world law enforcement casework latent prints as possible, while allowing for a wide range of individual randomness between study participants performing the same activity.

\subsection{Activity Descriptions}

study participants each performed approximately 10 activities, using a mixture of porous, semiporous, nonporous, and adhesive objects. Each object and activity is described below. An example image resulting from each activity can be seen in Figs. 6 and 7, and their corresponding activity code, 1A through 7D, can be referred to in the footer of each page. Once study participants completed their required tasks, they placed the objects used into an evidence bag labeled with their study identification number. For activities that required writing a name or address, fake information was provided to prevent study participant re-identification.

\section{Peering Into Window (1A, nonporous)}

The palmar surface of the hands are placed on the sides of the head, about an inch in front of each ear. The outside edge of the little finger extends forward beyond the nose. The hands and head are then brought toward a pane of glass until touching, simulating peering into a window at night while shadowing glare and reflections.

Fist Banging on Glass (1B, nonporous)

Make a fist and strike the little finger side on a pane of glass two or three times. This simulates knocking or angered banging on a door.

\section{Fingertip Window Slide (1C, nonporous)}

Fingertips are placed on a flat piece of glass. The hand is slid upwards with pressure, simulating opening a window sash without a handle. Examiners prompted the study participants randomly on the upward sliding angle to capture various tips and sides.

\section{Get-away Palm on Glass (1D, nonporous)}

Slap hand with fingers extended onto a piece of glass, simulating pushing open a push-exit door when in a rush. The hand will naturally slide upwards.

\section{"OK" Sign on Glass (1E, nonporous)}

Index finger is curled toward thumb, while middle, ring, and little fingers remain extended. The entire hand is placed on a pane of glass. This activity, along with $1 \mathrm{H}$, was designed to target extreme tips and sides of the distal phalanx.

\begin{tabular}{|c|c|c|c|c|c|c|c|c|c|}
\hline$\Omega$ & FBI Baseline & $\begin{array}{l}A \\
E\end{array}$ & $\begin{array}{l}\text { IDEMIA } \\
\text { Jenetric }\end{array}$ & $\begin{array}{l}\mathrm{B} \\
\mathrm{F}\end{array}$ & $\begin{array}{l}\text { Advanced Optical Systems } \\
\text { Touchless Biometric Systems }\end{array}$ & $\begin{array}{l}c \\
G\end{array}$ & $\begin{array}{l}\text { Green Bit } \\
\text { Crossmatch }\end{array}$ & $\begin{array}{l}\mathrm{D} \\
\mathrm{H}\end{array}$ & $\begin{array}{l}\text { Cornell University } \\
\text { Clarkson University }\end{array}$ \\
\hline $1 \mathrm{~A}$ & Peering Into Window & $1 \mathrm{~B}$ & Fist Banging on Glass & 1C & Fingertip Window Slide & 10 & Get-away Palm on Glass & $1 \mathrm{E}$ & "OK" Sign on Glass \\
\hline $1 \mathrm{~F}$ & Counter Vault on Glass & $1 \mathrm{G}$ & Cylinder Grab & $1 \mathrm{H}$ & Impatient Tapping on Glass & $2 \mathrm{~A}$ & Samsung Galaxy S5 & $2 \mathrm{~B}$ & Apple iPhone $5 \mathrm{~s}$ \\
\hline 3 & Check & $4 \mathrm{~A}$ & Lined Paper & $4 \mathrm{~B}$ & Low-quality Copy Paper & $4 \mathrm{C}$ & High-quality Copy Paper & $4 \mathrm{D}$ & Yellow Lined Paper \\
\hline $4 \mathrm{E}$ & Low-quality White Envelope & $4 \mathrm{~F}$ & Greeting Card and Envelope & $4 \mathrm{G}$ & Manila Envelope & $5 \mathrm{~A}$ & Photo Paper & $5 \mathrm{~B}$ & Glossy Magazine \\
\hline $5 c$ & U.S. Currency & $6 \mathrm{~A}$ & Stamp & $6 \mathrm{~B}$ & Address Label & $6 \mathrm{C}$ & Clear Packing Tape & $6 \mathrm{D}$ & Black Electrical Tape \\
\hline $6 \mathrm{E}$ & Duct Tape & $7 \mathrm{~A}$ & Circuit Board & $7 \mathrm{~B}$ & $\mathrm{CD} / \mathrm{DVD}$ & $7 \mathrm{C}$ & Clear Plastic Bag & $7 \mathrm{D}$ & Black Plastic Bag \\
\hline
\end{tabular}




\section{Counter Vault on Glass (1F, nonporous)}

All fingers are extended while pushing down on a pane of glass, simulating applying pressure to a table or desk in order to assist in standing up from a sitting position, or vaulting a counter during a robbery.

\section{Cylinder Grab (1G, nonporous)}

A cylindrical plastic tube is grasped, simulating gripping a weapon such as a baseball bat, knife, or pistol magazine.

\section{Impatient Tapping on Glass (1H, nonporous)}

With the heel of the hand resting on a pane of glass, tap your fingers impatiently, striking at various distances from the palm. This activity, along with $1 \mathrm{E}$, was designed to target extreme tips and sides of the distal phalanx.

\section{Samsung Galaxy S5 (2A, nonporous)}

Try to wake a Samsung Galaxy S5 by pressing its buttons and swiping and tapping on the screen. The device's battery was disconnected during the collection.

\section{Apple iPhone 5s (2B, nonporous)}

Try to wake an Apple iPhone 5s by pressing its buttons and swiping and tapping on the screen. The device's battery was disconnected during the collection.

\section{Check $(3$, porous $)$}

Write a check using American National Standards Institute (ANSI) X9 compliant magnetic ink checks from VersaCheck. Turn over the check and endorse it. Separate the check portion from the register portion of the paper.

Lined Paper (4A, porous)

Write a note on National college ruled, $27.94 \mathrm{~cm} \times 21.59 \mathrm{~cm}, \approx 64 \mathrm{~g} / \mathrm{m}^{2}$, letter-sized filler paper. Fold the note in half, tear on the fold, then fold in half again.

\section{Low-quality Copy Paper (4B, porous)}

Write a note on Staples 96 bright, $75 \mathrm{~g} / \mathrm{m}^{2}$, letter-sized inkjet paper. Fold the note in half, tear on the fold, then fold in half again.

\section{High-quality Copy Paper (4C, porous)}

Write a note on Hewlett Packard 165 bright, $24 \mathrm{~g} / \mathrm{m}^{2}$, letter-sized inkjet paper. Fold the note in half, tear on the fold, then fold in half again.

\section{Yellow Lined Paper (4D, porous)}

Write a note on a sheet of paper from a Staples $75 \mathrm{~g} / \mathrm{m}^{2}$ gold series letter-sized writing pad. Fold the note in half, tear on the fold, then fold in half again.

Low-quality White Envelope (4E, porous)

Address a Staples $90 \mathrm{~g} / \mathrm{m}^{2}, 10.5 \mathrm{~cm} \times 24.1 \mathrm{~cm}$ privacy-tint envelope. Fold the envelope in half.

\section{Greeting Card and Envelope (4F, porous)}

Write a note inside a high-quality $12.7 \mathrm{~cm} \times 17.78 \mathrm{~cm}$ greeting card from Markings by C.R. Gibson. Place the card into the provided greeting card envelope and address it. Fold the envelope in half.

Manila Envelope (4G, porous) Address a Staples $\mathrm{kraft}, 105 \mathrm{~g} / \mathrm{m}^{2}, 8.6 \mathrm{~cm} \times 15.2 \mathrm{~cm}$ gummed envelope. Fold the envelope in half.

\section{Photo Paper (5A, semiporous - processed as porous)}

Examine a piece of Kodak $10.2 \mathrm{~cm} \times 15.2 \mathrm{~cm}, 240 \mathrm{~g} / \mathrm{m}^{2}$, glossy premium letter-sized photo paper. Write a note on the back of it, then fold in half.

\section{Glossy Magazine (5B, semiporous - processed as porous)}

Hold a piece of letter-sized glossy magazine paper from a ULINE product catalog and identify a product of interest. Physically point out the item to the examiner, then fold in half.

\begin{tabular}{|c|c|c|c|c|c|c|c|c|c|}
\hline$\Omega$ & FBI Baseline & $\begin{array}{l}A \\
E\end{array}$ & $\begin{array}{l}\text { IDEMIA } \\
\text { Jenetric }\end{array}$ & $\begin{array}{l}\mathrm{B} \\
\mathrm{F}\end{array}$ & $\begin{array}{l}\text { Advanced Optical Systems } \\
\text { Touchless Biometric Systems }\end{array}$ & $\begin{array}{l}C \\
G\end{array}$ & $\begin{array}{l}\text { Green Bit } \\
\text { Crossmatch }\end{array}$ & $\begin{array}{l}\mathrm{D} \\
\mathrm{H}\end{array}$ & $\begin{array}{l}\text { Cornell University } \\
\text { Clarkson University }\end{array}$ \\
\hline 1A & owindowt r r r r & $1 \mathrm{~B}$ & Fist Banging on & $1 \mathrm{C}$ & Fingertip Window Slide & 1D & Get-away Palm on Glass & $1 \mathrm{E}$ & “OK” Sign on Glass \\
\hline $1 \mathrm{~F}$ & Counter Vault on Glass & $1 \mathrm{G}$ & Cylinder Grab & $1 \mathrm{H}$ & Impatient Tapping on Glass & $2 \mathrm{~A}$ & Samsung Galaxy S5 & $2 \mathrm{~B}$ & Apple iPhone $5 \mathrm{~s}$ \\
\hline 3 & Check & $4 \mathrm{~A}$ & Lined Paper & $4 \mathrm{~B}$ & Low-quality Copy Paper & $4 \mathrm{C}$ & High-quality Copy Paper & $4 \mathrm{D}$ & Yellow Lined Paper \\
\hline $4 \mathrm{E}$ & Low-quality White Envelope & $4 \mathrm{~F}$ & Greeting Card and Envelope & $4 G$ & Manila Envelope & $5 \mathrm{~A}$ & Photo Paper & $5 \mathrm{~B}$ & Glossy Magazine \\
\hline $5 c$ & U.S. Currency & $6 \mathrm{~A}$ & Stamp & $6 \mathrm{~B}$ & Address Label & $6 \mathrm{C}$ & Clear Packing Tape & $6 \mathrm{D}$ & Black Electrical Tape \\
\hline $6 \mathrm{E}$ & Duct Tape & $7 \mathrm{~A}$ & Circuit Board & $7 \mathrm{~B}$ & $\mathrm{CD} / \mathrm{DVD}$ & $7 \mathrm{C}$ & Clear Plastic Bag & $7 \mathrm{D}$ & Black Plastic Bag \\
\hline
\end{tabular}




\section{U.S. Currency (5C, semiporous - processed as porous)}

Examine an uncirculated $\$ 1$ United States currency note to see if it is real or fake. All currency notes were real.

\section{Stamp (6A, nonporous)}

Affix a self-adhesive United States Postal Service stamp to a piece of clear acetate. Only the adhesive side of the stamp was developed.

\section{Address Label (6B, nonporous)}

Affix a self-adhesive Avery $2.54 \mathrm{~cm} \times 6.68 \mathrm{~cm}$ address label to a piece of clear acetate. Only the adhesive side of the label was developed.

\section{Clear Packing Tape (6C, nonporous)}

Unroll a $15 \mathrm{~cm}$ strip of $S$ cotch $48 \mathrm{~mm}$ wide heavy duty shipping tape, and attach it to a piece of clear acetate. Only the adhesive side of the tape was developed. The examiner cut the end of the tape for the study participant with scissors.

\section{Black Electrical Tape (6D, nonporous)}

Unroll a $15 \mathrm{~cm}$ strip of Commercial Electric $19 \mathrm{~mm}$ wide black vinyl electrical tape, and attach it to a piece of clear acetate. Only the adhesive side of tape was developed. The examiner cut the end of the tape for the study participant with scissors.

\section{Duct Tape (6E, nonporous)}

Unroll a $15 \mathrm{~cm}$ strip of $3 M 48 \mathrm{~mm}$ wide red duct tape, and attach it to a piece of clear acetate. Only the adhesive side of tape was developed. The examiner cut the end of the tape for the study participant with scissors.

\section{Circuit Board (7A, nonporous)}

Ask the study participant to read the serial number from an uncirculated Cofufu $3 \mathrm{~cm} \times 7 \mathrm{~cm}$ doublesided universal printed circuit board. No circuit boards featured any serial numbers.

\section{CD/DVD (7B, nonporous)}

Pick up an uncirculated Memorex CD-R and hand it to the gloved examiner. The examiner holds onto the CD-R with moderate tension while the study participant pulls it away. This was to simulate loading and unloading a $\mathrm{CD}$ from a car stereo.

\section{Clear Plastic Bag (7C, nonporous)}

Smooth out an uncirculated Ziploc $16.5 \mathrm{~cm} \times 14.9 \mathrm{~cm}$ plastic sandwich bag, then turn it inside out and back again.

\section{Black Plastic Bag (7D, nonporous)}

Smooth out an uncirculated ULINE $10.16 \mathrm{~cm} \times 15.24 \mathrm{~cm}$ black bag, then turn it inside out and back again.

\subsection{Development}

The items used in the activities described in Section 5.1 were chosen in order to force a variety of latent friction ridge impressions and development techniques. Development or processing refers to the procedures under which a latent friction ridge on a surface is exposed. These techniques typically exploit properties of the various known oils, amino acids, lipids, and other compounds found in skin secretions.

There are numerous techniques in which a friction ridge can be developed that are documented in the National Institute of Justice (NIJ)'s The Fingerprint Sourcebook [3] and FBI's Processing Guide for Developing Latent Prints [4]. Although many processing techniques exist, four of the most popular and effective techniques were used in the Nail to Nail Fingerprint Challenge.

The technique used to process an object is chosen based on the substrate that makes up the object. In terms of latent development, there are three primary categories of materials: porous, semiporous, and nonporous. Simply put, porous materials absorb skin secretions and nonporous materials do not. A semiporous material

\begin{tabular}{|c|c|c|c|c|c|c|c|c|c|}
\hline$\Omega$ & FBI Baseline & $\begin{array}{l}A \\
E\end{array}$ & $\begin{array}{l}\text { IDEMIA } \\
\text { Jenetric }\end{array}$ & $\begin{array}{l}\mathrm{B} \\
\mathrm{F}\end{array}$ & $\begin{array}{l}\text { Advanced Optical Systems } \\
\text { Touchless Biometric Systems }\end{array}$ & $\begin{array}{l}\text { C } \\
G\end{array}$ & $\begin{array}{l}\text { Green Bit } \\
\text { Crossmatch }\end{array}$ & $\stackrel{D}{\mathrm{D}}$ & $\begin{array}{l}\text { Cornell University } \\
\text { Clarkson University }\end{array}$ \\
\hline $1 \mathrm{~A}$ & Peering Into Window & $1 \mathrm{~B}$ & Fist Banging on Glass & $1 \mathrm{C}$ & Fingertip Window Slide & 1D & Get-away Palm on Glass & $1 \mathrm{E}$ & “OK" Sign on Glass \\
\hline $1 \mathrm{~F}$ & Counter Vault on Glass & 16 & Cylinder Grab & $1 \mathrm{H}$ & Impatient Tapping on Glass & $2 \mathrm{~A}$ & Samsung Galaxy S5 & $2 \mathrm{~B}$ & Apple iPhone $5 \mathrm{~s}$ \\
\hline 3 & Check & $4 \mathrm{~A}$ & Lined Paper & $4 \mathrm{~B}$ & Low-quality Copy Paper & $4 \mathrm{C}$ & High-quality Copy Paper & $4 D$ & Yellow Lined Paper \\
\hline $4 \mathrm{E}$ & Low-quality White Envelope & $4 \mathrm{~F}$ & Greeting Card and Envelope & $4 G$ & Manila Envelope & $5 \mathrm{~A}$ & Photo Paper & $5 B$ & Glossy Magazine \\
\hline $5 \mathrm{C}$ & U.S. Currency & $6 \mathrm{~A}$ & Stamp & $6 \mathrm{~B}$ & Address Label & $6 \mathrm{C}$ & Clear Packing Tape & $6 \mathrm{D}$ & Black Electrical Tape \\
\hline $6 \mathrm{E}$ & Duct Tape & $7 \mathrm{~A}$ & Circuit Board & $7 \mathrm{~B}$ & $\mathrm{CD} / \mathrm{DVD}$ & $7 \mathrm{C}$ & Clear Plastic Bag & 70 & Black Plastic Bag \\
\hline
\end{tabular}




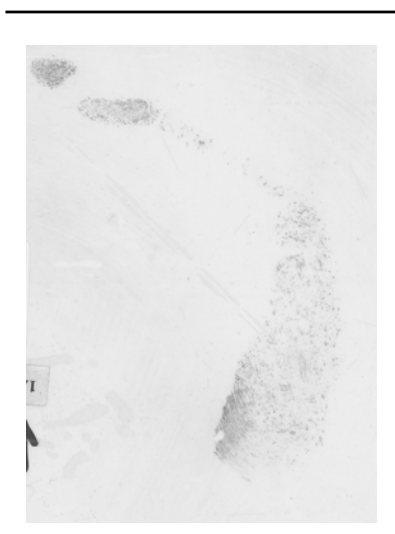

$1 \mathrm{~A}$

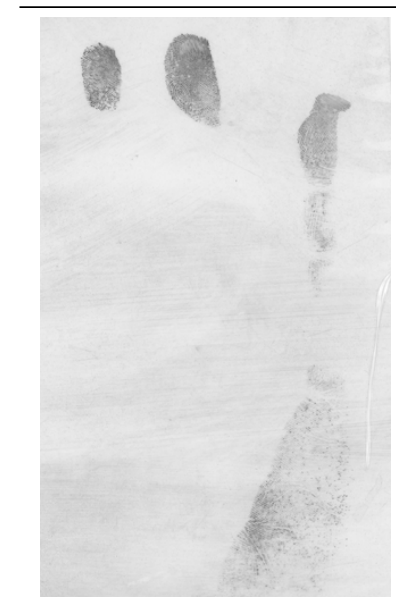

$1 \mathrm{E}$

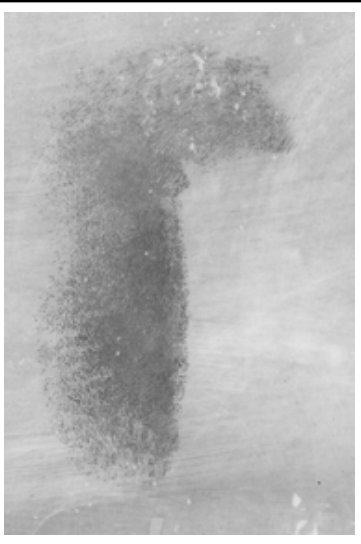

1B

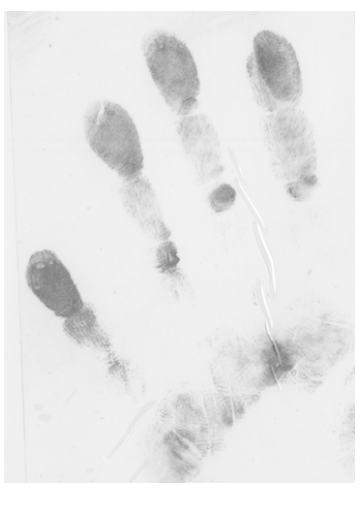

$1 \mathrm{~F}$
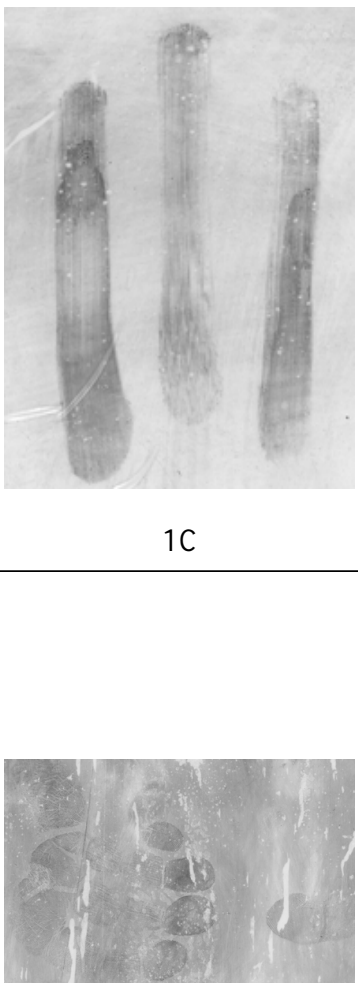

$2 \mathrm{~A}$

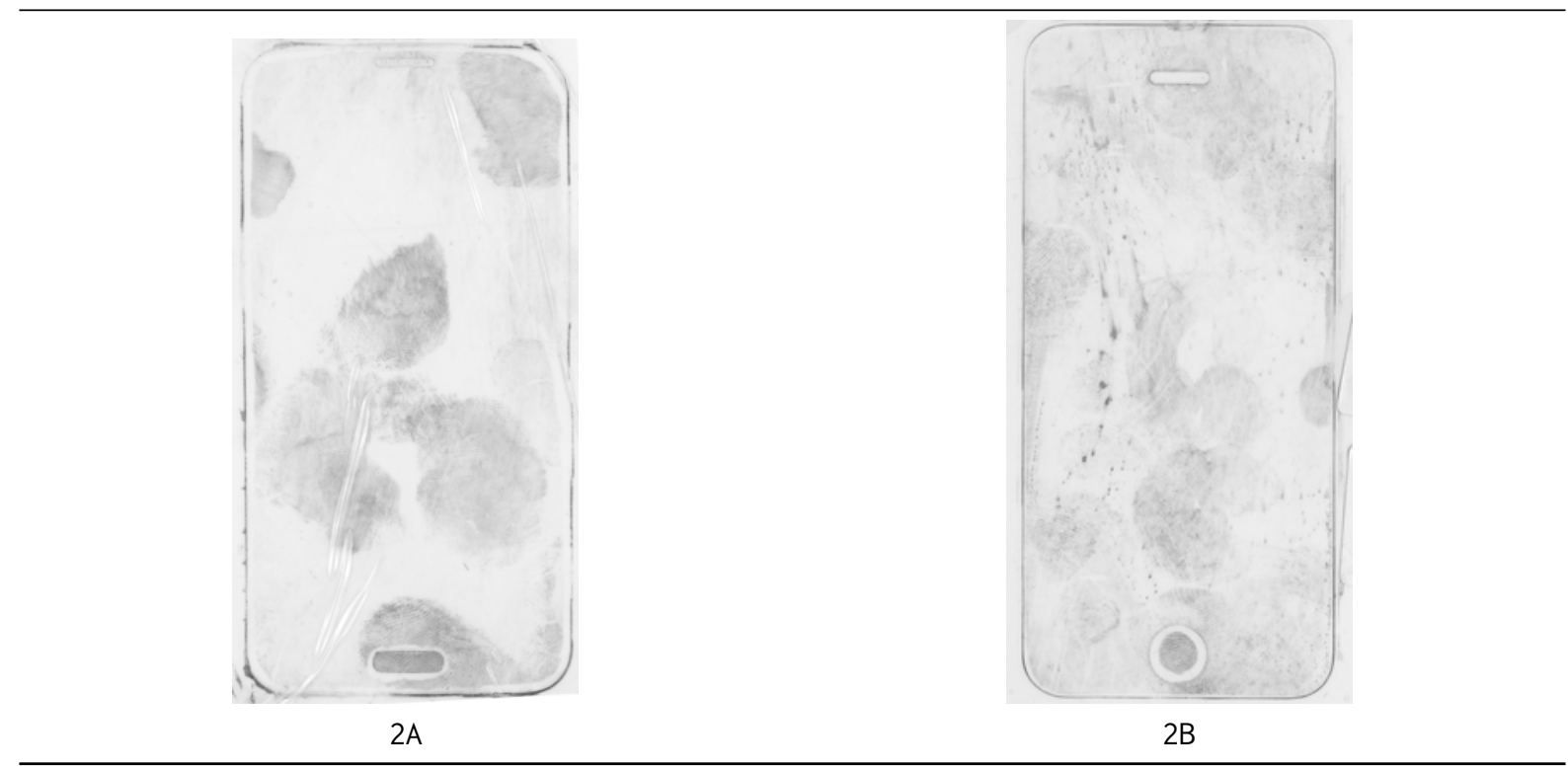

$1 \mathrm{C}$

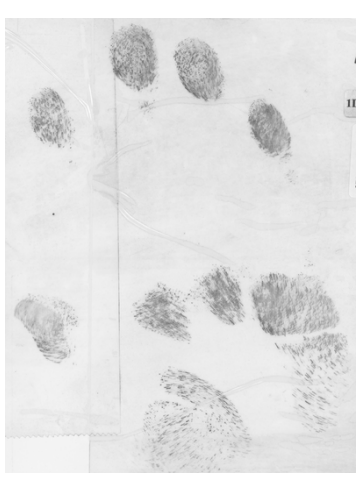

1D

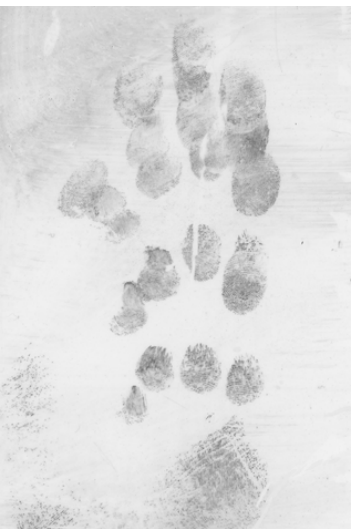

$1 G$

$1 \mathrm{H}$

Fig. 6. Examples of developing latent fingerprints for each latent activity using black powder and tape. The activities are described in Section 5.1.

\begin{tabular}{|c|c|c|c|c|c|c|c|c|c|}
\hline$\Omega$ & FBI Baseline & $\begin{array}{l}\mathrm{A} \\
\mathrm{E}\end{array}$ & $\begin{array}{l}\text { IDEMIA } \\
\text { Jenetric }\end{array}$ & $\begin{array}{l}\mathrm{B} \\
\mathrm{F}\end{array}$ & $\begin{array}{l}\text { Advanced Optical Systems } \\
\text { Touchless Biometric Systems }\end{array}$ & $\begin{array}{l}C \\
G\end{array}$ & $\begin{array}{l}\text { Green Bit } \\
\text { Crossmatch }\end{array}$ & $\begin{array}{l}\mathrm{D} \\
\mathrm{H}\end{array}$ & $\begin{array}{l}\text { Cornell University } \\
\text { Clarkson University }\end{array}$ \\
\hline $1 \mathrm{~A}$ & Peering Into Window & $1 \mathrm{~B}$ & Fist Banging on Glass & $1 \mathrm{C}$ & Fingertip Window Slide & 1D & Get-away Palm on Glass & $1 \mathrm{E}$ & "OK" Sign on Glass \\
\hline $1 \mathrm{~F}$ & Counter Vault on Glass & 16 & Cylinder Grab & $1 \mathrm{H}$ & Impatient Tapping on Glass & $2 \mathrm{~A}$ & Samsung Galaxy S5 & $2 \mathrm{~B}$ & Apple iPhone $5 \mathrm{~s}$ \\
\hline 3 & Check & $4 \mathrm{~A}$ & Lined Paper & $4 B$ & Low-quality Copy Paper & $4 \mathrm{C}$ & High-quality Copy Paper & $4 \mathrm{D}$ & Yellow Lined Paper \\
\hline $4 \mathrm{E}$ & Low-quality White Envelope & $4 \mathrm{~F}$ & Greeting Card and Envelope & $4 G$ & Manila Envelope & $5 \mathrm{~A}$ & Photo Paper & $5 \mathrm{~B}$ & Glossy Magazine \\
\hline $5 \mathrm{C}$ & U.S. Currency & $6 \mathrm{~A}$ & Stamp & $6 \mathrm{~B}$ & Address Label & $6 \mathrm{C}$ & Clear Packing Tape & $6 \mathrm{D}$ & Black Electrical Tape \\
\hline $6 \mathrm{E}$ & Duct Tape & $7 \mathrm{~A}$ & Circuit Board & $7 \mathrm{~B}$ & $\mathrm{CD} / \mathrm{DVD}$ & $7 \mathrm{C}$ & Clear Plastic Bag & $7 \mathrm{D}$ & Black Plastic Bag \\
\hline
\end{tabular}




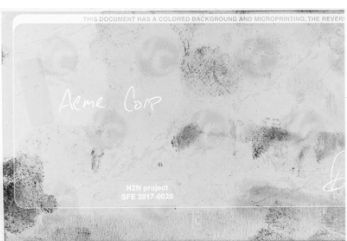

3

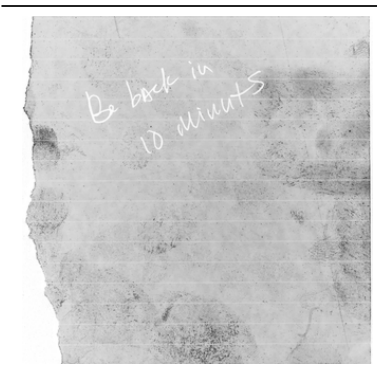

4D

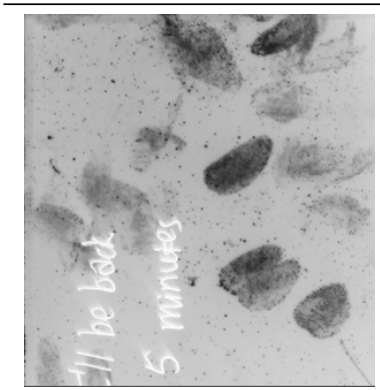

$5 \mathrm{~A}$

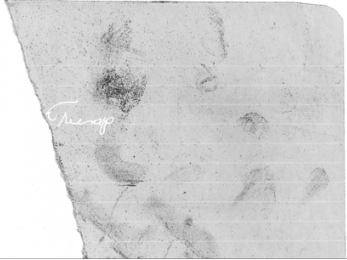

$4 \mathrm{~A}$

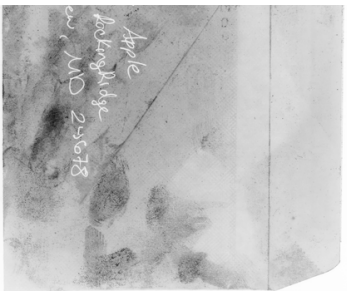

$4 \mathrm{E}$

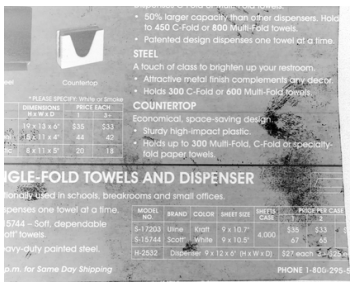

$5 B$

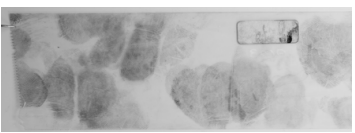

$6 C$

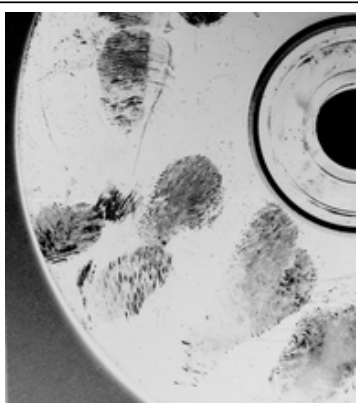

7B

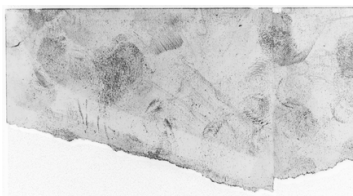

4B

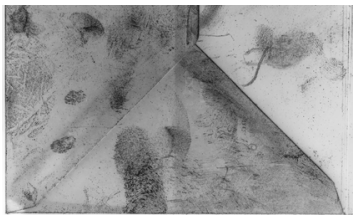

$4 \mathrm{~F}$
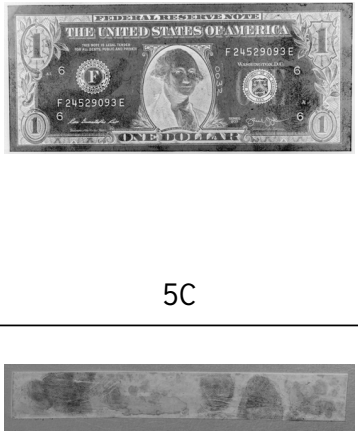

$6 \mathrm{D}$

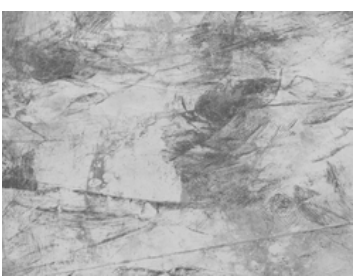

$7 C$

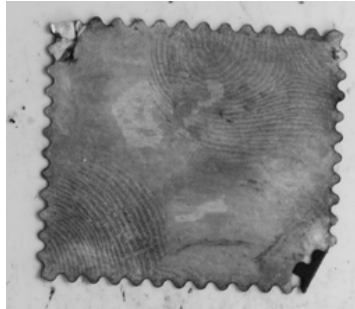

$6 \mathrm{~A}$

$6 \mathrm{E}$

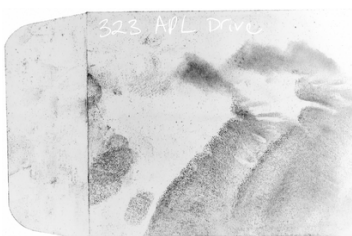

$4 G$
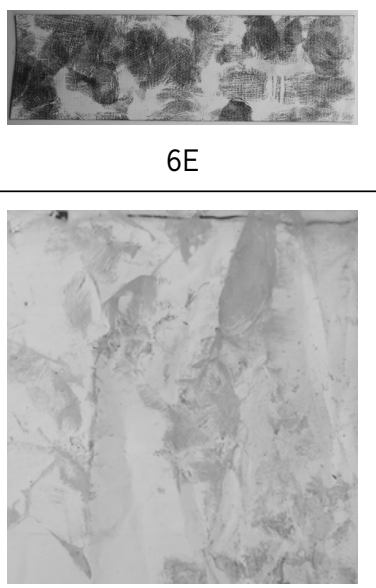

7D

Fig. 7. Examples of developing latent fingerprints for each latent activity as a result of chemical reactions. The activities are described in Section 5.1. All items collected for activity 6B were accidentally destroyed during processing.

\begin{tabular}{|c|c|c|c|c|c|c|c|c|c|}
\hline$\Omega$ & FBI Baseline & $\begin{array}{l}A \\
E\end{array}$ & $\begin{array}{l}\text { IDEMIA } \\
\text { Jenetric }\end{array}$ & $\begin{array}{l}\text { B } \\
F\end{array}$ & $\begin{array}{l}\text { Advanced Optical Systems } \\
\text { Touchless Biometric Systems }\end{array}$ & $\begin{array}{l}\mathrm{C} \\
\mathrm{G}\end{array}$ & $\begin{array}{l}\text { Green Bit } \\
\text { Crossmatch }\end{array}$ & $\begin{array}{l}\mathrm{D} \\
\mathrm{H}\end{array}$ & $\begin{array}{l}\text { Cornell University } \\
\text { Clarkson University }\end{array}$ \\
\hline $1 \mathrm{~A}$ & Peering Into Window & $1 \mathrm{~B}$ & Fist Banging on Glass & 1C & Fingertip Window Slide & $1 \mathrm{D}$ & Get-away Palm on Glass & $1 \mathrm{E}$ & "OK" Sign on Glass \\
\hline $1 \mathrm{~F}$ & Counter Vault on Glass & 16 & Cylinder Grab & $1 \mathrm{H}$ & Impatient Tapping on Glass & $2 \mathrm{~A}$ & Samsung Galaxy S5 & $2 \mathrm{~B}$ & Apple iPhone $5 \mathrm{~s}$ \\
\hline 3 & Check & $4 \mathrm{~A}$ & Lined Paper & $4 \mathrm{~B}$ & Low-quality Copy Paper & $4 \mathrm{C}$ & High-quality Copy Paper & 4D & Yellow Lined Paper \\
\hline $4 \mathrm{E}$ & Low-quality White Envelope & $4 \mathrm{~F}$ & Greeting Card and Envelope & $4 G$ & Manila Envelope & $5 \mathrm{~A}$ & Photo Paper & $5 B$ & Glossy Magazine \\
\hline $5 \mathrm{C}$ & U.S. Currency & $6 \mathrm{~A}$ & Stamp & $6 \mathrm{~B}$ & Address Label & $6 \mathrm{C}$ & Clear Packing Tape & $6 \mathrm{D}$ & Black Electrical Tape \\
\hline $6 \mathrm{E}$ & Duct Tape & $7 \mathrm{~A}$ & Circuit Board & $7 \mathrm{~B}$ & CD/DVD & $7 \mathrm{C}$ & Clear Plastic Bag & $7 D$ & Black Plastic Bag \\
\hline
\end{tabular}


may or may not absorb skin secretions, depending on the type and amount of secretion and the fidelity of the material. As such, development techniques for both porous and nonporous materials may be used on a semiporous object. An easy way to determine a material's porosity is to place a drop of water onto it. The water droplet will act similarly to skin secretions. Additional subcategories of substrates, such as adhesives and thermal paper, require different development methods and workflows.

\section{Black Powder}

The use of black powder in developing latent prints is one of the most common development techniques. The investigator coats a specialized brush made of strands of fiberglass or another soft material with a fine colored powder. The brush is then twirled or painted over a nonporous surface. The particles in the powder attach to the skin secretions deposited when study participants touched the surface.

After the print becomes visible, the investigator spreads a clear tape over the powdered surface and lifts the tape off, placing it on a white evidence card. The powder that sticks to the secreted oils also sticks to the clear tape in the same shape. The evidence card is then scanned into a computer using a flatbed scanner.

Activities 1A through 2B were developed with black powder.

\section{1,2-Indanedione}

One common skin secretion is sweat, which is a combination of many amino acids. On a nonporous surface, sweat dries quickly. When touching a porous material however, those small sweat secretions are absorbed into the substrate. 1,2-indanedione is a chemical reagent that reacts with the amino acids found in skin secretions. The reaction fluoresces when excited with green light.

To develop, the object is immersed or sprayed with a solution of 1,2-indanedione. The item is allowed to dry under a vent hood, followed by direct heat to develop the latent prints. The fluorescence on the object can be viewed by illuminating the object with a green laser $(532 \mathrm{~nm})$ and photographing it through a curved orange filter.

Activities 3 through $5 \mathrm{C}$ were developed with 1,2-indanedione.

\section{Adhesive-side Powder}

Although secretions and dead skin cells stick to the adhesive side of nonporous tape, so would all the fine particles in a powder typically used to develop a nonporous substrate. As an alternative, a mixture of water, a wetting agent, and a specialized adhesive-side powder can be combined to create a thin paste. This mixture is applied to the adhesive side of tape, allowed to sit on the surface to develop the latent prints, and then rinsed off. The adhesive-side powder will remain adhered to the latent skin secretions exposing the print, just like traditional black powder would adhere to skin secretions on a non-adhesive nonporous object.

Activities $6 \mathrm{~A}$ through $6 \mathrm{E}$ were developed with adhesive-side powder. The color of the powder used was white or black - whichever would contrast with the substrate. After digitizing, the image was converted to ensure ridges were black.

study participants stuck adhesive items from activities $6 \mathrm{~A}$ through $6 \mathrm{E}$ onto a sheet of clear acetate. To remove the object for development, the acetate sheet was frozen, making the adhesive easier to free without destroying latent prints. In the case of $6 \mathrm{~B}$, this process accidentally destroyed the object.

\section{Cyanoacrylate}

Cyanoacrylate, more commonly known as "superglue," can be used to develop prints from nonporous surfaces. To do so, an object is placed into a sealed chamber. Cyanoacrylate inside the chamber is heated to form a gaseous fume. After some time, the cyanoacrylate reacts with skin secretions to create a visible 3D polymer of print ridges on the surface of the object. The polymer can then simply be photographed.

This development technique is convenient for developing latent prints from multiple types of surfaces. It avoids a potential pitfall of lifting black powder with tape from a surface that is textured or has an odd shape. In these cases, the resulting latent print in black powder on the tape is likely to be

\begin{tabular}{|c|c|c|c|c|c|c|c|c|c|}
\hline$\Omega$ & FBI Baseline & $\begin{array}{l}A \\
E\end{array}$ & $\begin{array}{l}\text { IDEMIA } \\
\text { Jenetric }\end{array}$ & $\begin{array}{l}\mathrm{B} \\
\mathrm{F}\end{array}$ & $\begin{array}{l}\text { Advanced Optical Systems } \\
\text { Touchless Biometric Systems }\end{array}$ & $\begin{array}{l}c \\
G\end{array}$ & $\begin{array}{l}\text { Green Bit } \\
\text { Crossmatch }\end{array}$ & $\begin{array}{l}\mathrm{D} \\
\mathrm{H}\end{array}$ & $\begin{array}{l}\text { Cornell University } \\
\text { Clarkson University }\end{array}$ \\
\hline $1 \mathrm{~A}$ & Peering Into Window & $1 \mathrm{~B}$ & Fist Banging on Glass & 1C & Fingertip Window Slide & 10 & Get-away Palm on Glass & $1 \mathrm{E}$ & "OK" Sign on Glass \\
\hline $1 \mathrm{~F}$ & Counter Vault on Glass & $1 \mathrm{G}$ & Cylinder Grab & $1 \mathrm{H}$ & Impatient Tapping on Glass & $2 \mathrm{~A}$ & Samsung Galaxy S5 & $2 \mathrm{~B}$ & Apple iPhone $5 \mathrm{~s}$ \\
\hline 3 & Check & $4 \mathrm{~A}$ & Lined Paper & $4 \mathrm{~B}$ & Low-quality Copy Paper & $4 \mathrm{C}$ & High-quality Copy Paper & $4 \mathrm{D}$ & Yellow Lined Paper \\
\hline $4 \mathrm{E}$ & Low-quality White Envelope & $4 \mathrm{~F}$ & Greeting Card and Envelope & $4 \mathrm{G}$ & Manila Envelope & $5 \mathrm{~A}$ & Photo Paper & $5 \mathrm{~B}$ & Glossy Magazine \\
\hline $5 c$ & U.S. Currency & $6 \mathrm{~A}$ & Stamp & $6 \mathrm{~B}$ & Address Label & $6 \mathrm{C}$ & Clear Packing Tape & $6 \mathrm{D}$ & Black Electrical Tape \\
\hline $6 \mathrm{E}$ & Duct Tape & $7 \mathrm{~A}$ & Circuit Board & $7 \mathrm{~B}$ & $\mathrm{CD} / \mathrm{DVD}$ & $7 \mathrm{C}$ & Clear Plastic Bag & $7 \mathrm{D}$ & Black Plastic Bag \\
\hline
\end{tabular}


incomplete or distorted, lacking sufficient information for analysis. With cyanoacrylate, the developed polymer can be photographed without risk of destroying the print.

Activities 7A through 7D were developed using cyanoacrylate fuming.

\subsection{Digitization}

Once latent friction ridges have been developed, they must be digitized. This allows expert examiners to analyze the print as well as submit the print to an automated latent identification algorithm. The digitization technique used depends on the latent development technique.

\section{Flatbed Scanner}

Latent prints developed with black powder were lifted off objects with clear tape and adhered to a white evidence card. These latent prints were scanned using a flatbed scanner configured at various bit depths and resolutions. NIST software was deployed to automate the scan configuration changes without changing the region being scanned [5]. The scanners used in the Nail to Nail Fingerprint Challenge consisted of Epson models Perfection V700, Perfection V800, and Perfection V850. An International Organization for Standardization (ISO) 16067-1 reflective scanner test target and an IT8.7/2 color reflection test target were scanned prior to the evidence cards to confirm the scanners were digitizing correctly.

\section{Digital Camera}

For latent prints developed as a result of a chemical reaction, the reaction can simply be photographed. A ruler was placed on the same plane as the object being photographed in order to determine the capture resolution. A full-frame digital single-lens reflex camera from Nikon (model D800) was used to photograph Nail to Nail Fingerprint Challenge latent prints developed with 1,2-indanedione, adhesive-side powder, and cyanoacrylate.

\section{Full Spectral Imaging System}

Not all chemical reactions can be easily photographed with a camera in ambient light. Additionally, photographs of reactions that take place on a noisy or reflective background do not render well. A Full Spectral Imaging System (FSIS) can be used to produce better digitization for these objects. An FSIS can capture images in multiple ultraviolet, infrared, and visible light spectra. What an FSIS gains in detail over a digital camera, it can lack in resolution and dynamic range.

A Full Spectral Imaging System was used to digitize activities 7A and 7B. An example of the difference of using a digital camera and an FSIS is quite visible in Fig. 8. In the digital camera image, there's nearly no noticeable ridge structure. Under the various light spectrums produced by the FSIS, ridge structure begins to appear.
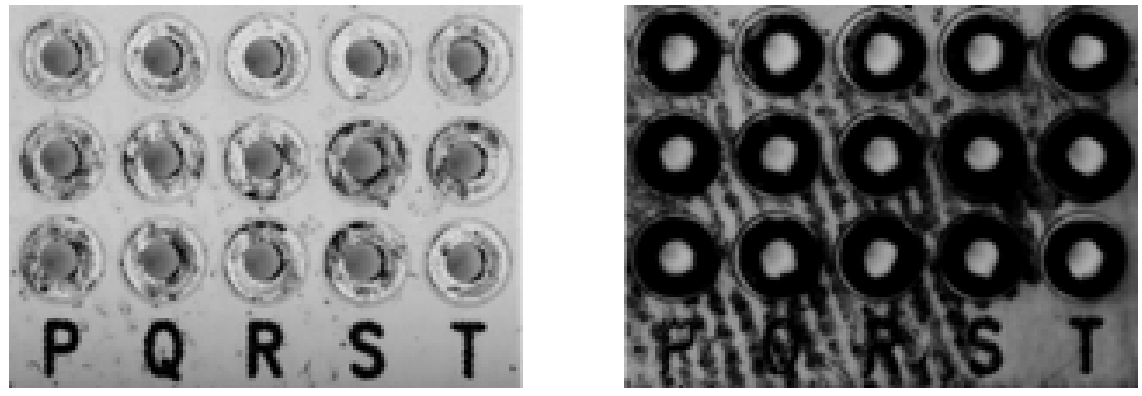

Fig. 8. A visual comparison of digital camera and FSIS latent digitization methods. On the left, a portion of an object from activity 7A is shown photographed using a Nikon D800 after cyanoacrylate fuming. Only very faint friction ridge detail is visible. On the right, the same object is imaged using a FSIS with $254 \mathrm{~nm}$ ultraviolet light and filter to create an image. The resulting image produced by the FSIS has much more pronounced ridge detail.

\begin{tabular}{|c|c|c|c|c|c|c|c|c|c|}
\hline$\Omega$ & FBI Baseline & $\begin{array}{l}A \\
E\end{array}$ & $\begin{array}{l}\text { IDEMIA } \\
\text { Jenetric }\end{array}$ & $\begin{array}{l}\mathrm{B} \\
\mathrm{F}\end{array}$ & $\begin{array}{l}\text { Advanced Optical Systems } \\
\text { Touchless Biometric Systems }\end{array}$ & $\begin{array}{l}c \\
G\end{array}$ & $\begin{array}{l}\text { Green Bit } \\
\text { Crossmatch }\end{array}$ & $\stackrel{D}{\mathrm{D}}$ & $\begin{array}{l}\text { Cornell University } \\
\text { Clarkson University }\end{array}$ \\
\hline $1 \mathrm{~A}$ & Peering Into Window & $1 \mathrm{~B}$ & Fist Banging on Glass & $1 \mathrm{C}$ & Fingertip Window Slide & 10 & Get-away Palm on Glass & $1 \mathrm{E}$ & "OK" Sign on Glass \\
\hline $1 \mathrm{~F}$ & Counter Vault on Glass & $1 \mathrm{G}$ & Cylinder Grab & $1 \mathrm{H}$ & Impatient Tapping on Glass & $2 \mathrm{~A}$ & Samsung Galaxy S5 & $2 \mathrm{~B}$ & Apple iPhone $5 \mathrm{~s}$ \\
\hline 3 & Check & $4 \mathrm{~A}$ & Lined Paper & $4 B$ & Low-quality Copy Paper & $4 \mathrm{C}$ & High-quality Copy Paper & $4 \mathrm{D}$ & Yellow Lined Paper \\
\hline $4 \mathrm{E}$ & Low-quality White Envelope & $4 \mathrm{~F}$ & Greeting Card and Envelope & $4 G$ & Manila Envelope & $5 \mathrm{~A}$ & Photo Paper & $5 \mathrm{~B}$ & Glossy Magazine \\
\hline $5 \mathrm{C}$ & U.S. Currency & $6 \mathrm{~A}$ & Stamp & $6 \mathrm{~B}$ & Address Label & $6 \mathrm{C}$ & Clear Packing Tape & $6 \mathrm{D}$ & Black Electrical Tape \\
\hline $6 \mathrm{E}$ & Duct Tape & $7 \mathrm{~A}$ & Circuit Board & $7 \mathrm{~B}$ & CD/DVD & $7 \mathrm{C}$ & Clear Plastic Bag & $7 \mathrm{D}$ & Black Plastic Bag \\
\hline
\end{tabular}




\subsection{Image Format}

Latents developed using the black powder and tape technique were scanned at several resolutions and color depths, encoded as lossless Tagged Image File Format (TIFF) files. NIST chose to use the 472.4 PPCM (1 200 PPI) 8 bit grayscale TIFF files for searching with the MAтсHER. 472.4 PPCM (1 200 PPI) was the first multiple of the scanner's native scanning resolution above 393.7 PPCM (1 000 PPI).

All other latents were photographed with a digital camera or an FSIS at varying resolutions calibrated to at least 393.7 PPCM (1 000 PPI). Objects were photographed in color and saved to a raw image file using 14 bits per channel. After processing and enhancement in color (adjustments to contrast, hue, etc.), grayscale TIFFs were exported. NIST extracted regions of interest (Section 5.5) from the grayscale image and saved them as PNG files for searching with the MATCHER.

\subsection{Regions of Interest}

Regions encompassing individual latent prints in each image were marked by hand by Certified Latent Print Examiners (CLPEs) at SFE. Examiners used the processed grayscale versions of images when defining these regions of interest. Using a graphics program, a polygonal path was defined around each latent print. Examiners had access to various image enhancement tools in the graphics program to help expose latent prints visually in the image. Each region of interest was marked as being from the distal phalanx, intermediate or proximal phalanges, palm, or other/unknown.

The coordinates of the polygon were provided to NIST software to losslessly extract the region from the the image. The MATCHER is color-agnostic, and so images were extracted from a grayscale version of the image at the actual capture resolution for searching.

The MAtcher operated in image-only mode. No quality values, minutia markings, background masks, or any examiner markup of any kind were provided to the MATCHER.

\subsection{Groundtruth}

Ensuring that objects and evidence cards were associated with the correct study participants and activities was extremely important. Prior to the fingerprint data collection, CLPEs prepared latent kits for each study participant. Each latent kit consisted of a plastic bag full of randomly distributed objects from activities 3 through $5 \mathrm{C}$ and $7 \mathrm{~A}$ through $7 \mathrm{D}$, along with a sheet of adhesive labels containing a unique identifier. One of the identifier labels was adhered to the outside of the bag.

At check-in, each study participant was provided with a set of adhesive labels depicting the QR code printed on their wristband. When a study participant arrived at the latent collection station, the SFE latent print technician adhered one of the study participant's QR code labels to the front of a new latent kit. After the fingerprint data collection, N2N test staff created a mapping between QR code identifiers and latent kit identifiers.

Activities $1 \mathrm{~A}$ through $1 \mathrm{H}$ were developed from a $61 \mathrm{~cm} \times 114 \mathrm{~cm} \times 1.2 \mathrm{~cm}$ sheet of clear tempered glass. The glass sat on a table overtop a map of predefined regions for each activity, as seen in Fig. 9. The activity regions were subdivided into left and right regions, corresponding to the hand position used to create the impression. When the study participant left the station, SFE technicians would perform black powder development over each region of the glass that was touched. After placing the developed print onto an evidence card, the SFE technician adhered an activity, hand position, and latent kit identifier label to each card. The SFE technician also drew an arrow on the evidence card to indicate the orientation of the prints relative to where the study participant stood. All evidence cards were placed into an envelope with the study participant's QR code label and latent kit identifier label on the front. A second SFE technician reviewed the contents of each evidence card and envelope before beginning digitization. An identical process was used for activities $2 \mathrm{~A}$ and $2 \mathrm{~B}$, although hand labeling was not possible, as study participants held the objects in both hands.

\begin{tabular}{|c|c|c|c|c|c|c|c|c|c|}
\hline$\Omega$ & FBI Baseline & $\begin{array}{l}\mathrm{A} \\
\mathrm{E}\end{array}$ & $\begin{array}{l}\text { IDEMIA } \\
\text { Jenetric }\end{array}$ & $\begin{array}{l}\mathrm{B} \\
\mathrm{F}\end{array}$ & $\begin{array}{l}\text { Advanced Optical Systems } \\
\text { Touchless Biometric Systems }\end{array}$ & $\begin{array}{l}\text { C } \\
\text { G }\end{array}$ & $\begin{array}{l}\text { Green Bit } \\
\text { Crossmatch }\end{array}$ & $\stackrel{D}{H}$ & $\begin{array}{l}\text { Cornell University } \\
\text { Clarkson University }\end{array}$ \\
\hline $1 \mathrm{~A}$ & Peering Into Window & $1 \mathrm{~B}$ & Fist Banging on Glass & $1 \mathrm{C}$ & Fingertip Window Slide & 10 & Get-away Palm on Glass & $1 \mathrm{E}$ & "OK" Sign on Glass \\
\hline $1 \mathrm{~F}$ & Counter Vault on Glass & 16 & Cylinder Grab & $1 \mathrm{H}$ & Impatient Tapping on Glass & $2 \mathrm{~A}$ & Samsung Galaxy S5 & $2 \mathrm{~B}$ & Apple iPhone $5 \mathrm{~s}$ \\
\hline 3 & Check & $4 \mathrm{~A}$ & Lined Paper & $4 B$ & Low-quality Copy Paper & $4 \mathrm{C}$ & High-quality Copy Paper & $4 D$ & Yellow Lined Paper \\
\hline $4 \mathrm{E}$ & Low-quality White Envelope & $4 \mathrm{~F}$ & Greeting Card and Envelope & $4 G$ & Manila Envelope & $5 \mathrm{~A}$ & Photo Paper & $5 \mathrm{~B}$ & Glossy Magazine \\
\hline $5 C$ & U.S. Currency & $6 \mathrm{~A}$ & Stamp & $6 \mathrm{~B}$ & Address Label & $6 \mathrm{C}$ & Clear Packing Tape & 60 & Black Electrical Tape \\
\hline $6 \mathrm{E}$ & Duct Tape & $7 \mathrm{~A}$ & Circuit Board & $7 \mathrm{~B}$ & $\mathrm{CD} / \mathrm{DVD}$ & $7 \mathrm{C}$ & Clear Plastic Bag & $7 \mathrm{D}$ & Black Plastic Bag \\
\hline
\end{tabular}



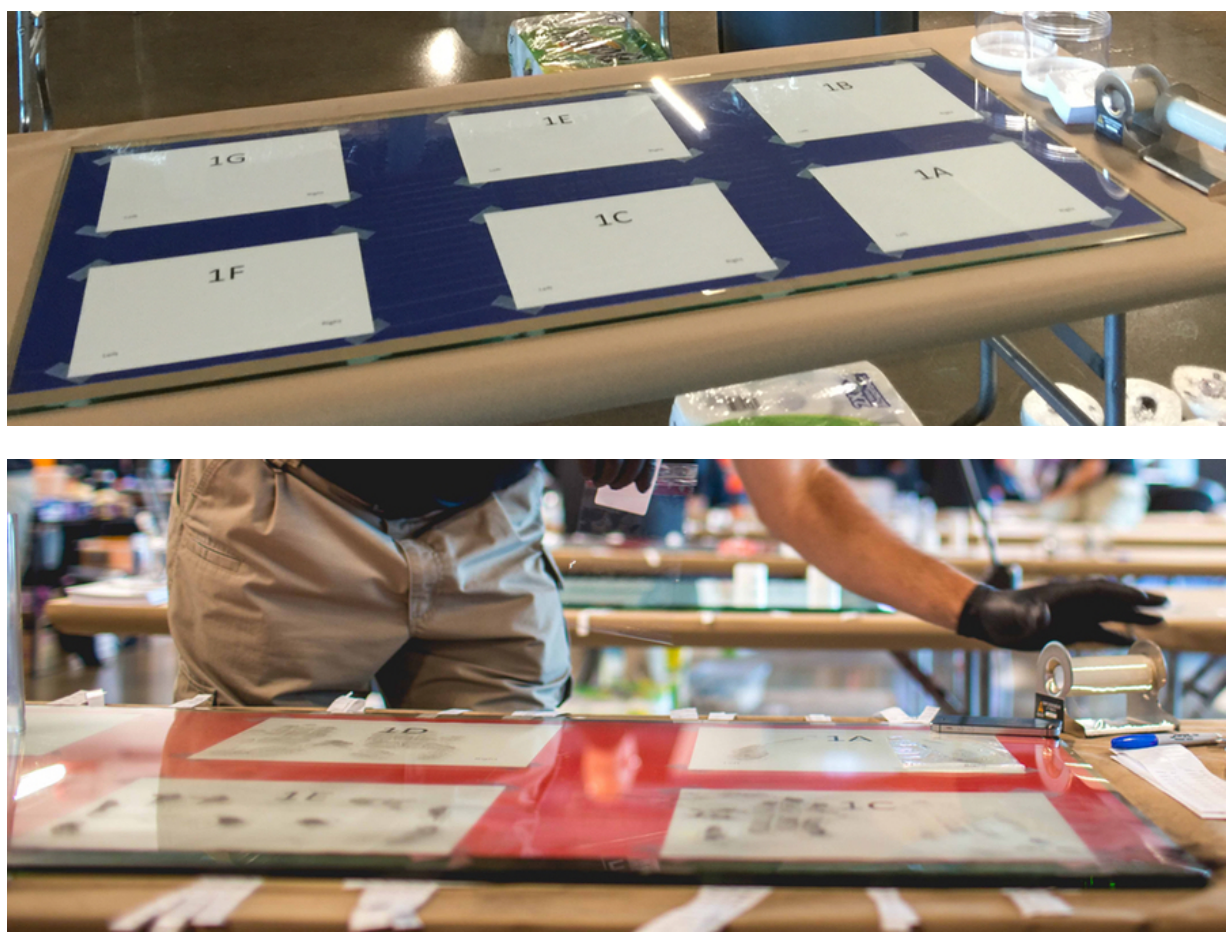

Fig. 9. On top, a picture of the glass configuration used during the latent print collection. When performing activities $1 \mathrm{~A}$ through $1 \mathrm{H}$, study participants were instructed to keep their touches within the corresponding region shown underneath the glass. CLPEs would perform black powder development over the surface and adhere an activity and hand label to evidence cards produced from each section. study participants performed at most six of the eight glass activities. Below, a picture of an SFE technician preparing to lift developed black powder latent prints from the glass with clear tape.

Digitizing evidence cards from activities $1 \mathrm{~A}$ through $2 \mathrm{~B}$ was performed one latent kit at a time, to reduce the risk of an erroneous latent kit identifier being entered. This was not feasible for activities 3 through 7D, due to the different ways the objects in each latent kit needed to be processed. Instead, these objects were developed and digitized by activity. Prior to development, a CLPE wearing gloves emptied each labeled evidence bag into a clean bin. The CLPE would take the remaining latent kit identifier labels and adhere them to each object from the bag. The CLPE also wrote the latent kit identifier directly on the object, to enable traceability if a label came loose during development. While there was a strong possibility that the identifier label would obscure latent prints for many of the objects, the groundtruth benefit provided by the label was more important. When photographing the objects, the CLPE placed a clean activity and latent kit identifier label in the frame with the object.

Identifiers in filenames were confirmed manually for all activities by CLPEs as they inspected every image when defining regions of interest. Hand positions recorded in filenames and labels were additionally confirmed for activities $1 \mathrm{~A}$ through $1 \mathrm{H}$ by examining the morphology of the hand.

No attempt was made to associate finger positions with any of the captured latents. Additionally, no hand information was recorded for any activity other than activities $1 \mathrm{~A}$ through $1 \mathrm{H}$.

\subsection{Public Data}

IARPA is pleased to be able to provide much of the developed latent print data to biometric researchers. Refer to Appendix $C$ for details.

\begin{tabular}{|c|c|c|c|c|c|c|c|c|c|}
\hline$\Omega$ & FBI Baseline & $\begin{array}{l}A \\
E\end{array}$ & $\begin{array}{l}\text { IDEMIA } \\
\text { Jenetric }\end{array}$ & $\begin{array}{l}\mathrm{B} \\
\mathrm{F}\end{array}$ & $\begin{array}{l}\text { Advanced Optical Systems } \\
\text { Touchless Biometric Systems }\end{array}$ & $\begin{array}{l}\text { C } \\
G\end{array}$ & $\begin{array}{l}\text { Green Bit } \\
\text { Crossmatch }\end{array}$ & $\begin{array}{l}\mathrm{D} \\
\mathrm{H}\end{array}$ & $\begin{array}{l}\text { Cornell University } \\
\text { Clarkson University }\end{array}$ \\
\hline $1 \mathrm{~A}$ & Peering Into Window & $1 \mathrm{~B}$ & Fist Banging on Glass & $1 \mathrm{c}$ & Fingertip Window Slide & 10 & Get-away Palm on Glass & $1 \mathrm{E}$ & "OK" Sign on Glass \\
\hline $1 \mathrm{~F}$ & Counter Vault on Glass & $1 \mathrm{G}$ & Cylinder Grab & $1 \mathrm{H}$ & Impatient Tapping on Glass & $2 \mathrm{~A}$ & Samsung Galaxy S5 & $2 \mathrm{~B}$ & Apple iPhone $5 \mathrm{~s}$ \\
\hline 3 & Check & $4 \mathrm{~A}$ & Lined Paper & $4 \mathrm{~B}$ & Low-quality Copy Paper & $4 \mathrm{C}$ & High-quality Copy Paper & $4 \mathrm{D}$ & Yellow Lined Paper \\
\hline $4 \mathrm{E}$ & Low-quality White Envelope & $4 \mathrm{~F}$ & Greeting Card and Envelope & $4 \mathrm{G}$ & Manila Envelope & $5 \mathrm{~A}$ & Photo Paper & $5 B$ & Glossy Magazine \\
\hline $5 c$ & U.S. Currency & $6 \mathrm{~A}$ & Stamp & $6 \mathrm{~B}$ & Address Label & $6 \mathrm{C}$ & Clear Packing Tape & $6 \mathrm{D}$ & Black Electrical Tape \\
\hline $6 \mathrm{E}$ & Duct Tape & $7 \mathrm{~A}$ & Circuit Board & $7 \mathrm{~B}$ & CD/DVD & $7 \mathrm{C}$ & Clear Plastic Bag & $7 \mathrm{D}$ & Black Plastic Bag \\
\hline
\end{tabular}




\section{Challengers}

Challengers in the Nail to Nail Fingerprint Challenge brought a variety of COTS and prototype devices for use. Descriptions of the devices, derived from information provided by the Challengers, are presented in Sections [6-6]. An example single finger capture from each Challenger is shown in Fig. 10. The same examples are shown in Fig. 11 with minutia extracted from the NIST-provided Fingerprint Feature Extractor (the EXTRACTOR) superimposed.

\section{Operator-Assisted Baseline Data $(\Omega)$}

The FBI training staff operated the traditional Baseline Data capture stations using Crossmatch L Scan 1000 live scan capture devices. These devices captured baseline N2N, 4-4-2 slap, and palm data at 393.7 PPCM (1000 PPI). Each device platen was equipped with a Crossmatch silicone membrane. More information about the collection of Baseline Data can be found in Section 4.2.

\section{IDEMIA (A)}

IDEMIA used its MorphoWave Desktop COTS device for the Nail to Nail Fingerprint Challenge. It is a touch-free device that captured images of the fingers as a study participant passed their hand horizontally over the scanning area. Its uses three-dimensional modeling and reconstruction technology to create a two-dimensional fingerprint image from a 4-4-1-1 slap sequence. The device had a hard metal and plastic body, and a glass scanning surface.

$\lceil\mathrm{https} / / /$ idemia.com

\section{Advanced Optical Systems (B)}

The Automated Non-Contact Distance Identity (ANDI) N2N product from Advanced Optical Systems is a kiosk device that used passive optical sensors to collect fingerprints from study participants without them touching the device. Multiple optical sensor heads were housed in a vertical configuration inside the kiosk. Upon prompting from a display, the study participant made vertical passes, top to bottom, through the well of the kiosk with each hand, and then again for each thumb (4-4-1-1). Images produced from the multiple sensors were stitched together to produce an N2N fingerprint image.

$\checkmark$ https://aos-inc.com

\section{Green Bit (C)}

Green Bit used its COTS DactyScan40i device for the N2N unattended rolled fingerprint capture. It is an FBI Appendix F certified dual flat finger/single rolled finger device with a scanning window of $4.06 \mathrm{~cm} \times 4.06 \mathrm{~cm}$ producing a 196.85 PPCM (500 PPI) image. Green Bit used algorithmic fingerprint quality assessments to accept only images that satisfied specific quality checks.

$\checkmark \mathrm{http}: / /$ greenbit.com

\section{Cornell University (D)}

Cornell's prototype single finger scanner used sonic and optical imaging for fingerprint capture. The study participant inserted one finger downward into a foam finger insert that sat at the top level of the device. Supported by a structure of acrylic and wood plates, metal screws, bolts, and shafts, the camera cylindrically swept around the centered finger insert to capture an image. The device supports liveness detection and touts removable finger inserts to support various finger sizes.

¿ http://sonicmems.ece.cornell.edu

\section{Jenetric (E)}

Marketed as the LIVETOUCH QUATTRO, Jenetric's FBI Appendix F certified COTS device collected fingerprints with a thin-film transistor (TFT) sensor. The sensor itself is transparent, and has a graphical display integrated underneath. The user interface on the integrated display prompted the study participant to collect fingerprints without human intervention.

$\checkmark$ https://jenetric.com

\section{Touchless Biometric Systems (F)}

Touchless Biometric Systems used its S120 enrollment device at the Nail to Nail Fingerprint Challenge. The device captures one finger at a time. The device sits a few inches high on a table and features a single circular cavity prominently on the front of the device. The study participant's finger is inserted

\begin{tabular}{|c|c|c|c|c|c|c|c|c|c|}
\hline$\Omega$ & FBI Baseline & $\begin{array}{l}A \\
E\end{array}$ & $\begin{array}{l}\text { IDEMIA } \\
\text { Jenetric }\end{array}$ & $\begin{array}{l}\mathrm{B} \\
\mathrm{F}\end{array}$ & $\begin{array}{l}\text { Advanced Optical Systems } \\
\text { Touchless Biometric Systems }\end{array}$ & $\begin{array}{l}\text { C } \\
G\end{array}$ & $\begin{array}{l}\text { Green Bit } \\
\text { Crossmatch }\end{array}$ & $\begin{array}{l}\mathrm{D} \\
\mathrm{H}\end{array}$ & $\begin{array}{l}\text { Cornell University } \\
\text { Clarkson University }\end{array}$ \\
\hline $1 \mathrm{~A}$ & Peering Into Window & $1 \mathrm{~B}$ & Fist Banging on Glass & $1 \mathrm{c}$ & Fingertip Window Slide & 10 & Get-away Palm on Glass & $1 \mathrm{E}$ & "OK" Sign on Glass \\
\hline $1 \mathrm{~F}$ & Counter Vault on Glass & $1 \mathrm{G}$ & Cylinder Grab & $1 \mathrm{H}$ & Impatient Tapping on Glass & $2 \mathrm{~A}$ & Samsung Galaxy S5 & $2 \mathrm{~B}$ & Apple iPhone $5 \mathrm{~s}$ \\
\hline 3 & Check & $4 \mathrm{~A}$ & Lined Paper & $4 \mathrm{~B}$ & Low-quality Copy Paper & $4 \mathrm{C}$ & High-quality Copy Paper & $4 \mathrm{D}$ & Yellow Lined Paper \\
\hline $4 \mathrm{E}$ & Low-quality White Envelope & $4 \mathrm{~F}$ & Greeting Card and Envelope & $4 \mathrm{G}$ & Manila Envelope & $5 \mathrm{~A}$ & Photo Paper & $5 B$ & Glossy Magazine \\
\hline $5 c$ & U.S. Currency & $6 \mathrm{~A}$ & Stamp & $6 \mathrm{~B}$ & Address Label & $6 \mathrm{C}$ & Clear Packing Tape & $6 \mathrm{D}$ & Black Electrical Tape \\
\hline $6 \mathrm{E}$ & Duct Tape & $7 \mathrm{~A}$ & Circuit Board & $7 \mathrm{~B}$ & CD/DVD & $7 \mathrm{C}$ & Clear Plastic Bag & $7 \mathrm{D}$ & Black Plastic Bag \\
\hline
\end{tabular}


into no-touch cavity and an image is captured.

$\checkmark$ https://tbs-biometrics.com

\section{Crossmatch (G)}

The Crossmatch Flexible Sensor is a prototype system that captures a single finger at a time and outputs an 8 bit grayscale 196.85 PPCM (500 PPI) rolled image. It consists of a flexible sensor and illumination electronics. A computer provides prompts for the study participant to place one finger onto a concave flexible sensor scanner film, nail side up. Mechanics supporting the flexible sensor scanner film receive a light downward pressure produced by the user, causing the sensor to wrap around the finger. Near-infrared $850 \mathrm{~nm}$ light-emitting diodes (LEDs) and a diffuser positioned above the flexible sensor project light towards the finger, which scatters out of the skin in roughly a Lambertian distribution. Pixels in contact with friction ridges contain more light than those sitting beneath valleys of the fingerprint.

$\checkmark$ https://crossmatch.com

\section{Clarkson University (H)}

Clarkson's device is a custom-built box of cameras designed to capture fingerprints in a traditional 4-4-2 finger scenario or two fingers at a time. The collection box is made of plastic with 3D printed components made out of photo-reactive resin. Inside are a set of 15 stationary cameras controlled through a computer that collects and processes the images. In combination, these cameras are capable of capturing 3280 pixel $\times 2464$ pixel stills. Neutral white LED strip lighting circled the inside of the box, providing illumination around inserted fingers.

$\lceil$ https://clarkson.edu/biomedical-signal-analysis-lab

\begin{tabular}{|c|c|c|c|c|c|c|c|c|c|}
\hline$\Omega$ & FBI Baseline & $\begin{array}{l}\text { A } \\
E\end{array}$ & $\begin{array}{l}\text { IDEMIA } \\
\text { Jenetric }\end{array}$ & $\begin{array}{l}\mathrm{B} \\
\mathrm{F}\end{array}$ & $\begin{array}{l}\text { Advanced Optical Systems } \\
\text { Touchless Biometric Systems }\end{array}$ & $\begin{array}{l}\text { C } \\
G\end{array}$ & $\begin{array}{l}\text { Green Bit } \\
\text { Crossmatch }\end{array}$ & $\begin{array}{l}\mathrm{D} \\
\mathrm{H}\end{array}$ & $\begin{array}{l}\text { Cornell University } \\
\text { Clarkson University }\end{array}$ \\
\hline $1 \mathrm{~A}$ & Peer & $1 \mathrm{~B}$ & Fist Banging on & $1 \mathrm{C}$ & Fingertip Window Slide & 10 & Get-away Palm on Glass & $1 \mathrm{E}$ & "OK" Sign on Glass \\
\hline $1 \mathrm{~F}$ & Counter Vault on Glass & $1 \mathrm{G}$ & Cylinder Grab & $1 \mathrm{H}$ & Impatient Tapping on Glass & $2 \mathrm{~A}$ & Samsung Galaxy S5 & $2 \mathrm{~B}$ & Apple iPhone $5 \mathrm{~s}$ \\
\hline 3 & Check & $4 \mathrm{~A}$ & Lined Paper & $4 \mathrm{~B}$ & Low-quality Copy Paper & $4 \mathrm{C}$ & High-quality Copy Paper & $4 \mathrm{D}$ & Yellow Lined Paper \\
\hline $4 \mathrm{E}$ & Low-quality White Envelope & $4 \mathrm{~F}$ & Greeting Card and Envelope & $4 G$ & Manila Envelope & $5 \mathrm{~A}$ & Photo Paper & $5 B$ & Glossy Magazine \\
\hline $5 \mathrm{C}$ & U.S. Currency & $6 \mathrm{~A}$ & Stamp & $6 \mathrm{~B}$ & Address Label & $6 \mathrm{C}$ & Clear Packing Tape & $6 \mathrm{D}$ & Black Electrical Tape \\
\hline $6 \mathrm{E}$ & Duct Tape & $7 \mathrm{~A}$ & Circuit Board & $7 \mathrm{~B}$ & $\mathrm{CD} / \mathrm{DVD}$ & $7 \mathrm{C}$ & Clear Plastic Bag & $7 D$ & Black Plastic Bag \\
\hline
\end{tabular}




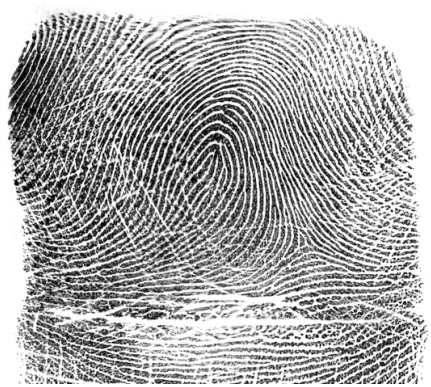

$\Omega$

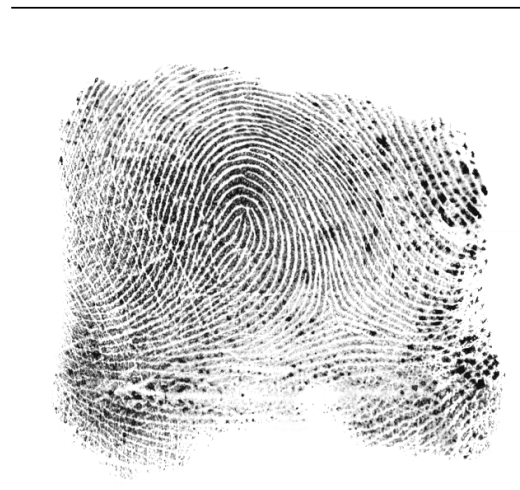

C

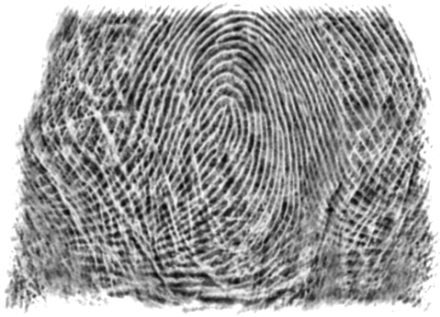

F

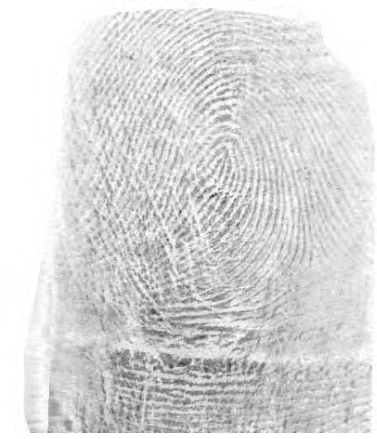

A

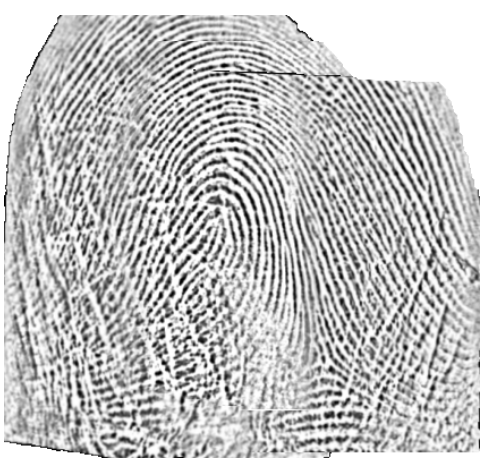

B

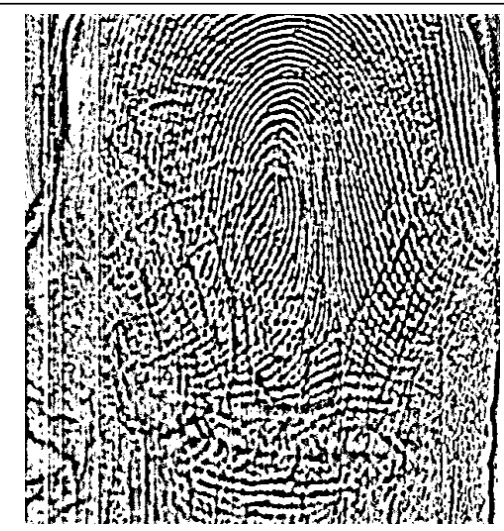

D

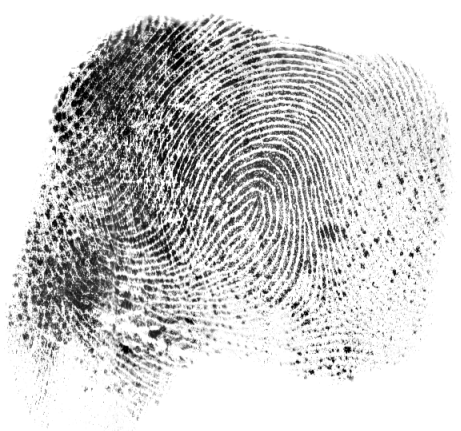

E

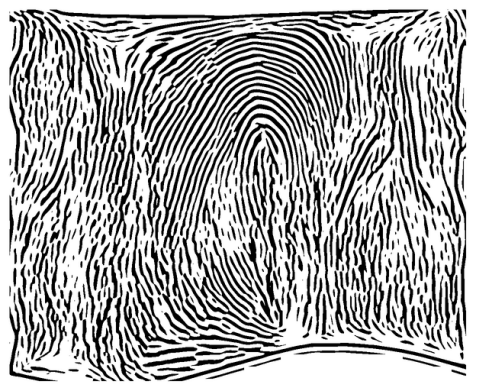

$\mathrm{H}$

Fig. 10. Example captures from each Challenger. Each capture shows the same left middle finger from the same study participant. Extracted minutia for these examples are shown in Fig. 11.

\begin{tabular}{|c|c|c|c|c|c|c|c|c|c|}
\hline$\Omega$ & FBI Baseline & $\begin{array}{l}\mathrm{A} \\
\mathrm{E}\end{array}$ & $\begin{array}{l}\text { IDEMIA } \\
\text { Jenetric }\end{array}$ & $\begin{array}{l}\mathrm{B} \\
\mathrm{F}\end{array}$ & $\begin{array}{l}\text { Advanced Optical Systems } \\
\text { Touchless Biometric Systems }\end{array}$ & $\begin{array}{l}C \\
G\end{array}$ & $\begin{array}{l}\text { Green Bit } \\
\text { Crossmatch }\end{array}$ & $\begin{array}{l}\mathrm{D} \\
\mathrm{H}\end{array}$ & $\begin{array}{l}\text { Cornell University } \\
\text { Clarkson University }\end{array}$ \\
\hline $1 \mathrm{~A}$ & Peering Into Window & $1 \mathrm{~B}$ & Fist Banging on Glass & $1 \mathrm{C}$ & Fingertip Window Slide & 1D & Get-away Palm on Glass & $1 \mathrm{E}$ & "OK" Sign on Glass \\
\hline $1 \mathrm{~F}$ & Counter Vault on Glass & 16 & Cylinder Grab & $1 \mathrm{H}$ & Impatient Tapping on Glass & $2 \mathrm{~A}$ & Samsung Galaxy S5 & $2 \mathrm{~B}$ & Apple iPhone $5 \mathrm{~s}$ \\
\hline 3 & Check & $4 \mathrm{~A}$ & Lined Paper & $4 B$ & Low-quality Copy Paper & $4 \mathrm{C}$ & High-quality Copy Paper & $4 \mathrm{D}$ & Yellow Lined Paper \\
\hline $4 \mathrm{E}$ & Low-quality White Envelope & $4 \mathrm{~F}$ & Greeting Card and Envelope & $4 G$ & Manila Envelope & $5 \mathrm{~A}$ & Photo Paper & $5 \mathrm{~B}$ & Glossy Magazine \\
\hline $5 \mathrm{C}$ & U.S. Currency & $6 \mathrm{~A}$ & Stamp & $6 \mathrm{~B}$ & Address Label & $6 \mathrm{C}$ & Clear Packing Tape & $6 \mathrm{D}$ & Black Electrical Tape \\
\hline $6 \mathrm{E}$ & Duct Tape & $7 \mathrm{~A}$ & Circuit Board & $7 \mathrm{~B}$ & $\mathrm{CD} / \mathrm{DVD}$ & $7 \mathrm{C}$ & Clear Plastic Bag & $7 \mathrm{D}$ & Black Plastic Bag \\
\hline
\end{tabular}




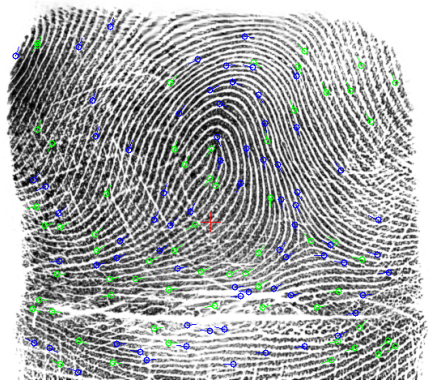

$\Omega$

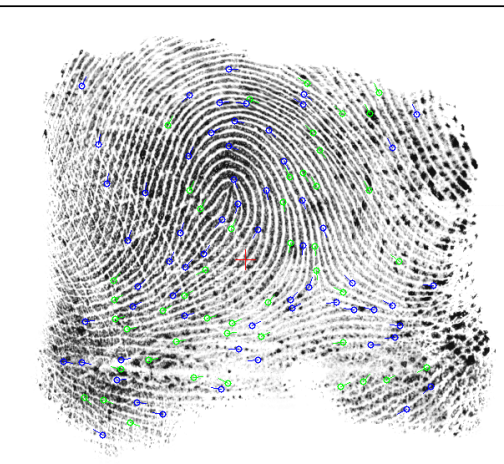

C

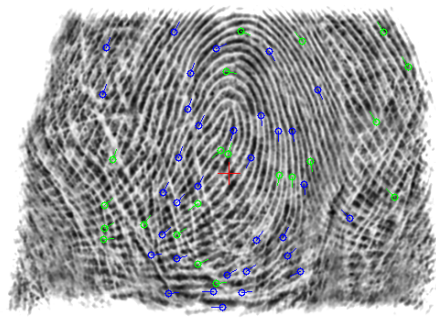

F

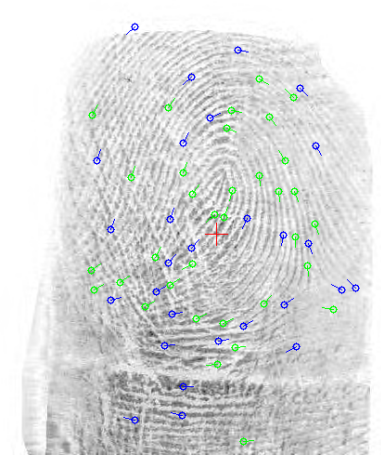

A

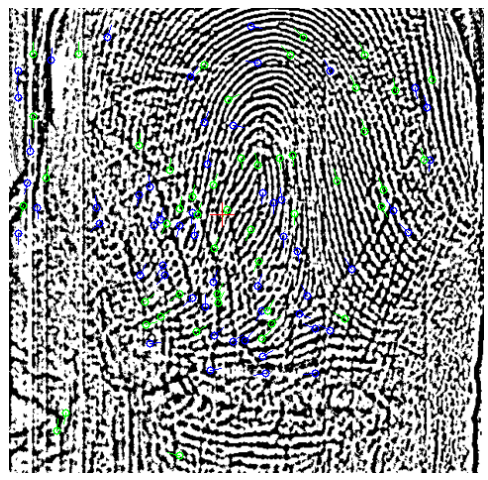

D

Permission not granted for reproduction.

G

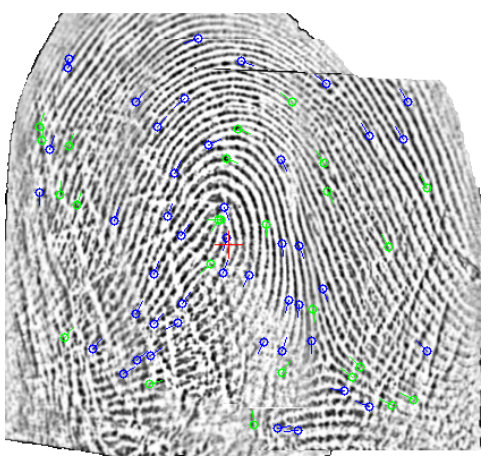

B

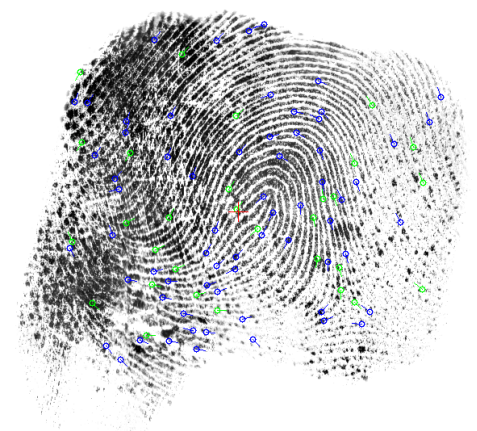

E

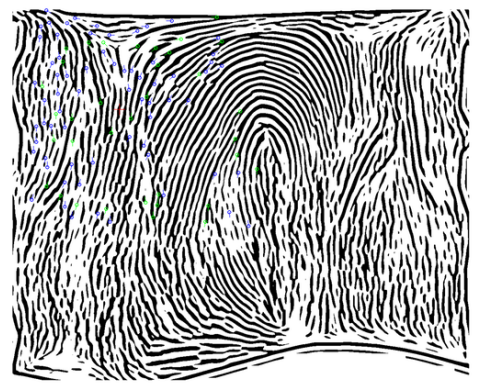

$\mathrm{H}$

Fig. 11. Example captures from each Challenger, with features discovered by the ExTRActor superimposed. Each capture shows the same left middle finger from the same study participant. Green circles represent ridge bifurcations and blue circles represent ridge endings. The direction of the colored lines show the angle of the minutia. The red cross represents the computed minutia center of mass. Minutia are only extracted for approximately half of $\mathrm{H}$, which may, in part, explain their poor identification performance. These images are shown without minutia superimposed in Fig. 10.

\begin{tabular}{|c|c|c|c|c|c|c|c|c|c|}
\hline$\Omega$ & FBI Baseline & $\begin{array}{l}A \\
E\end{array}$ & $\begin{array}{l}\text { IDEMIA } \\
\text { Jenetric }\end{array}$ & $\begin{array}{l}\mathrm{B} \\
\mathrm{F}\end{array}$ & $\begin{array}{l}\text { Advanced Optical Systems } \\
\text { Touchless Biometric Systems }\end{array}$ & $\begin{array}{l}\text { C } \\
G\end{array}$ & $\begin{array}{l}\text { Green Bit } \\
\text { Crossmatch }\end{array}$ & $\begin{array}{l}\mathrm{D} \\
\mathrm{H}\end{array}$ & $\begin{array}{l}\text { Cornell University } \\
\text { Clarkson University }\end{array}$ \\
\hline $1 \mathrm{~A}$ & Peering Into Window & $1 \mathrm{~B}$ & Fist Banging on Glass & $1 \mathrm{c}$ & Fingertip Window Slide & 10 & Get-away Palm on Glass & $1 \mathrm{E}$ & "OK" Sign on Glass \\
\hline $1 \mathrm{~F}$ & Counter Vault on Glass & $1 \mathrm{G}$ & Cylinder Grab & $1 \mathrm{H}$ & Impatient Tapping on Glass & $2 \mathrm{~A}$ & Samsung Galaxy S5 & $2 \mathrm{~B}$ & Apple iPhone $5 \mathrm{~s}$ \\
\hline 3 & Check & $4 \mathrm{~A}$ & Lined Paper & $4 \mathrm{~B}$ & Low-quality Copy Paper & $4 \mathrm{C}$ & High-quality Copy Paper & $4 \mathrm{D}$ & Yellow Lined Paper \\
\hline $4 \mathrm{E}$ & Low-quality White Envelope & $4 \mathrm{~F}$ & Greeting Card and Envelope & $4 \mathrm{G}$ & Manila Envelope & $5 \mathrm{~A}$ & Photo Paper & $5 B$ & Glossy Magazine \\
\hline $5 c$ & U.S. Currency & $6 \mathrm{~A}$ & Stamp & $6 \mathrm{~B}$ & Address Label & $6 \mathrm{C}$ & Clear Packing Tape & $6 \mathrm{D}$ & Black Electrical Tape \\
\hline $6 \mathrm{E}$ & Duct Tape & $7 \mathrm{~A}$ & Circuit Board & $7 \mathrm{~B}$ & CD/DVD & $7 \mathrm{C}$ & Clear Plastic Bag & $7 \mathrm{D}$ & Black Plastic Bag \\
\hline
\end{tabular}




\section{Metrics}

Metrics for determining prize winners were outlined in the Nail to Nail Fingerprint Challenge rules [6]. Each metric included a series of tiebreaker metrics that would be consulted if a tie on the primary metric was encountered.

\subsection{Accuracy}

A biometric identification system is a computer system that searches a biometric sample from an unknown subject against a set of samples from known subjects, to determine the identity of the source of the unknown sample. The set of samples from known subjects is referred to as an enrollment set. In an open-set identification system, not all searches have a corresponding known sample in the enrollment set.

Recognition error in an open-set biometric identification system can be measured by assessing the results of two distinct search scenarios. One type, a mated search, is the search of a biometric sample from a subject enrolled in the system. The second, a non-mated search, is the search of a biometric sample of a subject not enrolled in the system. Each search in a biometric identification system produces a candidate list, which is a list of subjects in decreasing order of perceived similarity from the searched biometric sample. Each subject in the candidate list has an associated comparison score or a numerical value used to quantify the similarity when compared with the searched biometric sample. Collectively, these scores are known as similarity scores, where the higher the similarity score, the more similar the subjects. Each entry in a candidate list is referred to by rank. The subject at rank 1 - the subject in the candidate list with the highest similarity score - is the subject that the system determined to be the most similar to the searched biometric sample. When examining candidate lists, it is critical to consider similarity scores and not just ranks. In a mated search, the subject at rank 1 will ideally have a comparably-large similarity score. In a non-mated search, the subject at rank 1 will ideally have a comparably-small similarity score, indicating that the subject in the searched sample is not enrolled.

Because there is not always a mate in the enrollment set for every search, open-set biometric identification systems, including the system used to perform all comparisons for the Nail to Nail Fingerprint Challenge, can produce two types of recognition error when searching. Type I error, or false positive, occurs during a non-mated search, when an enrolled subject is returned with a high similarity score, even though a subject not enrolled in the system was searched. The second type of error, Type II, or miss, occurs during a mated search, when the system returns an incorrect subject while searching with a sample of an enrolled subject.

The accuracy metrics described herein borrow heavily from those outlined in Fingerprint Vendor Technology Evaluation (FpVTE), NIST's one-to-many fingerprint identification technology evaluation [7].

\subsubsection{Type I}

The rate at which a Type I error occurs is quantified as the False Positive Identification Rate (FPIR). FPIR is the fraction of the non-mated searches where one or more enrolled identities are returned at or above threshold (T). FPIR is a function of the size of the enrollment set $(N)$, the length of candidate lists $(L)$, and the score threshold $(T)$. In the general case, this can be summarized as shown in Equation (1).

$$
\operatorname{FPIR}(N, T, L)=\quad \frac{\begin{array}{c}
\text { Number of searches with any non-mates returned } \\
\text { above threshold } T \text { on candidate list length } L
\end{array}}{\text { Number of non-mated searches conducted }}
$$

Equation (1) is equivalent to Equation (2), where $Q$ is the number of searches performed for which there exists no mate in the enrollment set and $d_{q 1}$ is the highest similarity score reported by the MATCHER for the $q$-th search.

\begin{tabular}{|c|c|c|c|c|c|c|c|c|c|}
\hline$\Omega$ & FBI Baseline & $\begin{array}{l}A \\
E\end{array}$ & $\begin{array}{l}\text { IDEMIA } \\
\text { Jenetric }\end{array}$ & $\begin{array}{l}\mathrm{B} \\
\mathrm{F}\end{array}$ & $\begin{array}{l}\text { Advanced Optical Systems } \\
\text { Touchless Biometric Systems }\end{array}$ & $\begin{array}{l}C \\
G\end{array}$ & $\begin{array}{l}\text { Green Bit } \\
\text { Crossmatch }\end{array}$ & $\begin{array}{l}\mathrm{D} \\
\mathrm{H}\end{array}$ & $\begin{array}{l}\text { Cornell University } \\
\text { Clarkson University }\end{array}$ \\
\hline $1 \mathrm{~A}$ & Peering Into Window & $1 \mathrm{~B}$ & Fist Banging on Glass & $1 \mathrm{C}$ & Fingertip Window Slide & 10 & Get-away Palm on Glass & $1 \mathrm{E}$ & “OK” Sign on Glass \\
\hline $1 \mathrm{~F}$ & Counter Vault on Glass & $1 \mathrm{G}$ & Cylinder Grab & $1 \mathrm{H}$ & Impatient Tapping on Glass & $2 \mathrm{~A}$ & Samsung Galaxy S5 & $2 \mathrm{~B}$ & Apple iPhone $5 \mathrm{~s}$ \\
\hline 3 & Check & $4 \mathrm{~A}$ & Lined Paper & $4 \mathrm{~B}$ & Low-quality Copy Paper & $4 \mathrm{C}$ & High-quality Copy Paper & $4 \mathrm{D}$ & Yellow Lined Paper \\
\hline $4 \mathrm{E}$ & Low-quality White Envelope & $4 \mathrm{~F}$ & Greeting Card and Envelope & $4 \mathrm{G}$ & Manila Envelope & $5 \mathrm{~A}$ & Photo Paper & $5 B$ & Glossy Magazine \\
\hline $5 c$ & U.S. Currency & $6 \mathrm{~A}$ & Stamp & $6 \mathrm{~B}$ & Address Label & $6 \mathrm{C}$ & Clear Packing Tape & $6 \mathrm{D}$ & Black Electrical Tape \\
\hline $6 \mathrm{E}$ & Duct Tape & $7 \mathrm{~A}$ & Circuit Board & $7 \mathrm{~B}$ & $\mathrm{CD} / \mathrm{DVD}$ & $7 \mathrm{C}$ & Clear Plastic Bag & $7 \mathrm{D}$ & Black Plastic Bag \\
\hline
\end{tabular}




$$
\operatorname{FPIR}(T)=\frac{\sum_{q=1}^{Q} \mathrm{H}\left(d_{q 1}-T\right)}{Q}
$$

The function $\mathrm{H}(x)$ used in Equation (2) is the Heaviside step function, shown in Equation (3).

$$
\mathrm{H}(x)= \begin{cases}0, & \text { if } x<0 \\ 1, & \text { if } x \geq 0\end{cases}
$$

\subsubsection{Type II}

The rate at which a Type II error occurs is quantified as False Negative Identification Rate (FNIR). FNIR is the fraction of the mated searches where the enrolled mate is outside the top $R$ rank or the similarity score is below threshold $(T)$. FNIR is a function of the size of the enrollment set $(N)$, the length of candidate lists $(L)$, the score threshold $(T)$, and the number of top candidates being considered $(R)$. This is summarized in the general case as depicted in Equation (4).

$$
\operatorname{FNIR}(N, R, T, L)=\frac{\begin{array}{c}
\text { Number of searches with mates outside top } R \text { ranks or } \\
\text { below threshold } T \text { on candidate list length } L
\end{array}}{\text { Number of mated searches conducted }}
$$

Equation (4) is equivalent to Equation (5), where $P$ is the number of searches performed for which there exists a mate in the enrollment set, $d_{p r}$ is the $r$-th lowest similarity score reported by the MATCHER for the $p$-th search, and $I_{p r}$ is 1 if the identity of the $r$-th candidate is the same as the identity of search $p$, or 0 otherwise.

$$
\operatorname{FNIR}(T)=1-\frac{1}{P} \sum_{p=1}^{P} \sum_{r=1}^{L} I_{p r}\left[1-H\left(d_{p r}-T\right)\right]
$$

All types of misses are accounted for identically when calculating FNIR. This includes situations in which the MATCHER could not generate a template from the image data provided, or the fingerprints were labeled incorrectly by the Challenger. Challengers were responsible for providing the correct finger positions. To be counted as correct identification, the Challenger needed to identify both the correct study participant identifier and the correct finger position. Refer to Sections 7.1.4 and 8 for more details on accounting for failures and strategies for successful identification.

Cumulative Match Characteristic Cumulative Match Characteristic (CMC) is the fraction of mated searches where the enrolled mate is at rank $R$ or better, regardless of its comparison score. CMC is a special case of FNIR when the constraint on threshold is removed. It is generally considered an inadequate accuracy metric because it ignores comparison scores and does not report Type I errors.

\subsubsection{Detection Error Tradeoff}

Detection Error Tradeoff (DET) characteristic curves are the primary accuracy metric for offline testing of biometric recognition algorithms. Each point on a DET curve exhibits the false positive and negative identification rates associated with a certain threshold value. The DET curve spans the entire range of

\begin{tabular}{|c|c|c|c|c|c|c|c|c|c|}
\hline$\Omega$ & FBI Baseline & $\begin{array}{l}A \\
E\end{array}$ & $\begin{array}{l}\text { IDEMIA } \\
\text { Jenetric }\end{array}$ & $\begin{array}{l}\mathrm{B} \\
\mathrm{F}\end{array}$ & $\begin{array}{l}\text { Advanced Optical Systems } \\
\text { Touchless Biometric Systems }\end{array}$ & $\begin{array}{l}C \\
G\end{array}$ & $\begin{array}{l}\text { Green Bit } \\
\text { Crossmatch }\end{array}$ & $\begin{array}{l}\mathrm{D} \\
\mathrm{H}\end{array}$ & $\begin{array}{l}\text { Cornell University } \\
\text { Clarkson University }\end{array}$ \\
\hline 1A & Peer & 1B & Fist Bangir & 1C & Fingertip Window Slide & $1 \mathrm{D}$ & Get-away Palm on Glass & $1 \mathrm{E}$ & "OK" Sign on Glass \\
\hline $1 \mathrm{~F}$ & Counter Vault on Glass & 16 & Cylinder Grab & $1 \mathrm{H}$ & Impatient Tapping on Glass & $2 \mathrm{~A}$ & Samsung Galaxy S5 & $2 \mathrm{~B}$ & Apple iPhone $5 \mathrm{~s}$ \\
\hline 3 & Check & $4 \mathrm{~A}$ & Lined Paper & $4 B$ & Low-quality Copy Paper & $4 \mathrm{C}$ & High-quality Copy Paper & $4 \mathrm{D}$ & Yellow Lined Paper \\
\hline $4 \mathrm{E}$ & Low-quality White Envelope & $4 \mathrm{~F}$ & Greeting Card and Envelope & $4 G$ & Manila Envelope & $5 \mathrm{~A}$ & Photo Paper & $5 \mathrm{~B}$ & Glossy Magazine \\
\hline $5 \mathrm{C}$ & U.S. Currency & $6 \mathrm{~A}$ & Stamp & $6 \mathrm{~B}$ & Address Label & $6 \mathrm{C}$ & Clear Packing Tape & $6 \mathrm{D}$ & Black Electrical Tape \\
\hline $6 \mathrm{E}$ & Duct Tape & $7 \mathrm{~A}$ & Circuit Board & $7 \mathrm{~B}$ & CD/DVD & $7 \mathrm{C}$ & Clear Plastic Bag & $7 \mathrm{D}$ & Black Plastic Bag \\
\hline
\end{tabular}
possible threshold values, which is normally the range of the similarity scores.

DET curves are presented for each Challenger in Figs. 15 and 17. In a DET curve, Type I error rates are plotted on the $x$-axis and Type II error rates are plotted on the $y$-axis, giving uniform treatment to both types 
of error. Both axes use a logarithmic scale, which spreads out the plot and better distinguishes different well-performing systems. When calculating FPIR and FNIR, all ranks were considered $(L=R=220)$.

\subsubsection{Handling Failures}

\section{Failure to Acquire}

Challengers were required to capture an image of all ten fingers and study participants were required to have all ten fingers. As such, Challengers were inherently penalized during searches for any fingers that they failed to acquire (Section 7.3), since it would not be possible to correctly identify a latent fingerprint from a study participant's finger that was not acquired. This miss increased the FNIR.

\section{Failure to Extract/Encode}

The EXTRACTOR extracts fingerprint features and encodes the feature data into two types of templates: enrollment and search. In the event that an enrollment template could not be created, all mated latent searches would miss, increasing FNIR. If a search template could not be created during N2N identification, it was similarly counted as miss. Misses were accounted for by adding an instance of the lowest non-mated score to the set of mated scores.

Failures to extract features in latent search template generation were removed from the test, since all search queries were identical for each Challenger. There was a noticeably high percentage of latent search failures. Latent search template failures to extract are a result of either the developed latent image or the MATCHER, and not the Challenger.

\section{Failure to Search}

The MATCHER takes in search templates and produces a candidate list. Typically, if a biometric algorithm fails to perform a search and produce a candidate list, it is counted as a miss. However, a property of the MATcher is that a candidate list is always produced as long as a search template is produced. This means the only failures to search would be the result of the ExTRACTOR failing to create a search template.

\subsubsection{Tiebreaker}

FNIR was measured at an FPIR of $10^{-1}$. In the event of an FNIR tie, medians of the following NIST Fingerprint Image Quality (NFIQ) 2.0 feature values calculated over the Challenger's captured images would be used to break the tie:

1. NFIQ 2.0

2. NFIQ 2.0: Frequency Domain Analysis (Standard Deviation)

3. NFIQ 2.0: Ridge Valley Uniformity (Standard Deviation)

\subsection{Timing}

The time to acquire images of a study participant's ten fingers was recorded by the JHU APL facility API, as explained in Section 3.8. The metric for determining the fastest overall acquisition time is defined in Equation (6).

$$
\text { Timing Score }=\text { median } \times(1+\mid \text { skew } \mid)
$$

Median time is a more robust measure of the location of a distribution than the mean because means are greatly affected by outliers, such as study participants that are extremely difficult to fingerprint.

Skew is a measure of the symmetry of a distribution from the left and right of the median, with 0 indicating a normal distribution. Skew was incorporated into the timing metric to observe the weight of the tails of

\begin{tabular}{|c|c|c|c|c|c|c|c|c|c|}
\hline$\Omega$ & FBI Baseline & $\begin{array}{l}A \\
E\end{array}$ & $\begin{array}{l}\text { IDEMIA } \\
\text { Jenetric }\end{array}$ & $\begin{array}{l}\mathrm{B} \\
\mathrm{F}\end{array}$ & $\begin{array}{l}\text { Advanced Optical Systems } \\
\text { Touchless Biometric Systems }\end{array}$ & $\begin{array}{l}\text { C } \\
G\end{array}$ & $\begin{array}{l}\text { Green Bit } \\
\text { Crossmatch }\end{array}$ & $\begin{array}{l}\mathrm{D} \\
\mathrm{H}\end{array}$ & $\begin{array}{l}\text { Cornell University } \\
\text { Clarkson University }\end{array}$ \\
\hline $1 \mathrm{~A}$ & Peering Into Window & $1 \mathrm{~B}$ & Fist Banging on Glass & $1 \mathrm{c}$ & Fingertip Window Slide & 10 & Get-away Palm on Glass & $1 \mathrm{E}$ & "OK" Sign on Glass \\
\hline $1 \mathrm{~F}$ & Counter Vault on Glass & $1 \mathrm{G}$ & Cylinder Grab & $1 \mathrm{H}$ & Impatient Tapping on Glass & $2 \mathrm{~A}$ & Samsung Galaxy S5 & $2 \mathrm{~B}$ & Apple iPhone $5 \mathrm{~s}$ \\
\hline 3 & Check & $4 \mathrm{~A}$ & Lined Paper & $4 \mathrm{~B}$ & Low-quality Copy Paper & $4 \mathrm{C}$ & High-quality Copy Paper & $4 \mathrm{D}$ & Yellow Lined Paper \\
\hline $4 \mathrm{E}$ & Low-quality White Envelope & $4 \mathrm{~F}$ & Greeting Card and Envelope & $4 \mathrm{G}$ & Manila Envelope & $5 \mathrm{~A}$ & Photo Paper & $5 B$ & Glossy Magazine \\
\hline $5 c$ & U.S. Currency & $6 \mathrm{~A}$ & Stamp & $6 \mathrm{~B}$ & Address Label & $6 \mathrm{C}$ & Clear Packing Tape & $6 \mathrm{D}$ & Black Electrical Tape \\
\hline $6 \mathrm{E}$ & Duct Tape & $7 \mathrm{~A}$ & Circuit Board & $7 \mathrm{~B}$ & CD/DVD & $7 \mathrm{C}$ & Clear Plastic Bag & $7 \mathrm{D}$ & Black Plastic Bag \\
\hline
\end{tabular}


the timing distribution. Extra processing time for a study participant would translate into longer wait times for enrollees as a queue forms when such a device is deployed in an operational setting.

For the Nail to Nail Fingerprint Challenge, skew was defined as shown in Equation (7) [8], where $X$ is the set of all acquisition times, $\bar{X}$ is the mean of $X$, and $n$ is the length of $X$.

$$
\text { Skew }=\frac{\frac{1}{n} \sum_{i=1}^{n}\left(X_{i}-\bar{X}\right)^{3}}{\left\{\frac{1}{n} \sum_{i=1}^{n}\left(X_{i}-\bar{X}\right)^{2}\right\}^{3 / 2}}
$$

\subsubsection{Tiebreaker}

In the event of identical acquisition timing scores, the median acquisition time would be used to break the tie.

\subsection{Acquisition Rate}

All study participants were required to have all ten fingers accessible to be fingerprinted. If there was a study participant whose fingerprints could not be acquired by the traditional operator-assisted method, the study participant was excused from the fingerprint data collection. This means that it was possible to achieve a $100 \%$ acquisition rate.

A successful acquisition was achieved by acquiring images for all ten fingers from a subject, regardless of quality. Acquiring (1 to 9) fingers was considered a failure to acquire in terms of the acquisition rate metric. Regardless of the calculated acquisition rate, all images submitted to the N2N backend server were used when performing searches.

\begin{tabular}{|c|c|c|c|c|c|c|c|c|c|}
\hline$\Omega$ & FBI Baseline & $\begin{array}{l}A \\
E\end{array}$ & $\begin{array}{l}\text { IDEMIA } \\
\text { Jenetric }\end{array}$ & $\begin{array}{l}\mathrm{B} \\
\mathrm{F}\end{array}$ & $\begin{array}{l}\text { Advanced Optical Systems } \\
\text { Touchless Biometric Systems }\end{array}$ & $\begin{array}{l}C \\
G\end{array}$ & $\begin{array}{l}\text { Green Bit } \\
\text { Crossmatch }\end{array}$ & $\begin{array}{l}\mathrm{D} \\
\mathrm{H}\end{array}$ & $\begin{array}{l}\text { Cornell University } \\
\text { Clarkson University }\end{array}$ \\
\hline $1 \mathrm{~A}$ & Peering Into Window & $1 \mathrm{~B}$ & Fist Banging on Glass & $1 \mathrm{C}$ & Fingertip Window Slide & 10 & Get-away Palm on Glass & $1 \mathrm{E}$ & "OK" Sign on Glass \\
\hline $1 \mathrm{~F}$ & Counter Vault on Glass & $1 \mathrm{G}$ & Cylinder Grab & $1 \mathrm{H}$ & Impatient Tapping on Glass & $2 \mathrm{~A}$ & Samsung Galaxy S5 & $2 \mathrm{~B}$ & Apple iPhone 5s \\
\hline 3 & Check & $4 \mathrm{~A}$ & Lined Paper & $4 \mathrm{~B}$ & Low-quality Copy Paper & $4 \mathrm{C}$ & High-quality Copy Paper & $4 \mathrm{D}$ & Yellow Lined Paper \\
\hline $4 \mathrm{E}$ & Low-quality White Envelope & $4 \mathrm{~F}$ & Greeting Card and Envelope & $4 \mathrm{G}$ & Manila Envelope & $5 \mathrm{~A}$ & Photo Paper & $5 B$ & Glossy Magazine \\
\hline $5 c$ & U.S. Currency & $6 \mathrm{~A}$ & Stamp & $6 \mathrm{~B}$ & Address Label & $6 \mathrm{C}$ & Clear Packing Tape & $6 \mathrm{D}$ & Black Electrical Tape \\
\hline $6 \mathrm{E}$ & Duct Tape & $7 \mathrm{~A}$ & Circuit Board & $7 \mathrm{~B}$ & $\mathrm{CD} / \mathrm{DVD}$ & $7 \mathrm{C}$ & Clear Plastic Bag & $7 \mathrm{D}$ & Black Plastic Bag \\
\hline
\end{tabular}




\section{Methodology}

A large-scale operational fingerprint feature extractor (EXTRACTOR) and identification algorithm (MATCHER) were used to generate similarity scores. Each search with the MATCHER resulted in a candidate list of at most 220 candidates.

\subsection{Identification Algorithms}

The MATChER produced all similarity scores required to calculate FNIR and FPIR. The system consists of two distinct set of algorithms, one for N2N identification and another for latent print identification. Both algorithms are distributed systems, operating across many networked machines simultaneously. Identification was performed on a per-finger (not per-subject) basis. Finger positions were provided to the algorithm when searching with $\mathrm{N} 2 \mathrm{~N}$ samples only.

Although the exact mechanisms for identification in these two systems are proprietary and were not shared with Challenge staff, both do export minutia from search samples. Refer to Fig. 10 and Fig. 12 for examples of the types of minutia extracted. When operating in latent mode, the MATCHER searches the latent image by rotating in increments of $360^{\circ}$, making the original orientation of the image inconsequential. In N2N mode, the MATCHER does not rotate the search image, and so it was important that Challengers adhere to the Challenge image specifications detailed in Section 4.1, requiring that the image be in an approximately upright orientation.

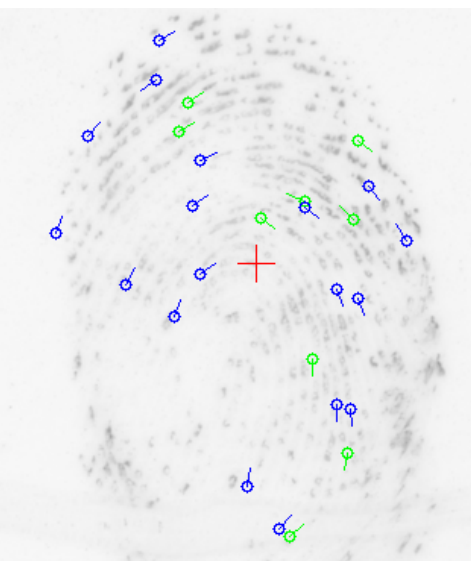

Fig. 12. Example of minutia detected by the ExтRActor superimposed on a latent fingerprint image. Green circles represent ridge bifurcations and blue circles represent ridge endings. The direction of the colored line shows the angle of the minutia. The red cross represents the computed minutia center of mass.

For fairness, in addition to using the MATCHER, Challengers were given an option to submit their own template generation and identification algorithms that complied to the N2N Challenge API [9]. This option was designed for Challengers that felt images generated by their device would be better recognized by their own software. NIST would have computed all figures of merit from both the MATCHER and the Challenger's software, and reported the better of the two.

No Challengers opted to submit software.

\begin{aligned}$\Omega &$ FBI Baseline \\ \hline IA & Peering Into Window \\ 1 F & Counter Vault on Glass \\ 3 & Check \\ $4 E &$ Low-quality White Envelope \\ $5 C &$ U.S. Currency \\ $6 \mathrm{E} &$ Duct Tape \end{aligned}

\begin{tabular}{cl} 
A & IDEMIA \\
E & Jenetric \\
\hline 1B & Fist Banging on Glass \\
1G & Cylinder Grab \\
4A & Lined Paper \\
4F & Greeting Card and Envelope \\
6A & Stamp \\
7A & Circuit Board
\end{tabular}

Advanced Optical Systems
Touchless Biometric Systems
Fingertip Window Slide
Impatient Tapping on Glass
Low-quality Copy Paper
Manila Envelope
Address Label
CD/DVD

Green Bit
Crossmatch
Get-away Palm on Glass
Samsung Galaxy S5
High-quality Copy Paper
Photo Paper
Clear Packing Tape
Clear Plastic Bag

Cornell University Clarkson University "OK" Sign on Glas Yellow Lined Paper Glossy Magazine Black Electrical Tap Black Plastic Bag 


\subsection{Nail to Nail Identification}

Up to $3310 \mathrm{~N} 2 \mathrm{~N}$ fingerprint images from 331 study participants were searched against a ten-print enrollment set from each of 2999999 non-mated subjects plus 331 study participants from Baseline Data in the N2N identification portion of the Nail to Nail Fingerprint Challenge. Each of the 2999999 non-mated subjects had between 1 and 10 rolled fingerprint images, for a total of 29982781 non-mated fingerprint images. Individual fingerprint images from each N2N study participant were enrolled as separate subjects in the enrollment set - one finger per subject — for a total of 3003309 subjects identifiers and 29986091 fingers in the enrollment set.

\subsubsection{Nail to Nail Non-mated Searches}

Operationally-collected law enforcement rolled fingerprint images from 2999999 subjects were encoded and inserted into the enrollment set of the MATCHER. Each Challenger image was then encoded and searched against the enrollment set that contained no known mates. Each finger was searched separately, for at most 10 non-mated searches per study participant per Challenger, totaling 25835 non-mated searches.

\subsubsection{Nail to Nail Mated Searches}

For each study participant, 10 individual finger images from $\Omega 1$ - the first of two sets of operator-assisted N2N Baseline Data (Section 3.4) - were encoded and inserted into the enrollment set of the MATCHER. Operationally-collected law enforcement rolled fingerprint images from 2999999 non-mated subjects were added to the enrollment set. Each finger image collected by each Challenger was searched separately, for at most 10 mated searches per study participant per Challenger. For $\Omega$, images from $\Omega 2$ - the second of two sets of operator-assisted N2N Baseline Data (Section 3.4) - were used. A correct result was defined as returning the correct study participant identifier and correct finger position. Any failures by Challengers to acquire study participant fingerprint images or failures to extract features from acquired images by the MATCHER counted as a false negative by adding a small similarity score for the mated search that would have been performed (Section 7.1.4). In total, 25835 mated searches were performed.

\subsection{Latent Identification}

62721 latent fingerprint images were searched against ten-print enrollment sets of 2999999 non-mated subjects plus 331 study participants from each Challenger in the latent identification portion of the Nail to Nail Fingerprint Challenge. Each of the 2999999 non-mated subjects had between 1 and 10 rolled fingerprint images, for a total of 29982781 non-mated fingerprint images. Individual fingerprint images from each $\mathrm{N} 2 \mathrm{~N}$ study participant were enrolled as a separate subject in the enrollment set - one finger per subject - for a total of 3003309 subject identifiers and 29986091 fingers in the enrollment set. Each latent fingerprint contained traces of only one fingerprint. Only regions marked as distal phalanx by CLPEs were searched.

\subsubsection{Latent Non-mated Searches}

Operationally-collected law enforcement rolled fingerprint images from 2999999 subjects were encoded and inserted into the enrollment set of the MATCHER. Each image extracted from a region of interest defined by CLPEs was then encoded and searched against the enrollment set that contained no known mates. A total of 62721 non-mated latent searches were performed.

\begin{tabular}{|c|c|c|c|c|c|c|c|c|c|}
\hline$\Omega$ & FBI Baseline & $\begin{array}{l}A \\
E\end{array}$ & $\begin{array}{l}\text { IDEMIA } \\
\text { Jenetric }\end{array}$ & $\begin{array}{l}\mathrm{B} \\
\mathrm{F}\end{array}$ & $\begin{array}{l}\text { Advanced Optical Systems } \\
\text { Touchless Biometric Systems }\end{array}$ & $\begin{array}{l}\text { C } \\
G\end{array}$ & $\begin{array}{l}\text { Green Bit } \\
\text { Crossmatch }\end{array}$ & $\begin{array}{l}\mathrm{D} \\
\mathrm{H}\end{array}$ & $\begin{array}{l}\text { Cornell University } \\
\text { Clarkson University }\end{array}$ \\
\hline 1A & Jnto Window & $1 \mathrm{~B}$ & Fist Banging on & $1 \mathrm{C}$ & Fingertip Window Slide & 10 & Get-away Palm on Glass & $1 \mathrm{E}$ & “OK" Sign on Glass \\
\hline $1 \mathrm{~F}$ & Counter Vault on Glass & $1 \mathrm{G}$ & Cylinder Grab & $1 \mathrm{H}$ & Impatient Tapping on Glass & $2 \mathrm{~A}$ & Samsung Galaxy S5 & $2 \mathrm{~B}$ & Apple iPhone $5 \mathrm{~s}$ \\
\hline 3 & Check & $4 \mathrm{~A}$ & Lined Paper & $4 B$ & Low-quality Copy Paper & $4 \mathrm{C}$ & High-quality Copy Paper & $4 \mathrm{D}$ & Yellow Lined Paper \\
\hline $4 \mathrm{E}$ & Low-quality White Envelope & $4 \mathrm{~F}$ & Greeting Card and Envelope & $4 G$ & Manila Envelope & $5 \mathrm{~A}$ & Photo Paper & $5 B$ & Glossy Magazine \\
\hline $5 c$ & U.S. Currency & $6 \mathrm{~A}$ & Stamp & $6 \mathrm{~B}$ & Address Label & $6 \mathrm{C}$ & Clear Packing Tape & $6 \mathrm{D}$ & Black Electrical Tape \\
\hline $6 \mathrm{E}$ & Duct Tape & $7 \mathrm{~A}$ & Circuit Board & $7 \mathrm{~B}$ & CD/DVD & $7 \mathrm{C}$ & Clear Plastic Bag & $7 \mathrm{D}$ & Black Plastic Bag \\
\hline
\end{tabular}




\subsubsection{Latent Mated Searches}

For each Challenger, the images used to search the enrollment set in N2N identification were encoded and inserted to the enrollment set of the MATCHER (Section 8.2). For $\Omega$, images from $\Omega 2$ were used. Operationallycollected law enforcement rolled fingerprint images from 2999999 non-mated subjects were added to the enrollment set.

Each image extracted from a region of interest defined by CLPEs was then encoded and searched against the enrollment set. A correct result was defined as returning any finger position from the correct study participant identifier. In cases where the hand leaving the latent print was known (left or right), it was required that a finger position from the known hand be returned with the correct study participant identifier to be considered a correct result. There were no latent fingerprints for which the correct finger position was known ahead of time, and activities $1 \mathrm{~A}$ through $1 \mathrm{H}$ had a known hand. Details regarding handling failures to search can be found in Section 7.1.4, and affected all Challengers equally. A total of 564489 mated latent searches were performed.

\begin{tabular}{|c|c|c|c|c|c|c|c|c|c|}
\hline$\Omega$ & FBI Baseline & $\begin{array}{l}A \\
E\end{array}$ & $\begin{array}{l}\text { IDEMIA } \\
\text { Jenetric }\end{array}$ & $\begin{array}{l}\mathrm{B} \\
\mathrm{F}\end{array}$ & $\begin{array}{l}\text { Advanced Optical Systems } \\
\text { Touchless Biometric Systems }\end{array}$ & $\begin{array}{l}c \\
G\end{array}$ & $\begin{array}{l}\text { Green Bit } \\
\text { Crossmatch }\end{array}$ & $\begin{array}{l}\mathrm{D} \\
\mathrm{H}\end{array}$ & $\begin{array}{l}\text { Cornell University } \\
\text { Clarkson University }\end{array}$ \\
\hline $1 \mathrm{~A}$ & Peering Into Window & $1 \mathrm{~B}$ & Fist Banging on Glass & $1 \mathrm{C}$ & Fingertip Window Slide & 1D & Get-away Palm on Glass & $1 \mathrm{E}$ & “OK" Sign on Glass \\
\hline $1 \mathrm{~F}$ & Counter Vault on Glass & 16 & Cylinder Grab & $1 \mathrm{H}$ & Impatient Tapping on Glass & $2 \mathrm{~A}$ & Samsung Galaxy S5 & $2 \mathrm{~B}$ & Apple iPhone $5 \mathrm{~s}$ \\
\hline 3 & Check & $4 \mathrm{~A}$ & Lined Paper & $4 \mathrm{~B}$ & Low-quality Copy Paper & $4 \mathrm{C}$ & High-quality Copy Paper & $4 \mathrm{D}$ & Yellow Lined Paper \\
\hline $4 \mathrm{E}$ & Low-quality White Envelope & $4 \mathrm{~F}$ & Greeting Card and Envelope & $4 \mathrm{G}$ & Manila Envelope & $5 \mathrm{~A}$ & Photo Paper & $5 B$ & Glossy Magazine \\
\hline $5 c$ & U.S. Currency & $6 \mathrm{~A}$ & Stamp & $6 \mathrm{~B}$ & Address Label & 6c & Clear Packing Tape & $6 \mathrm{D}$ & Black Electrical Tape \\
\hline $6 \mathrm{E}$ & Duct Tape & $7 \mathrm{~A}$ & Circuit Board & $7 \mathrm{~B}$ & CD/DVD & $7 \mathrm{C}$ & Clear Plastic Bag & 70 & Black Plastic Bag \\
\hline
\end{tabular}




\section{Results - Acquisitions}

Observed acquisition rates and times are detailed in Sections 9.2 and 9.3. Caveats listed in Section 9.1 help explain some particularly unusual values.

\subsection{Caveats}

On the first day of the Challenge, B and D disclosed that they experienced failures using their software to submit acquired images to the $\mathrm{N} 2 \mathrm{~N}$ backend server. It was determined that the issue resided on the Challengers' systems and not the N2N backend server. The N2N Judging Committee decided to allow Challengers to resubmit data that was missing from the N2N backend server but saved locally on Challenger hardware. In doing so, the Challenger would be voluntarily disqualifying themselves from any prizes related to acquisition timing (Section 9.3), due to the fact that timing is recorded by the JHU APL facility API. D opted to resubmit their missing data, but B did not.

On the second day of the Challenge, G's device, a prototype, was beginning to experience damage. The Challenger chose not to participate in the data collection on the third day, so that their device would still be presentable for a United States Government open house scheduled for that evening. On the fourth day, the Challenger continued to collect data until the device ultimately experienced irreparable damage.

After interacting with several study participants, $\mathrm{H}$ observed that they were frequently unable to acquire a complete set of fingerprints from a study participant within the five min the study participant visited their acquisition station. The Challenger continued to participate in the fingerprint data collection and opted to capture as many fingers from each study participant as possible, realizing that their acquisition rate would make them ineligible for many performance-based prizes.

Challengers were permitted to process captured data after a study participant had left their capture station, so long as the data was submitted to the $\mathrm{N} 2 \mathrm{~N}$ backend server by the end of the Challenge. D performed a large amount of post-processing. Additionally, D resubmitted data missed on the first day of the Challenge at various times throughout the week, creating large acquisition timing outliers.

\subsection{Acquisition Rate}

A successful acquisition in the Nail to Nail Fingerprint Challenge was defined as capturing all 10 fingers for a single study participant. All study participants were required to have all 10 fingers accessible, so acquiring anything less than 10 fingers was considered a failure to acquire. Refer to Section 7.3 for complete details on the metrics for determining acquisition rate.

The observed acquisition rate outcomes are plotted in Fig. 13. To be eligible for most Nail to Nail Fingerprint Challenge prizes, Challengers needed to acquire fingerprint images from at least $90 \%$ of study participants. This value was achieved for all Challengers, except for $\mathrm{G}$ and H. $\Omega$ was required to achieve a $100 \%$ acquisition rate in order to establish baseline metrics.

\subsection{Acquisition Time}

A prize was awarded for having the best acquisition timing metric. The metric for acquisition time incorporated both the Challenger's median acquisition time and the skew of the set of acquisition times. This was important in order to incorporate outliers into the prize. Refer to Section 7.2 for complete details on the acquisition time metric.

The observed median acquisition time and timing metric are reported in Table 4. Boxplots and violin plots of acquisition times are shown in Fig. 14.

Acquisition time statistics do not depend on the acquisition rate and are an overall reflection of acquisitions performed during the Nail to Nail Fingerprint Challenge. That is, the times reported are respective of a

\begin{tabular}{|c|c|c|c|c|c|c|c|c|c|}
\hline$\Omega$ & FBI Baseline & $\begin{array}{l}A \\
E\end{array}$ & $\begin{array}{l}\text { IDEMIA } \\
\text { Jenetric }\end{array}$ & $\begin{array}{l}\mathrm{B} \\
\mathrm{F}\end{array}$ & $\begin{array}{l}\text { Advanced Optical Systems } \\
\text { Touchless Biometric Systems }\end{array}$ & $\begin{array}{l}c \\
G\end{array}$ & $\begin{array}{l}\text { Green Bit } \\
\text { Crossmatch }\end{array}$ & $\begin{array}{l}\mathrm{D} \\
\mathrm{H}\end{array}$ & $\begin{array}{l}\text { Cornell University } \\
\text { Clarkson University }\end{array}$ \\
\hline $1 \mathrm{~A}$ & Peering Into Window & $1 \mathrm{~B}$ & Fist Banging on Glass & 1C & Fingertip Window Slide & 10 & Get-away Palm on Glass & $1 \mathrm{E}$ & "OK" Sign on Glass \\
\hline $1 \mathrm{~F}$ & Counter Vault on Glass & $1 \mathrm{G}$ & Cylinder Grab & $1 \mathrm{H}$ & Impatient Tapping on Glass & $2 \mathrm{~A}$ & Samsung Galaxy S5 & $2 \mathrm{~B}$ & Apple iPhone $5 \mathrm{~s}$ \\
\hline 3 & Check & $4 \mathrm{~A}$ & Lined Paper & $4 \mathrm{~B}$ & Low-quality Copy Paper & $4 \mathrm{C}$ & High-quality Copy Paper & $4 \mathrm{D}$ & Yellow Lined Paper \\
\hline $4 \mathrm{E}$ & Low-quality White Envelope & $4 \mathrm{~F}$ & Greeting Card and Envelope & $4 \mathrm{G}$ & Manila Envelope & $5 \mathrm{~A}$ & Photo Paper & $5 \mathrm{~B}$ & Glossy Magazine \\
\hline $5 c$ & U.S. Currency & $6 \mathrm{~A}$ & Stamp & $6 \mathrm{~B}$ & Address Label & $6 \mathrm{C}$ & Clear Packing Tape & $6 \mathrm{D}$ & Black Electrical Tape \\
\hline $6 \mathrm{E}$ & Duct Tape & $7 \mathrm{~A}$ & Circuit Board & $7 \mathrm{~B}$ & $\mathrm{CD} / \mathrm{DVD}$ & $7 \mathrm{C}$ & Clear Plastic Bag & $7 \mathrm{D}$ & Black Plastic Bag \\
\hline
\end{tabular}




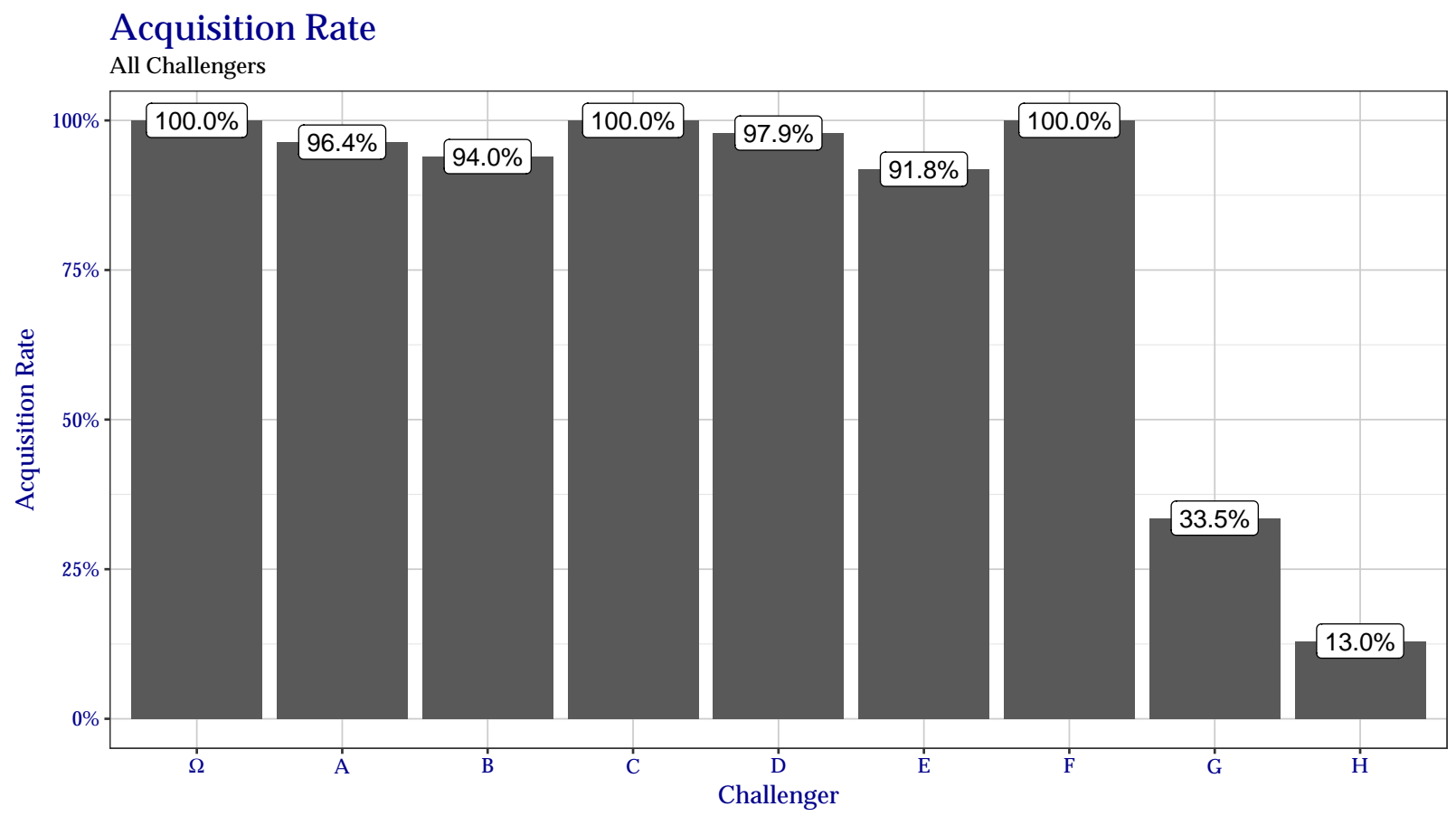

Fig. 13. The rate of acquisition for all Challengers, in percentage of study participants acquired. The actual rate of acquisition is printed at the top of each Challenger bar. A successful acquisition was defined as acquiring all 10 fingers from a study participant. $G$ and $H$ encountered unique issues that were documented in Section 9.1, and as such, did not meet the minimum $90 \%$ acquisition rate to be eligible for most performance-based prizes.

different number of study participants (in the case of G) or a considerably lower acquisition rate (in the case of $\mathrm{H})$. This was done to not penalize Challengers that struggled during the Challenge twice.

\section{Discussion}

- B's decision not to resubmit data, as explained in Section 9.1, worked out in their favor.

- Several Challengers acquired images faster than $\Omega$.

- The acquisition timing metric incorporating skew proved to be significant. The fastest Challenger, A, had many outliers, greatly skewing their timing distribution higher. Additionally, outliers caused Challengers with similar median times $(B, C$, and $E)$ to achieve vastly different scores.

Prize Winner The Nail to Nail Fingerprint Challenge award listing in Table 1 indicates that the Speed Prize should be awarded to the Challenger with the smallest acquisition time score that also acquired $\geq 90 \%$ of all data and scored within $80 \%$ of $\Omega$. This criteria is met by B.

\begin{tabular}{|c|c|c|c|c|c|c|c|c|c|}
\hline$\Omega$ & FBI Baseline & $\begin{array}{l}A \\
E\end{array}$ & $\begin{array}{l}\text { IDEMIA } \\
\text { Jenetric }\end{array}$ & $\begin{array}{l}\mathrm{B} \\
\mathrm{F}\end{array}$ & $\begin{array}{l}\text { Advanced Optical Systems } \\
\text { Touchless Biometric Systems }\end{array}$ & $\begin{array}{l}c \\
G\end{array}$ & $\begin{array}{l}\text { Green Bit } \\
\text { Crossmatch }\end{array}$ & $\begin{array}{l}\mathrm{D} \\
\mathrm{H}\end{array}$ & $\begin{array}{l}\text { Cornell University } \\
\text { Clarkson University }\end{array}$ \\
\hline $1 \mathrm{~A}$ & Peering Into Window & $1 \mathrm{~B}$ & Fist Banging on Glass & 1C & Fingertip Window Slide & 10 & Get-away Palm on Glass & $1 \mathrm{E}$ & "OK" Sign on Glass \\
\hline $1 \mathrm{~F}$ & Counter Vault on Glass & $1 \mathrm{G}$ & Cylinder Grab & $1 \mathrm{H}$ & Impatient Tapping on Glass & $2 \mathrm{~A}$ & Samsung Galaxy S5 & $2 \mathrm{~B}$ & Apple iPhone $5 \mathrm{~s}$ \\
\hline 3 & Check & $4 \mathrm{~A}$ & Lined Paper & $4 \mathrm{~B}$ & Low-quality Copy Paper & $4 \mathrm{C}$ & High-quality Copy Paper & $4 \mathrm{D}$ & Yellow Lined Paper \\
\hline $4 \mathrm{E}$ & Low-quality White Envelope & $4 \mathrm{~F}$ & Greeting Card and Envelope & $4 \mathrm{G}$ & Manila Envelope & $5 \mathrm{~A}$ & Photo Paper & $5 \mathrm{~B}$ & Glossy Magazine \\
\hline $5 c$ & U.S. Currency & $6 \mathrm{~A}$ & Stamp & $6 \mathrm{~B}$ & Address Label & $6 \mathrm{C}$ & Clear Packing Tape & $6 \mathrm{D}$ & Black Electrical Tape \\
\hline $6 \mathrm{E}$ & Duct Tape & $7 \mathrm{~A}$ & Circuit Board & $7 \mathrm{~B}$ & $\mathrm{CD} / \mathrm{DVD}$ & $7 \mathrm{C}$ & Clear Plastic Bag & $7 \mathrm{D}$ & Black Plastic Bag \\
\hline
\end{tabular}




\begin{tabular}{lrr}
\hline Challenger & Median & Score \\
\hline$\Omega$ & 144 & 314.0 \\
$\mathrm{~A}$ & 159 & 2281.5 \\
$\mathrm{~B}$ & ${ }^{4} 159$ & 1278.9 \\
$\mathrm{C}$ & ${ }^{5} 160$ & 5342.5 \\
$\mathrm{D}$ & 7267 & 7761.4 \\
$\mathrm{E}$ & ${ }^{6} 179$ & ${ }^{4} 328.8$ \\
$\mathrm{~F}$ & ${ }^{2} 105$ & 3285.0 \\
$\mathrm{G}$ & ${ }^{3} 133$ & ${ }^{6} 492.4$ \\
$\mathrm{H}$ & ${ }^{8} 984$ & 82880.8 \\
\hline
\end{tabular}

Table 4. and acquisition timing score for all Challengers. The first column is the Challenger's letter identifier. The second column is the Median acquisition time, reported in s. The third column is the acquisition timing Score (Section 7.2), which incorporates the skew of all observed acquisition times. The Baseline Data is recorded in blue. The best non-baseline values in each column are reported in green and the worst are in red. Challenger values that meet or beat the baseline are shaded in blue. Superscript numbers preceding values represent the ranking of this value in each column. Several Challengers outperformed the $\Omega$, a desired outcome of the Nail to Nail Fingerprint Challenge.

Acquisition Time

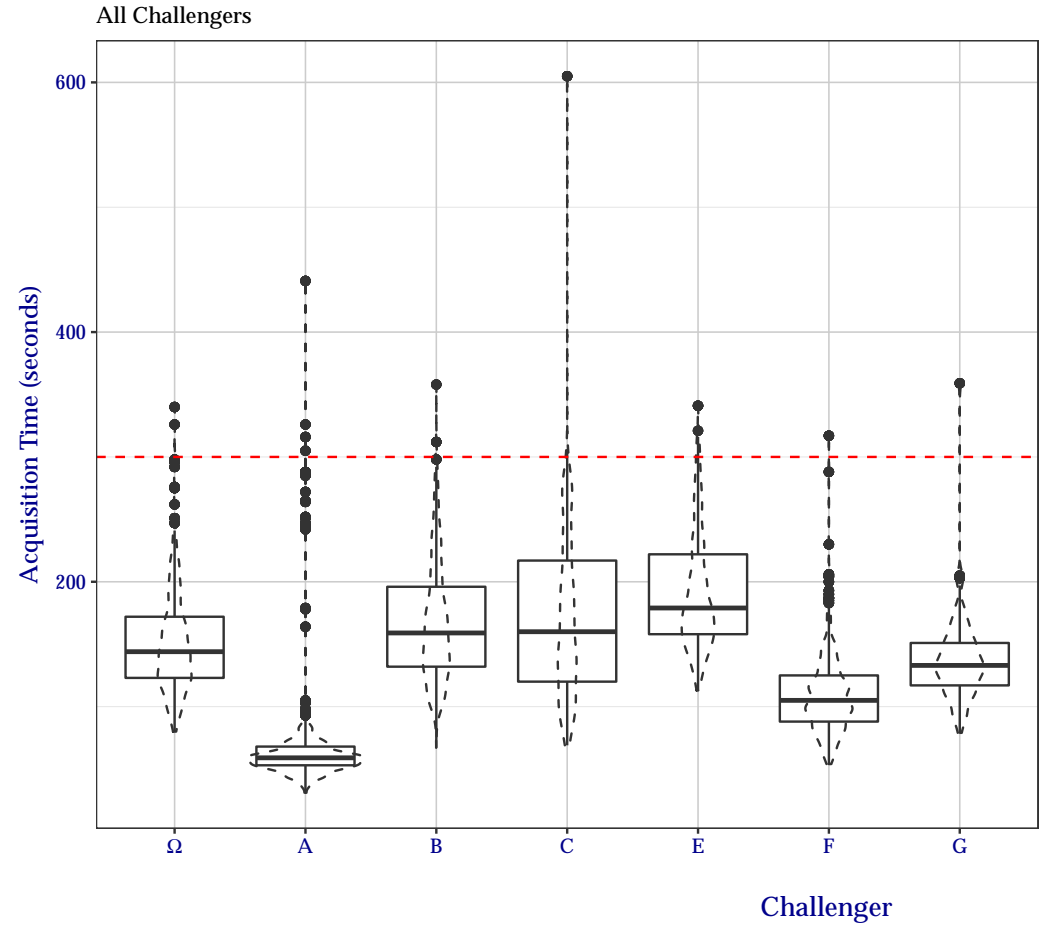

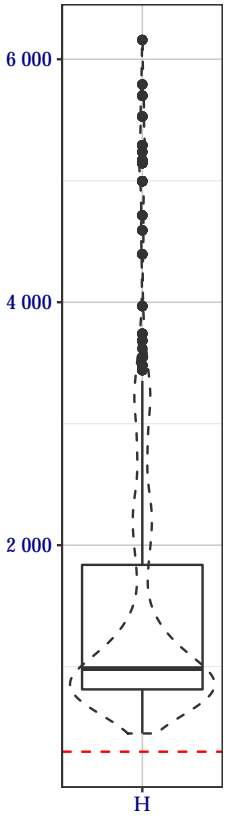

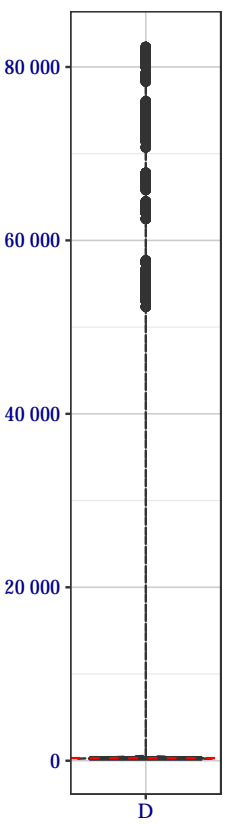

Fig. 14. Boxplots and violin plots of acquisition times for all Challengers. Acquisition time is defined as the number of $s$ between first encountering a study participant until the last fingerprint image of that study participant is received by the N2N backend server. Challengers are plotted amongst three different $y$ axis scales in order to display data and outliers comfortably. The upper and lower hinges of the boxplots indicate the first and third quartiles, and the center lines indicates the medians. The dashed-outline violin plots show the density of the distribution for all values of the set, becoming wider in areas with higher density. A horizontal red dashed line is shown at $300 \mathrm{~s}$, the maximum time in which a Challenger was permitted to interact with a study participant. Times significantly above $300 \mathrm{~s}$ indicate post-processing or an otherwise delayed submission of data, as noted in Section 9.1. Most Challengers were able to collect all 10 fingerprints around the same speed as or faster than the traditional operator-assisted N2N capture technique.

\begin{tabular}{|c|c|c|c|c|c|c|c|c|c|}
\hline$\Omega$ & FBI Baseline & $\begin{array}{l}A \\
E\end{array}$ & $\begin{array}{l}\text { IDEMIA } \\
\text { Jenetric }\end{array}$ & $\begin{array}{l}\mathrm{B} \\
\mathrm{F}\end{array}$ & $\begin{array}{l}\text { Advanced Optical Systems } \\
\text { Touchless Biometric Systems }\end{array}$ & $\begin{array}{l}C \\
G\end{array}$ & $\begin{array}{l}\text { Green Bit } \\
\text { Crossmatch }\end{array}$ & $\begin{array}{l}\mathrm{D} \\
\mathrm{H}\end{array}$ & $\begin{array}{l}\text { Cornell University } \\
\text { Clarkson University }\end{array}$ \\
\hline $1 \mathrm{~A}$ & Peering Into Window & $1 \mathrm{~B}$ & Fist Banging on Glass & 1c & Fingertip Window Slide & $1 \mathrm{D}$ & Get-away Palm on Glass & $1 \mathrm{E}$ & “OK" Sign on Glass \\
\hline $1 \mathrm{~F}$ & Counter Vault on Glass & $1 \mathrm{G}$ & Cylinder Grab & $1 \mathrm{H}$ & Impatient Tapping on Glass & $2 \mathrm{~A}$ & Samsung Galaxy S5 & $2 \mathrm{~B}$ & Apple iPhone 5s \\
\hline 3 & Check & $4 \mathrm{~A}$ & Lined Paper & 4B & Low-quality Copy Paper & $4 \mathrm{C}$ & High-quality Copy Paper & $4 \mathrm{D}$ & Yellow Lined Paper \\
\hline $4 \mathrm{E}$ & Low-quality White Envelope & $4 \mathrm{~F}$ & Greeting Card and Envelope & $4 \mathrm{G}$ & Manila Envelope & $5 \mathrm{~A}$ & Photo Paper & $5 B$ & Glossy Magazine \\
\hline $5 \mathrm{C}$ & U.S. Currency & $6 \mathrm{~A}$ & Stamp & $6 \mathrm{~B}$ & Address Label & $6 \mathrm{C}$ & Clear Packing Tape & $6 \mathrm{D}$ & Black Electrical Tape \\
\hline $6 \mathrm{E}$ & Duct Tape & $7 \mathrm{~A}$ & Circuit Board & $7 \mathrm{~B}$ & $\mathrm{CD} / \mathrm{DVD}$ & $7 \mathrm{C}$ & Clear Plastic Bag & $7 \mathrm{D}$ & Black Plastic Bag \\
\hline
\end{tabular}




\section{Results - Nail to Nail Identification}

The accuracy of the MATCHER when searching N2N images from Challengers against an enrollment set of traditional operator-assisted N2N captures are shown in DET curves in Fig. 15 and Table 5. CMC curves showing hit rate are shown in Fig. 16 and Table 6.

\section{Discussion}

- Three distinct groupings of Challengers emerge.

- No Challenger outperforms $\Omega$, and the closest Challenger has an FNIR $11 \%$ larger than $\Omega$.

- DET curves are relatively flat, showing that FNIR does not dramatically change by threshold.

- CMC curves are also relatively flat, showing that for N2N identification for all Challengers, the MATCHER typically finds the correct mate at rank 1, or does not find the mate at all.

- Although suffering from a severe lack of study participants, $G$ was not the worst performer.

- None of H's N2N images were successfully identified. Availability of minutia, as seen in Fig. 11, may be part of the problem, although visual inspection shows that most fingerprint captures do not resemble the exemplar.

Prize Winner The Nail to Nail Fingerprint Challenge award listing in Table 1 indicates that the Gallery Accuracy Prize should be awarded to the Challenger with the best N2N identification performance, so long as the Challenger acquires $\geq 90 \%$ of all data. This criteria is met by $\mathrm{C}$.

The closest any Challenger comes to meeting $\Omega$ 's FNIR value is $11 \%$, achieved by $\mathrm{C}$. A criterion for the Grand Prize is to achieve FNIR within $2 \%$ of $\Omega$, indicating that no Challenger could win the Grand Prize.

\begin{tabular}{|c|c|c|c|c|c|c|c|c|c|}
\hline$\Omega$ & FBI Baseline & $\begin{array}{l}A \\
E\end{array}$ & $\begin{array}{l}\text { IDEMIA } \\
\text { Jenetric }\end{array}$ & $\begin{array}{l}\mathrm{B} \\
\mathrm{F}\end{array}$ & $\begin{array}{l}\text { Advanced Optical Systems } \\
\text { Touchless Biometric Systems }\end{array}$ & $\begin{array}{l}c \\
G\end{array}$ & $\begin{array}{l}\text { Green Bit } \\
\text { Crossmatch }\end{array}$ & $\begin{array}{l}\mathrm{D} \\
\mathrm{H}\end{array}$ & $\begin{array}{l}\text { Cornell University } \\
\text { Clarkson University }\end{array}$ \\
\hline $1 \mathrm{~A}$ & Peering Into Window & $1 \mathrm{~B}$ & Fist Banging on Glass & 1C & Fingertip Window Slide & 10 & Get-away Palm on Glass & $1 \mathrm{E}$ & "OK" Sign on Glass \\
\hline $1 \mathrm{~F}$ & Counter Vault on Glass & $1 \mathrm{G}$ & Cylinder Grab & $1 \mathrm{H}$ & Impatient Tapping on Glass & $2 \mathrm{~A}$ & Samsung Galaxy S5 & $2 \mathrm{~B}$ & Apple iPhone $5 \mathrm{~s}$ \\
\hline 3 & Check & $4 \mathrm{~A}$ & Lined Paper & $4 \mathrm{~B}$ & Low-quality Copy Paper & $4 \mathrm{C}$ & High-quality Copy Paper & $4 \mathrm{D}$ & Yellow Lined Paper \\
\hline $4 \mathrm{E}$ & Low-quality White Envelope & $4 \mathrm{~F}$ & Greeting Card and Envelope & $4 \mathrm{G}$ & Manila Envelope & $5 \mathrm{~A}$ & Photo Paper & $5 \mathrm{~B}$ & Glossy Magazine \\
\hline $5 c$ & U.S. Currency & $6 \mathrm{~A}$ & Stamp & $6 \mathrm{~B}$ & Address Label & $6 \mathrm{C}$ & Clear Packing Tape & $6 \mathrm{D}$ & Black Electrical Tape \\
\hline $6 \mathrm{E}$ & Duct Tape & $7 \mathrm{~A}$ & Circuit Board & $7 \mathrm{~B}$ & $\mathrm{CD} / \mathrm{DVD}$ & $7 \mathrm{C}$ & Clear Plastic Bag & $7 \mathrm{D}$ & Black Plastic Bag \\
\hline
\end{tabular}




\begin{tabular}{lr}
\hline Challenger & FNIR @ FPIR $=10^{-1}$ \\
\hline$\Omega$ & $0.088 \pm 0.006$ \\
A & ${ }^{3} 0.214 \pm 0.008$ \\
$B$ & ${ }^{5} 0.279 \pm 0.009$ \\
$C$ & ${ }^{1} 0.098 \pm 0.006$ \\
$D$ & ${ }^{7} 0.824 \pm 0.008$ \\
E & ${ }^{2} 0.198 \pm 0.008$ \\
$F$ & ${ }^{4} 0.235 \pm 0.009$ \\
G & ${ }^{6} 0.724 \pm 0.009$ \\
$H$ & ${ }^{8} 1.000 \pm 0.0002$ \\
\hline
\end{tabular}

Table 5. Values for FNIR at a fixed FPIR of $10^{-1}$ for N2N identification. These values are extracted from those plotted on the vertical dashed line in Fig. 15. The Baseline Data is recorded in blue. The best non-baseline value is reported in green and the worst in red. Challenger values that meet or beat the baseline are shaded in blue. Superscript numbers preceding the FNIR value represent its ranking. The confidence intervals depicted are a $90 \%$ Wilson confidence interval [10].

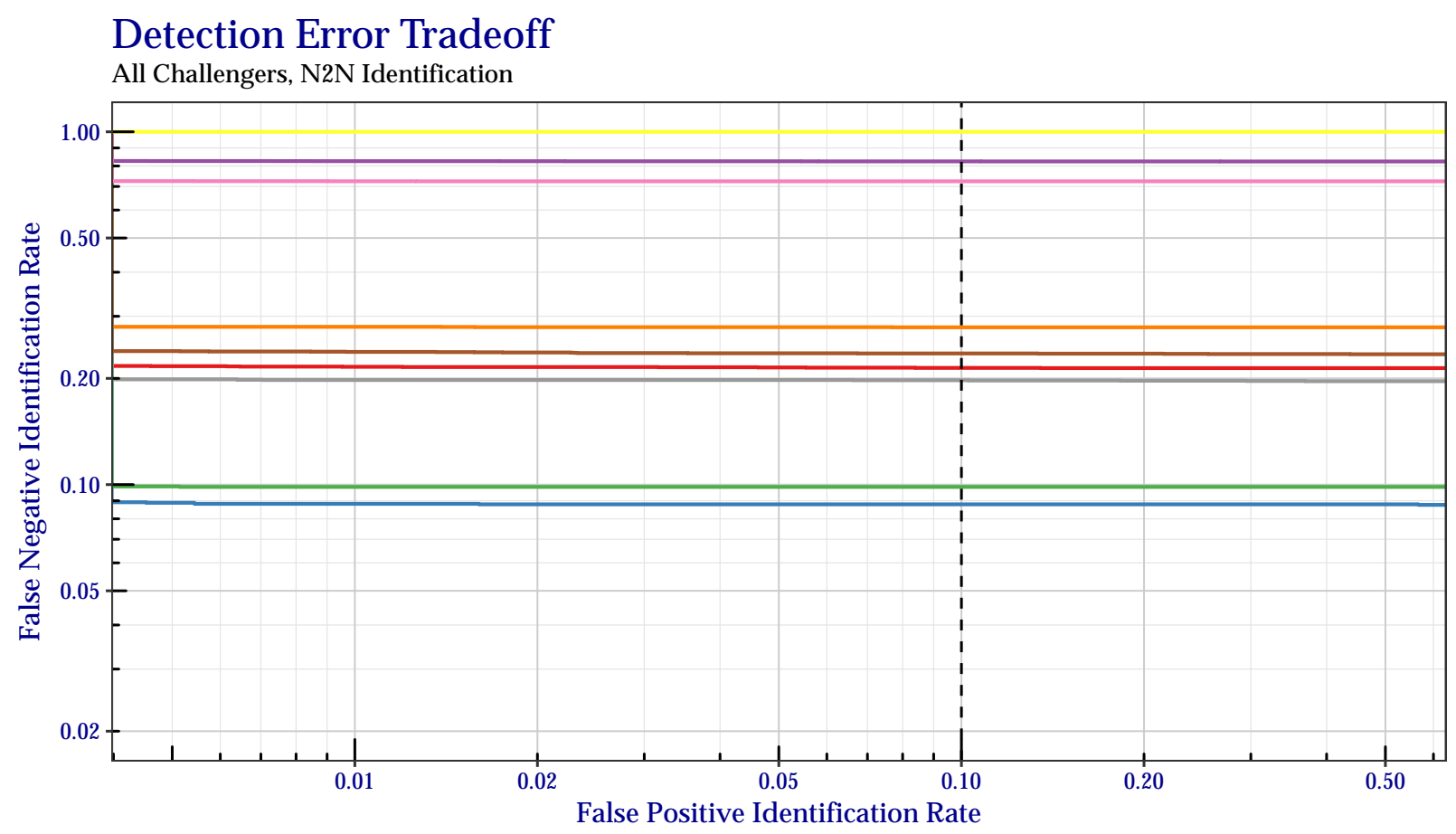

Challenger $-\Omega-\mathrm{A}-\mathrm{B}-\mathrm{C}-\mathrm{D}-\mathrm{E}-\mathrm{F}-\mathrm{G}-\mathrm{H}$

Fig. 15. DET curves for each Challenger for N2N identification. This plot shows the accuracy of the MATCHER when searching N2N images from each Challenger against the same enrollment set of traditional operator-assisted N2N captures. The vertical dashed line indicates the FPIR at which a prize was to be awarded for the lowest FNIR, and the values lying on this line are reported in Table 5.

\begin{tabular}{|c|c|c|c|c|c|c|c|c|c|}
\hline$\Omega$ & FBI Baseline & $\begin{array}{l}A \\
E\end{array}$ & $\begin{array}{l}\text { IDEMIA } \\
\text { Jenetric }\end{array}$ & $\begin{array}{l}\mathrm{B} \\
\mathrm{F}\end{array}$ & $\begin{array}{l}\text { Advanced Optical Systems } \\
\text { Touchless Biometric Systems }\end{array}$ & $\begin{array}{l}C \\
G\end{array}$ & $\begin{array}{l}\text { Green Bit } \\
\text { Crossmatch }\end{array}$ & $\stackrel{D}{\mathrm{H}}$ & $\begin{array}{l}\text { Cornell University } \\
\text { Clarkson University }\end{array}$ \\
\hline $1 \mathrm{~A}$ & Peering Into & $1 \mathrm{~B}$ & Fist Banging on Glass & $1 \mathrm{C}$ & Fingertip Window Slide & $1 \mathrm{D}$ & Get-away Palm on Glass & $1 \mathrm{E}$ & “OK” Sign on Glass \\
\hline $1 \mathrm{~F}$ & Counter Vault on Glass & 16 & Cylinder Grab & $1 \mathrm{H}$ & Impatient Tapping on Glass & $2 \mathrm{~A}$ & Samsung Galaxy S5 & $2 \mathrm{~B}$ & Apple iPhone $5 \mathrm{~s}$ \\
\hline 3 & Check & $4 \mathrm{~A}$ & Lined Paper & $4 \mathrm{~B}$ & Low-quality Copy Paper & $4 \mathrm{C}$ & High-quality Copy Paper & $4 \mathrm{D}$ & Yellow Lined Paper \\
\hline $4 \mathrm{E}$ & Low-quality White Envelope & $4 \mathrm{~F}$ & Greeting Card and Envelope & $4 G$ & Manila Envelope & $5 \mathrm{~A}$ & Photo Paper & $5 B$ & Glossy Magazine \\
\hline $5 \mathrm{C}$ & U.S. Currency & $6 \mathrm{~A}$ & Stamp & $6 \mathrm{~B}$ & Address Label & $6 \mathrm{C}$ & Clear Packing Tape & $6 \mathrm{D}$ & Black Electrical Tape \\
\hline $6 \mathrm{E}$ & Duct Tape & $7 \mathrm{~A}$ & Circuit Board & $7 \mathrm{~B}$ & $\mathrm{CD} / \mathrm{DVD}$ & $7 \mathrm{C}$ & Clear Plastic Bag & $7 \mathrm{D}$ & Black Plastic Bag \\
\hline
\end{tabular}




\begin{tabular}{lr}
\hline Challenger & Hit Rate (Rank 1) \\
\hline$\Omega$ & $91.2 \%$ \\
A & $378.6 \%$ \\
$B$ & $572.1 \%$ \\
$C$ & $190.2 \%$ \\
D & $717.6 \%$ \\
E & $280.4 \%$ \\
F & $476.6 \%$ \\
G & $627.6 \%$ \\
$H$ & $80.0 \%$ \\
\hline
\end{tabular}

Table 6. Hit rate for rank 1 for the MATcher when searching N2N images from each Challenger against the same enrollment set of traditional operator-assisted N2N captures. The Baseline Data is recorded in blue. The best non-baseline value is reported in green and the worst in red. Challenger values that meet or beat the baseline are shaded in blue. Superscript numbers preceding the hit rate value represent its ranking. All ranks are depicted in Fig. 16, but the flatness of the curves indicate that the MATCHER typically finds the correct mate at rank 1 or not at all.

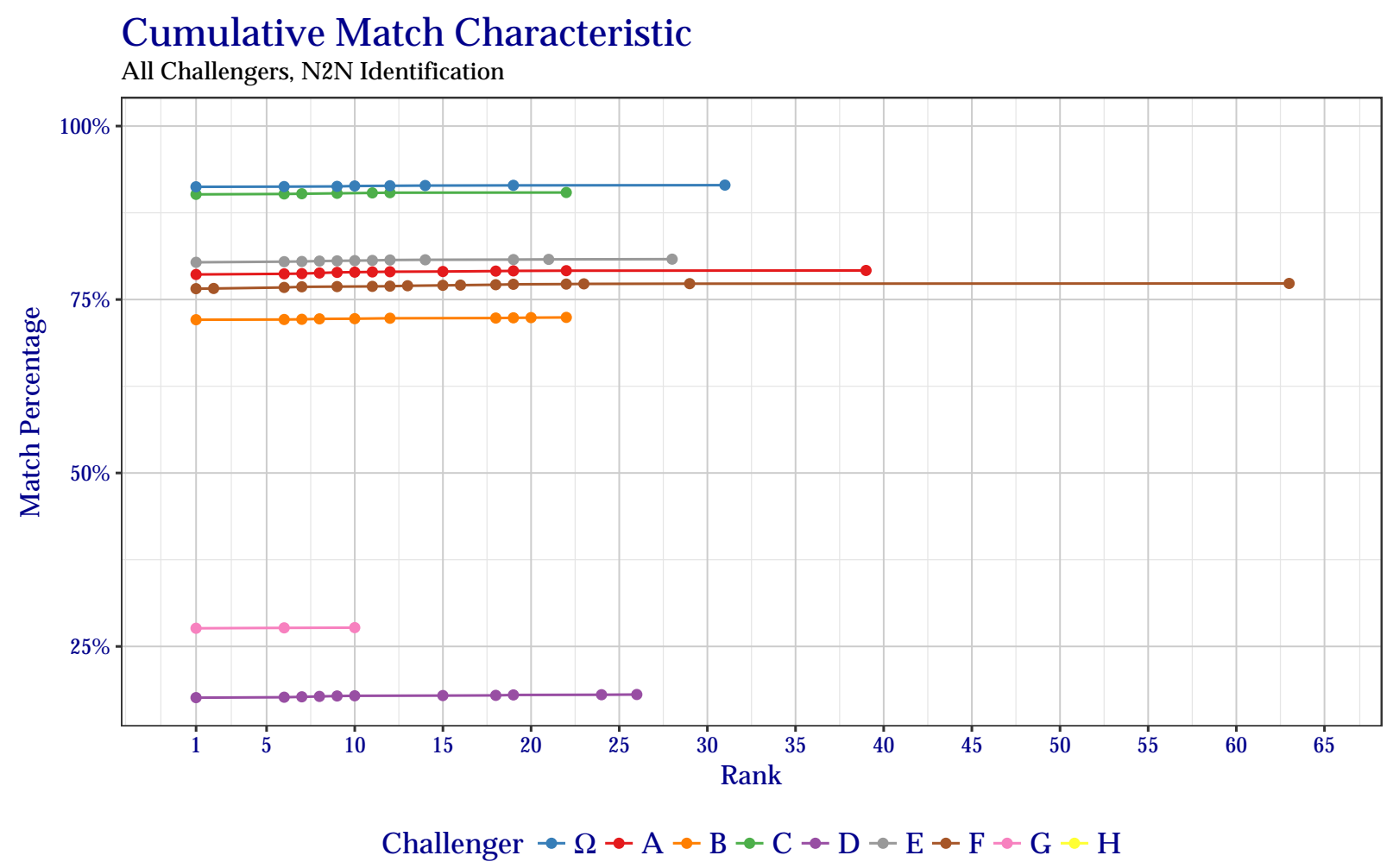

Fig. 16. CMC curves for each Challenger for N2N identification. This plot shows the rate at which the MATCHER, when searching N2N images from each Challenger against the same enrollment set of traditional operator-assisted N2N captures, found the correct mate, regardless of similarity score. The values for rank 1 are reported in Table 6 . If a curve stops before reaching the far right of the plot, it indicates that a mate was never found past the last corresponding rank. $\mathrm{H}$ is not visible on the plot because their hit rate never increased above the minimum match percentage shown for any rank.

\begin{tabular}{|c|c|c|c|c|c|c|c|c|c|}
\hline$\Omega$ & FBI Baseline & $\begin{array}{l}A \\
E\end{array}$ & $\begin{array}{l}\text { IDEMIA } \\
\text { Jenetric }\end{array}$ & $\begin{array}{l}\text { B } \\
F\end{array}$ & $\begin{array}{l}\text { Advanced Optical Systems } \\
\text { Touchless Biometric Systems }\end{array}$ & $\begin{array}{l}\mathrm{C} \\
\mathrm{G}\end{array}$ & $\begin{array}{l}\text { Green Bit } \\
\text { Crossmatch }\end{array}$ & $\begin{array}{l}\mathrm{D} \\
\mathrm{H}\end{array}$ & $\begin{array}{l}\text { Cornell University } \\
\text { Clarkson University }\end{array}$ \\
\hline $1 \mathrm{~A}$ & Peering Into Window & $1 \mathrm{~B}$ & Fist Banging on Glass & $1 \mathrm{C}$ & Fingertip Window Slide & $1 \mathrm{D}$ & Get-away Palm on Glass & $1 \mathrm{E}$ & “OK" Sign on Glass \\
\hline $1 \mathrm{~F}$ & Counter Vault on Glass & 16 & Cylinder Grab & $1 \mathrm{H}$ & Impatient Tapping on Glass & $2 \mathrm{~A}$ & Samsung Galaxy S5 & $2 \mathrm{~B}$ & Apple iPhone $5 \mathrm{~s}$ \\
\hline 3 & Check & $4 \mathrm{~A}$ & Lined Paper & $4 \mathrm{~B}$ & Low-quality Copy Paper & $4 \mathrm{C}$ & High-quality Copy Paper & 4D & Yellow Lined Paper \\
\hline $4 \mathrm{E}$ & Low-quality White Envelope & $4 \mathrm{~F}$ & Greeting Card and Envelope & $4 \mathrm{G}$ & Manila Envelope & $5 \mathrm{~A}$ & Photo Paper & $5 B$ & Glossy Magazine \\
\hline $5 \mathrm{C}$ & U.S. Currency & $6 \mathrm{~A}$ & Stamp & $6 \mathrm{~B}$ & Address Label & $6 \mathrm{C}$ & Clear Packing Tape & $6 \mathrm{D}$ & Black Electrical Tape \\
\hline $6 \mathrm{E}$ & Duct Tape & $7 \mathrm{~A}$ & Circuit Board & $7 \mathrm{~B}$ & $\mathrm{CD} / \mathrm{DVD}$ & $7 \mathrm{C}$ & Clear Plastic Bag & 70 & Black Plastic Bag \\
\hline
\end{tabular}




\section{Results - Latent Identification}

The accuracy of the MATCHER when searching study participant latent fingerprint images against an enrollment set seeded with N2N captures from each Challenger are shown in DET curves in Fig. 17, with FNIR values recorded at the Challenge's fixed FPIR figure of merit in Table 7. CMC curves showing hit rate are shown in Fig. 18 and Table 8.

Some Challengers performed better on particular latent activities. Results separated by activity are available in Appendix A.

\section{Discussion}

- Overall automated latent identification performance is quite poor. Future analysis will study this latent dataset with varying smaller enrollment set sizes to see if it is a significant factor (Table 7).

- Groupings present in N2N identification are less pronounced in latent identification (Fig. 17).

- C outperforms $\Omega$ (Table 7). Given that C's N2N identification results were comparable with $\Omega$ suggests that $C$ might capture a larger fingerprint surface area than $\Omega$.

- Unlike N2N identification (Fig. 16), most Challengers do see an improvement in hit rate within the first (5 to \$10) ranks, although performance is still poor (Fig. 18).

- Despite not correctly identifying any N2N images, the MATCHER does achieve some hits during latent identification with $\mathrm{H}$, perhaps indicating that certain areas of the finger are imaged more accurately than others with H's device (Fig. 18).

- Activity and substrate appear to make a difference (Appendix A). Future studies will look into understanding why the differences exist.

Prize Winner The Nail to Nail Fingerprint Challenge award listing in Table 1 indicates that the Latent Accuracy Prize should be awarded to the Challenger with the best latent identification accuracy that also collected $\geq 90 \%$ of data. Using values from Table 7, the winner of the Latent Accuracy Prize is C.

\subsection{In Context}

Latent print identification results in this section deviate from expectations created by prior NIST studies. In Evaluation of Latent Fingerprint Technologies: Extended Feature Sets (ELFT-EFS) (Evaluation \#2) [11], the best rank 1 identification rates for image-only identification are upwards of $60 \%$. These rates decrease when taking into account the latent print's initial rotation angle (25\% to $50 \%$ when unknown) and origin ( $20 \%$ to $40 \%$ when casework). However, hit rates at a particular rank do not scale as enrollment set sizes increase, and the Nail to Nail Fingerprint Challenge makes use of an enrollment set 30 times larger than the enrollment set used in ELFT-EFS. Even still, FNIR values are more likely to be stable across different enrollment set sizes, and ELFT-EFS indicates the best overall FNIR at FPIR $=10^{-1}$ is $\approx 0.4$.

Latent prints in the N2N dataset are of varying quality and have unknown initial rotation angles. They are considered to be of law enforcement casework origin. Regions showing any amount of ridge structure were isolated by CLPEs and searched without any CLPE-assigned enhancements or feature demarcations. Visual inspection of the dataset indicates that there are numerous images of poor quality that would not be searched operationally without at least minimal feature extractions by CLPEs. Angle, feature, and quality quantification as well as the effect of the size of the enrollment set are topics for further examination.

\begin{tabular}{|c|c|c|c|c|c|c|c|c|c|}
\hline$\Omega$ & FBI Baseline & $\begin{array}{l}A \\
E\end{array}$ & $\begin{array}{l}\text { IDEMIA } \\
\text { Jenetric }\end{array}$ & $\begin{array}{l}\mathrm{B} \\
\mathrm{F}\end{array}$ & $\begin{array}{l}\text { Advanced Optical Systems } \\
\text { Touchless Biometric Systems }\end{array}$ & $\begin{array}{l}\mathrm{C} \\
\mathrm{G}\end{array}$ & $\begin{array}{l}\text { Green Bit } \\
\text { Crossmatch }\end{array}$ & $\stackrel{D}{\mathrm{D}}$ & $\begin{array}{l}\text { Cornell University } \\
\text { Clarkson University }\end{array}$ \\
\hline $1 \mathrm{~A}$ & Peering Into Window & $1 \mathrm{~B}$ & Fist Banging on Glass & $1 \mathrm{C}$ & Fingertip Window Slide & 1D & Get-away Palm on Glass & $1 \mathrm{E}$ & “OK” Sign on Glass \\
\hline $1 \mathrm{~F}$ & Counter Vault on Glass & 16 & Cylinder Grab & $1 \mathrm{H}$ & Impatient Tapping on Glass & $2 \mathrm{~A}$ & Samsung Galaxy S5 & $2 \mathrm{~B}$ & Apple iPhone $5 \mathrm{~s}$ \\
\hline 3 & Check & $4 \mathrm{~A}$ & Lined Paper & $4 \mathrm{~B}$ & Low-quality Copy Paper & $4 \mathrm{C}$ & High-quality Copy Paper & $4 \mathrm{D}$ & Yellow Lined Paper \\
\hline $4 \mathrm{E}$ & Low-quality White Envelope & $4 \mathrm{~F}$ & Greeting Card and Envelope & $4 \mathrm{G}$ & Manila Envelope & $5 \mathrm{~A}$ & Photo Paper & $5 \mathrm{~B}$ & Glossy Magazine \\
\hline $5 c$ & U.S. Currency & $6 \mathrm{~A}$ & Stamp & $6 \mathrm{~B}$ & Address Label & $6 \mathrm{C}$ & Clear Packing Tape & $6 \mathrm{D}$ & Black Electrical Tape \\
\hline $6 \mathrm{E}$ & Duct Tape & $7 \mathrm{~A}$ & Circuit Board & $7 \mathrm{~B}$ & $\mathrm{CD} / \mathrm{DVD}$ & 7C & Clear Plastic Bag & $7 \mathrm{D}$ & Black Plastic Bag \\
\hline
\end{tabular}




\begin{tabular}{lr}
\hline Challenger & FNIR @ FPIR $=10^{-1}$ \\
\hline$\Omega$ & $0.921 \pm 0.001$ \\
A & ${ }^{2} 0.927 \pm 0.001$ \\
$B$ & ${ }^{4} 0.934 \pm 0.001$ \\
$C$ & ${ }^{1} 0.915 \pm 0.001$ \\
$D$ & ${ }^{7} 0.983 \pm 0.0006$ \\
E & ${ }^{2} 0.927 \pm 0.001$ \\
$F$ & ${ }^{5} 0.950 \pm 0.001$ \\
G & ${ }^{6} 0.981 \pm 0.0006$ \\
$H$ & ${ }^{8} .000 \pm 0.00001$ \\
\hline
\end{tabular}

Table 7. Values for FNIR at a fixed FPIR of $10^{-1}$ for latent identification with an enrollment set of 3003309 subjects. These values are extracted from those plotted on the vertical dashed line in Fig. 17. The Baseline Data is recorded in blue. The best non-baseline value is reported in green and the worst in red. Challenger values that meet or beat the baseline are shaded in blue. Superscript numbers preceding the FNIR value represent its ranking. The confidence intervals depicted are a $90 \%$ Wilson confidence interval [10]. The identification performance depicted is quite poor.

\section{Detection Error Tradeoff}

\section{All Challengers, Latent Identification}

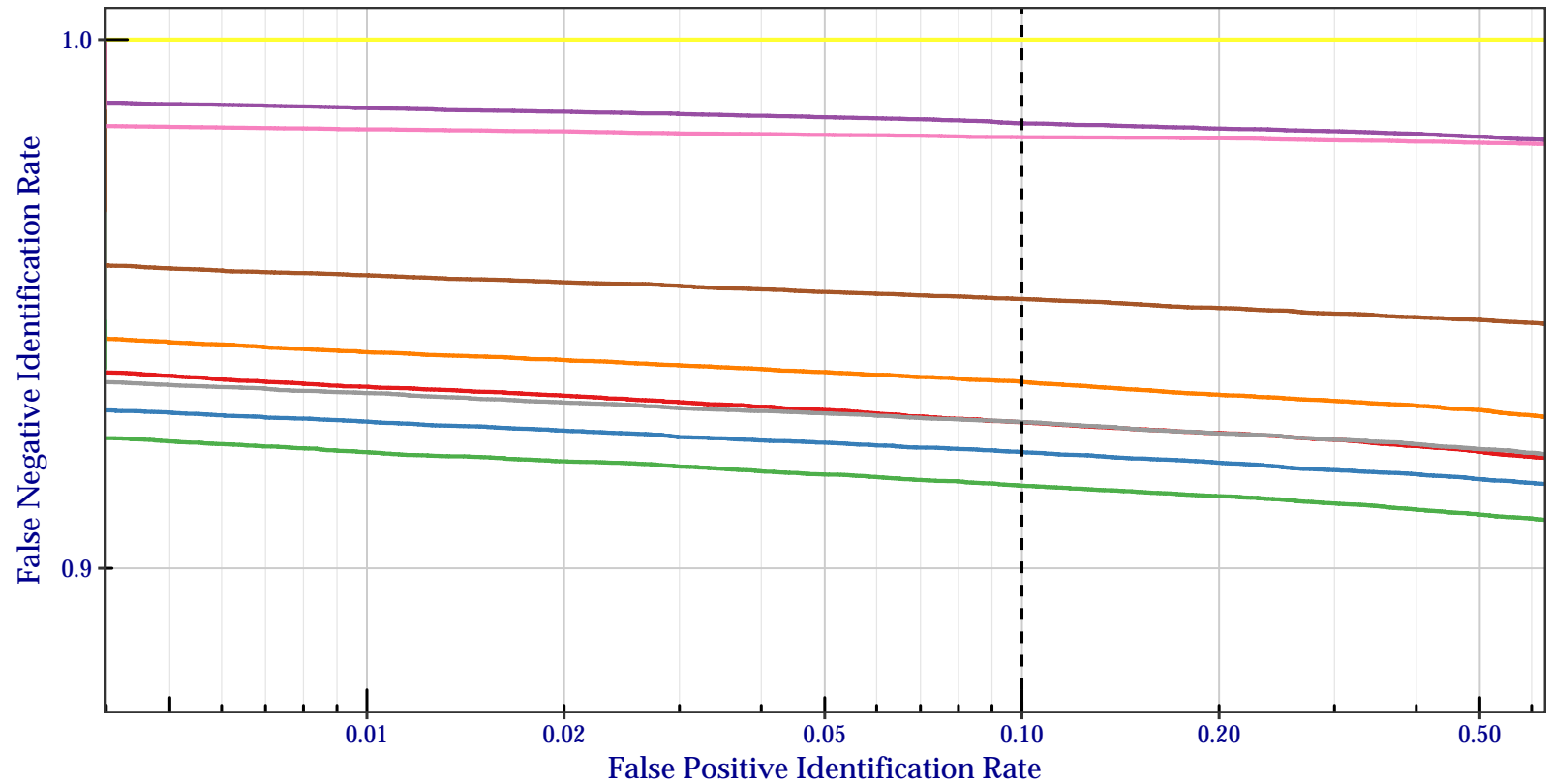

Challenger $-\Omega-\mathrm{A}-\mathrm{B}-\mathrm{C}-\mathrm{D}-\mathrm{E}-\mathrm{F}-\mathrm{G}-\mathrm{H}$

Fig. 17. DET curves for each Challenger for latent identification. This plot shows the accuracy of the MATCHER when searching study participant latent fingerprint images against an enrollment set seeded with N2N images from each Challenger. The vertical dashed line indicates the FPIR at which a prize was to be awarded for the lowest FNIR, and the values lying on this line are reported in Table 7.

\begin{tabular}{|c|c|c|c|c|c|c|c|c|c|}
\hline$\Omega$ & FBI Baseline & $\begin{array}{l}A \\
E\end{array}$ & $\begin{array}{l}\text { IDEMIA } \\
\text { Jenetric }\end{array}$ & $\begin{array}{l}\mathrm{B} \\
\mathrm{F}\end{array}$ & $\begin{array}{l}\text { Advanced Optical Systems } \\
\text { Touchless Biometric Systems }\end{array}$ & $\begin{array}{l}\text { C } \\
G\end{array}$ & $\begin{array}{l}\text { Green Bit } \\
\text { Crossmatch }\end{array}$ & $\begin{array}{l}\mathrm{D} \\
\mathrm{H}\end{array}$ & $\begin{array}{l}\text { Cornell University } \\
\text { Clarkson University }\end{array}$ \\
\hline $1 \mathrm{~A}$ & Peering Into Windc & $1 \mathrm{~B}$ & Fist Bangin & $1 \mathrm{C}$ & Fingertip Window Slide & 10 & Get-away Palm on Glass & $1 \mathrm{E}$ & "OK" Sign on Glass \\
\hline $1 \mathrm{~F}$ & Counter Vault on Glass & $1 \mathrm{G}$ & Cylinder Grab & $1 \mathrm{H}$ & Impatient Tapping on Glass & $2 \mathrm{~A}$ & Samsung Galaxy S5 & $2 \mathrm{~B}$ & Apple iPhone $5 \mathrm{~s}$ \\
\hline 3 & Check & $4 \mathrm{~A}$ & Lined Paper & $4 \mathrm{~B}$ & Low-quality Copy Paper & $4 \mathrm{C}$ & High-quality Copy Paper & $4 \mathrm{D}$ & Yellow Lined Paper \\
\hline $4 E$ & Low-quality White Envelope & $4 \mathrm{~F}$ & Greeting Card and Envelope & $4 \mathrm{G}$ & Manila Envelope & $5 \mathrm{~A}$ & Photo Paper & $5 \mathrm{~B}$ & Glossy Magazine \\
\hline $5 \mathrm{C}$ & U.S. Currency & $6 \mathrm{~A}$ & Stamp & $6 \mathrm{~B}$ & Address Label & $6 \mathrm{C}$ & Clear Packing Tape & $6 \mathrm{D}$ & Black Electrical Tape \\
\hline $6 \mathrm{E}$ & Duct Tape & $7 \mathrm{~A}$ & Circuit Board & $7 \mathrm{~B}$ & $\mathrm{CD} / \mathrm{DVD}$ & $7 \mathrm{C}$ & Clear Plastic Bag & $7 \mathrm{D}$ & Black Plastic Bag \\
\hline
\end{tabular}




\begin{tabular}{lrrr}
\hline Challenger & Hit Rate (Rank 1) & Hit Rate (Rank 5) & Hit Rate (Rank 10) \\
\hline$\Omega$ & $8.2 \%$ & $8.7 \%$ & $8.8 \%$ \\
A & $27.6 \%$ & $28.2 \%$ & $28.3 \%$ \\
B & $46.9 \%$ & $47.5 \%$ & $47.6 \%$ \\
$C$ & $18.8 \%$ & $19.3 \%$ & $19.4 \%$ \\
D & $71.8 \%$ & $72.1 \%$ & $62.2 \%$ \\
E & $37.6 \%$ & $38.1 \%$ & $38.2 \%$ \\
F & $55.3 \%$ & $55.6 \%$ & $55.7 \%$ \\
G & $62.0 \%$ & $62.1 \%$ & $72.1 \%$ \\
$H$ & $80.0 \%$ & $80.0 \%$ & $80.0 \%$ \\
\hline
\end{tabular}

Table 8. Hit rate for ranks 1, 5, and 10 for the MATCHER when searching study participant latent fingerprint images against an enrollment set of Challenger N2N images. The best non-baseline value is reported in green and the worst in red. Challenger values that meet or beat the baseline are shaded in blue. All ranks are depicted in Fig. 18. A gradual improvement is noticed between rank 1 and rank 10 for most Challengers, although the hit rates at highest rank are still poor.

\section{Cumulative Match Characteristic}

All Challengers, Latent Identification

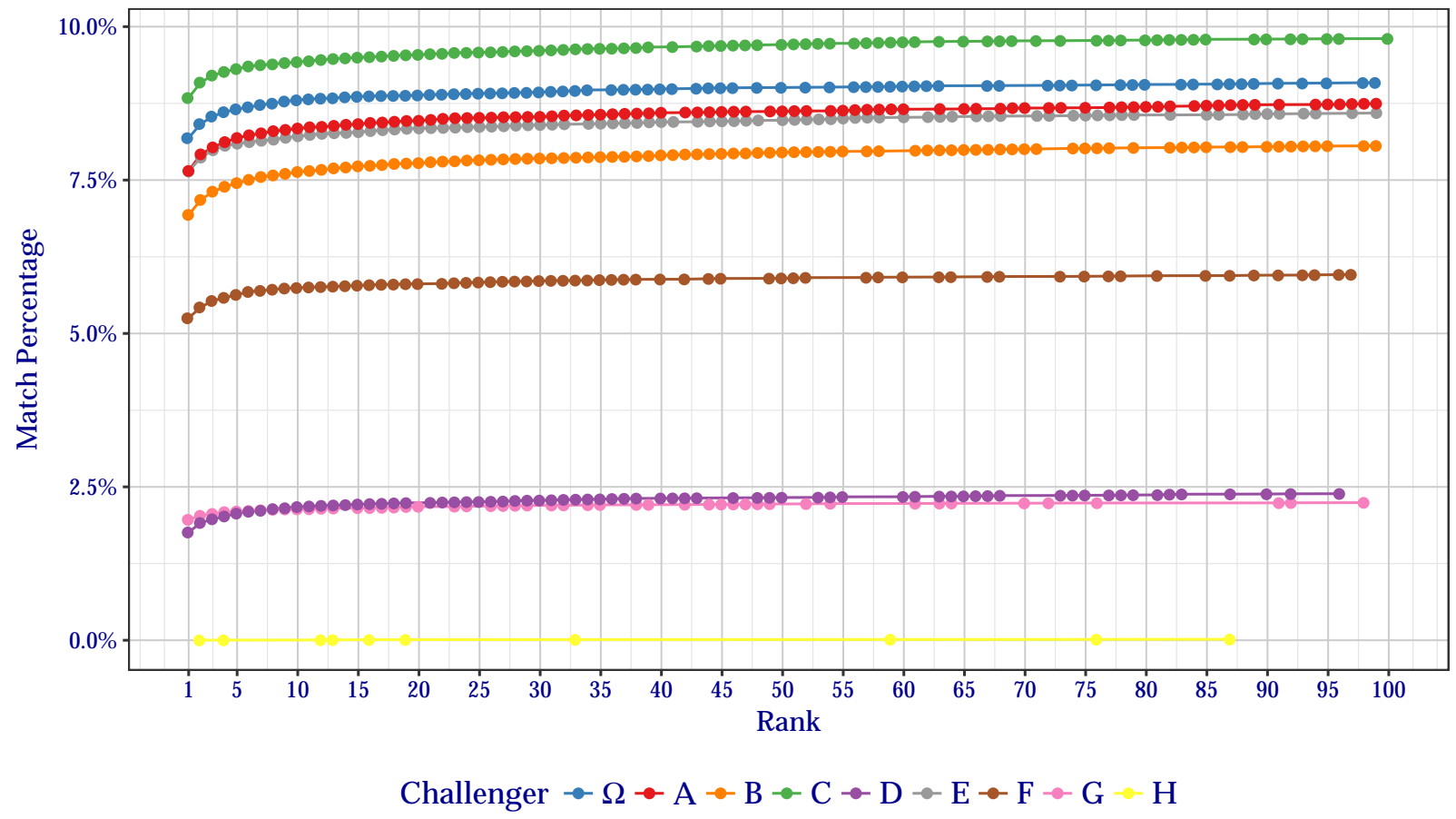

Fig. 18. CMC curves for each Challenger for latent identification. This plot shows the rate at which the MATCHER, when searching study participant latent fingerprint images against an enrollment set seeded with N2N images from each Challenger, found the correct mate, regardless of similarity score. The values for ranks 1, 5, and 10 are reported in Table 8. If a curve stops before reaching the far right of the plot, it indicates that a mate was never found past the last corresponding rank.

\begin{tabular}{|c|c|c|c|c|c|c|c|c|c|}
\hline$\Omega$ & FBI Baseline & $\begin{array}{l}A \\
E\end{array}$ & $\begin{array}{l}\text { IDEMIA } \\
\text { Jenetric }\end{array}$ & $\begin{array}{l}B \\
F\end{array}$ & $\begin{array}{l}\text { Advanced Optical Systems } \\
\text { Touchless Biometric Systems }\end{array}$ & $\begin{array}{l}C \\
G\end{array}$ & $\begin{array}{l}\text { Green Bit } \\
\text { Crossmatch }\end{array}$ & $\begin{array}{l}\mathrm{D} \\
\mathrm{H}\end{array}$ & $\begin{array}{l}\text { Cornell University } \\
\text { Clarkson University }\end{array}$ \\
\hline $1 \mathrm{~A}$ & Peering Into Window & $1 \mathrm{~B}$ & Fist Banging on Glass & $1 \mathrm{C}$ & Fingertip Window Slide & $1 \mathrm{D}$ & Get-away Palm on Glass & $1 \mathrm{E}$ & "OK" Sign on Glass \\
\hline $1 \mathrm{~F}$ & Counter Vault on Glass & $1 \mathrm{G}$ & Cylinder Grab & $1 \mathrm{H}$ & Impatient Tapping on Glass & $2 \mathrm{~A}$ & Samsung Galaxy S5 & $2 B$ & Apple iPhone $5 \mathrm{~s}$ \\
\hline 3 & Check & $4 \mathrm{~A}$ & Lined Paper & 4B & Low-quality Copy Paper & $4 \mathrm{C}$ & High-quality Copy Paper & 4D & Yellow Lined Paper \\
\hline $4 \mathrm{E}$ & Low-quality White Envelope & $4 \mathrm{~F}$ & Greeting Card and Envelope & $4 G$ & Manila Envelope & $5 \mathrm{~A}$ & Photo Paper & $5 B$ & Glossy Magazine \\
\hline $5 c$ & U.S. Currency & $6 \mathrm{~A}$ & Stamp & $6 \mathrm{~B}$ & Address Label & $6 \mathrm{C}$ & Clear Packing Tape & $6 \mathrm{D}$ & Black Electrical Tape \\
\hline $6 \mathrm{E}$ & Duct Tape & $7 \mathrm{~A}$ & Circuit Board & $7 \mathrm{~B}$ & $\mathrm{CD} / \mathrm{DVD}$ & $7 \mathrm{C}$ & Clear Plastic Bag & $7 D$ & Black Plastic Bag \\
\hline
\end{tabular}




\begin{tabular}{|c|c|c|c|c|c|c|c|c|c|}
\hline$\Omega$ & FBI Baseline & $\begin{array}{l}\mathrm{A} \\
\mathrm{E}\end{array}$ & $\begin{array}{l}\text { IDEMIA } \\
\text { Jenetric }\end{array}$ & $\begin{array}{l}\mathrm{B} \\
\mathrm{F}\end{array}$ & $\begin{array}{l}\text { Advanced Optical Systems } \\
\text { Touchless Biometric Systems }\end{array}$ & $\begin{array}{l}C \\
G\end{array}$ & $\begin{array}{l}\text { Green Bit } \\
\text { Crossmatch }\end{array}$ & $\begin{array}{l}\mathrm{D} \\
\mathrm{H}\end{array}$ & $\begin{array}{l}\text { Cornell University } \\
\text { Clarkson University }\end{array}$ \\
\hline $1 \mathrm{~A}$ & Peering Into Window & $1 \mathrm{~B}$ & Fist Banging on Glass & $1 \mathrm{C}$ & Fingertip Window Slide & 10 & Get-away Palm on Glass & $1 \mathrm{E}$ & "OK" Sign on Glass \\
\hline $1 \mathrm{~F}$ & Counter Vault on Glass & 16 & Cylinder Grab & $1 \mathrm{H}$ & Impatient Tapping on Glass & $2 \mathrm{~A}$ & Samsung Galaxy S5 & $2 \mathrm{~B}$ & Apple iPhone $5 \mathrm{~s}$ \\
\hline 3 & Check & $4 \mathrm{~A}$ & Lined Paper & $4 B$ & Low-quality Copy Paper & $4 \mathrm{C}$ & High-quality Copy Paper & $4 D$ & Yellow Lined Paper \\
\hline $4 \mathrm{E}$ & Low-quality White Envelope & $4 \mathrm{~F}$ & Greeting Card and Envelope & $4 G$ & Manila Envelope & $5 \mathrm{~A}$ & Photo Paper & $5 \mathrm{~B}$ & Glossy Magazine \\
\hline $5 C$ & U.S. Currency & $6 \mathrm{~A}$ & Stamp & $6 \mathrm{~B}$ & Address Label & $6 \mathrm{C}$ & Clear Packing Tape & 60 & Black Electrical Tape \\
\hline $6 \mathrm{E}$ & Duct Tape & $7 \mathrm{~A}$ & Circuit Board & $7 \mathrm{~B}$ & CD/DVD & $7 \mathrm{C}$ & Clear Plastic Bag & $7 \mathrm{D}$ & Black Plastic Bag \\
\hline
\end{tabular}




\section{Acknowledgments}

A data collection of the size and scale presented at the Nail to Nail Fingerprint Challenge requires the coordination and cooperation of dozens of individuals, without whom the Challenge would not have been possible.

- Thank you to the Intelligence Advanced Research Projects Activity for sponsoring the Nail to Nail Fingerprint Challenge and supporting advancements in fingerprint capture and recognition.

- Thank you to Rebecca Allegar, Nathaniel Short, and the many members of the Booz Allen Hamilton (BAH) team that helped IARPA create, organize, plan, and successfully execute the Nail to Nail Fingerprint Challenge.

- Thank you to Ellen Fuller, Christopher Nardone, and the rest of the Johns Hopkins University Applied Physics Laboratory team for graciously hosting the Nail to Nail Fingerprint Challenge and providing the infrastructure by which N2N Challengers submitted imagery.

- Thank you to the many Johns Hopkins University Applied Physics Laboratory, Booz Allen Hamilton, Intelligence Advanced Research Projects Activity, National Institute of Standards and Technology, and Schwarz Forensic Enterprises employees who spent countless hours digitizing and isolating latents.

- Thank you to the Arizona Department of Public Safety, the Federal Bureau of Investigation, the Los Angeles County Sheriff's Department, and the Texas Department of Public Safety for their donation of operational rolled images that were used to seed the MATCHER's enrollment set with impostor candidates.

- Thank you to Crossmatch and IDEMIA for providing high-resolution palm scanners for the week of the Nail to Nail Fingerprint Challenge in order to help capture exemplar palm data for distribution with the Challenge latent print dataset.

- Thank you to the Biometrics Research Group at Michigan State University for providing a prototype open source single finger capture device for auxiliary data collection.

- Thank you to staff of the Department of Homeland Security Maryland Test Facility for their assistance in prototyping the Challenge data collection.

\begin{tabular}{|c|c|c|c|c|c|c|c|c|c|}
\hline$\Omega$ & FBI Baseline & $\begin{array}{l}\mathrm{A} \\
\mathrm{E}\end{array}$ & $\begin{array}{l}\text { IDEMIA } \\
\text { Jenetric }\end{array}$ & $\begin{array}{l}B \\
F\end{array}$ & $\begin{array}{l}\text { Advanced Optical Systems } \\
\text { Touchless Biometric Systems }\end{array}$ & $\begin{array}{l}C \\
G\end{array}$ & $\begin{array}{l}\text { Green Bit } \\
\text { Crossmatch }\end{array}$ & $\begin{array}{l}\mathrm{D} \\
\mathrm{H}\end{array}$ & $\begin{array}{l}\text { Cornell University } \\
\text { Clarkson University }\end{array}$ \\
\hline $1 \mathrm{~A}$ & Peering Into Window & $1 \mathrm{~B}$ & Fist Banging on Glass & $1 \mathrm{C}$ & Fingertip Window Slide & 10 & Get-away Palm on Glass & $1 \mathrm{E}$ & "OK" Sign on Glass \\
\hline $1 \mathrm{~F}$ & Counter Vault on Glass & $1 \mathrm{G}$ & Cylinder Grab & $1 \mathrm{H}$ & Impatient Tapping on Glass & $2 \mathrm{~A}$ & Samsung Galaxy S5 & $2 \mathrm{~B}$ & Apple iPhone $5 \mathrm{~s}$ \\
\hline 3 & Check & $4 \mathrm{~A}$ & Lined Paper & $4 B$ & Low-quality Copy Paper & $4 \mathrm{C}$ & High-quality Copy Paper & 4D & Yellow Lined Paper \\
\hline $4 \mathrm{E}$ & Low-quality White Envelope & $4 \mathrm{~F}$ & Greeting Card and Envelope & $4 \mathrm{G}$ & Manila Envelope & $5 \mathrm{~A}$ & Photo Paper & $5 B$ & Glossy Magazine \\
\hline $5 \mathrm{C}$ & U.S. Currency & $6 \mathrm{~A}$ & Stamp & $6 \mathrm{~B}$ & Address Label & $6 \mathrm{C}$ & Clear Packing Tape & $6 \mathrm{D}$ & Black Electrical Tape \\
\hline $6 \mathrm{E}$ & Duct Tape & $7 \mathrm{~A}$ & Circuit Board & $7 \mathrm{~B}$ & CD/DVD & $7 \mathrm{C}$ & Clear Plastic Bag & $7 \mathrm{D}$ & Black Plastic Bag \\
\hline
\end{tabular}




\section{References}

[1] Simpson JA, Weiner ESC (1989) The Oxford English Dictionary. Vol. IX (Oxford University Press), 2nd Ed.

[2] MathWorks MATLAB imresize, https://www.mathworks.com/help/images/ref/imresize.html.

[3] International Association for Identification, et al (2011) The Fingerprint Sourcebook (National Institute of Justice), 1st Ed.

[4] Trozzi TA, Schwartz RL, Hollars ML (2000) Processing Guide for Developing Latent Prints, https:// archives.fbi.gov/archives/about-us/lab/forensic-science-communications/fsc/jan2001/lpu.pdf. [Online; accessed 15 February 2018].

[5] Grantham J (2017) NISTscan, https://github.com/usnistgov/NISTscan. [Online; accessed 15 February 2018].

[6] Intelligence Advanced Research Projects Activity (2017) IARPA Nail-to-Nail Challenge Rules \& Regulations, https://www.iarpa.gov/challenges/n2n/N2NChallengeRules.pdf. [Online; accessed 15 February 2018].

[7] Watson C, et al. (2014) Fingerprint Vendor Technology Evaluation. NIST Interagency Report 8034 https: //doi.org/10.6028/NIST.IR.8034

[8] Shapiro SS, Wilk MB, Chen HJ (1968) A Comparative Study of Various Tests for Normality. Journal of the American Statistical Association 63(324):1343-1372. URL http://www.jstor.org/stable/2285889.

[9] Fiumara G (2017) Nail-to-Nail Fingerprint Capture Challenge: Software Test Plan, https://github.com/ usnistgov/IARPA-N2N. [Online; accessed 15 February 2018].

[10] Wilson EB (1927) Probable Inference, the Law of Succession, and Statistical Inference. Journal of the American Statistical Association 22(158):209-212. URL http://www.jstor.org/stable/2276774.

[11] Indovina M, Dvornychenko V, Hicklin RA, Kiebuzinski GI (2012) Evaluation of Latent Fingerprint Technologies: Extended Feature Sets [Evaluation \#2]. NIST Interagency Report 7859 https://doi.org/ 10.6028/NIST.IR.7859

[12] Tabassi E (2016) Development of NFIQ 2.0, https://www.nist.gov/services-resources/software/ development-nfiq-20. [Online; accessed 15 February 2018].

\begin{tabular}{|c|c|c|c|c|c|c|c|c|c|}
\hline$\Omega$ & FBI Baseline & $\begin{array}{l}A \\
E\end{array}$ & $\begin{array}{l}\text { IDEMIA } \\
\text { Jenetric }\end{array}$ & $\begin{array}{l}\mathrm{B} \\
\mathrm{F}\end{array}$ & $\begin{array}{l}\text { Advanced Optical Systems } \\
\text { Touchless Biometric Systems }\end{array}$ & $\begin{array}{l}c \\
G\end{array}$ & $\begin{array}{l}\text { Green Bit } \\
\text { Crossmatch }\end{array}$ & $\begin{array}{l}\mathrm{D} \\
\mathrm{H}\end{array}$ & $\begin{array}{l}\text { Cornell University } \\
\text { Clarkson University }\end{array}$ \\
\hline $1 \mathrm{~A}$ & Peering Into Window & $1 \mathrm{~B}$ & Fist Banging on Glass & 1C & Fingertip Window Slide & 10 & Get-away Palm on Glass & $1 \mathrm{E}$ & "OK" Sign on Glass \\
\hline $1 \mathrm{~F}$ & Counter Vault on Glass & $1 \mathrm{G}$ & Cylinder Grab & $1 \mathrm{H}$ & Impatient Tapping on Glass & $2 \mathrm{~A}$ & Samsung Galaxy S5 & $2 \mathrm{~B}$ & Apple iPhone $5 \mathrm{~s}$ \\
\hline 3 & Check & $4 \mathrm{~A}$ & Lined Paper & $4 \mathrm{~B}$ & Low-quality Copy Paper & $4 \mathrm{C}$ & High-quality Copy Paper & $4 \mathrm{D}$ & Yellow Lined Paper \\
\hline $4 \mathrm{E}$ & Low-quality White Envelope & $4 \mathrm{~F}$ & Greeting Card and Envelope & $4 \mathrm{G}$ & Manila Envelope & $5 \mathrm{~A}$ & Photo Paper & $5 \mathrm{~B}$ & Glossy Magazine \\
\hline $5 c$ & U.S. Currency & $6 \mathrm{~A}$ & Stamp & $6 \mathrm{~B}$ & Address Label & $6 \mathrm{C}$ & Clear Packing Tape & $6 \mathrm{D}$ & Black Electrical Tape \\
\hline $6 \mathrm{E}$ & Duct Tape & $7 \mathrm{~A}$ & Circuit Board & $7 \mathrm{~B}$ & $\mathrm{CD} / \mathrm{DVD}$ & $7 \mathrm{C}$ & Clear Plastic Bag & $7 \mathrm{D}$ & Black Plastic Bag \\
\hline
\end{tabular}




\section{A. Results - Latent Identification - By Activity}

Overall performance for latent identification is quite poor (Section 11). Some Challengers perform comparably well on particular activities, while failing to identify any study participants in others.

Activities that were more prone to leave behind the center area of the distal phalanx performed better, while those that encouraged leaving extreme tips and sides, a goal of a true N2N capture, did not. Regardless, even the best performing activities demonstrate poor accuracy.

FNIRs for each activity can be seen in Table 9 and Fig. 19. CMCs for each activity can be seen in Table 10 and Fig. 20.

A breakdown of the number of searches performed in each activity is shown in Table 11. Only those images that were successfully searched by the MATCHER are represented. Not all study participants left behind latent prints for a given activity, and so they are not represented in Table 11. Additionally, not all collected data was able to be developed and digitized prior to this results distribution.

\begin{tabular}{|c|c|c|c|c|c|c|c|c|c|}
\hline Activity & $\Omega$ & A & B & C & D & E & $\mathrm{F}$ & G & $\mathrm{H}$ \\
\hline $1 \mathrm{~A}$ & 0.890 & ${ }^{3} 0.928$ & ${ }^{4} 0.940$ & 10.860 & ${ }^{6} 0.972$ & ${ }^{2} 0.890$ & ${ }^{5} 0.945$ & ${ }^{7} 0.985$ & 81.000 \\
\hline 1B & 000 & ${ }^{1} 1.000$ & ${ }^{1} 1.000$ & ${ }^{1} 1.000$ & ${ }^{1} 1.000$ & ${ }^{1} 1.000$ & ${ }^{1} 1.000$ & ${ }^{1} 1.000$ & ${ }^{1} 1.000$ \\
\hline $1 \mathrm{C}$ & 905 & ${ }^{2} 0.919$ & ${ }^{4} 0.932$ & ${ }^{1} 0.907$ & ${ }^{7} 0.987$ & ${ }^{3} 0.920$ & ${ }^{5} 0.949$ & ${ }^{6} 0.983$ & ${ }^{8} 1.000$ \\
\hline 1D & 710 & ${ }^{3} 0.744$ & ${ }^{4} 0.763$ & ${ }^{1} 0.684$ & ${ }^{7} 0.932$ & ${ }^{2} 0.722$ & ${ }^{5} 0.792$ & ${ }^{6} 0.924$ & 81.000 \\
\hline $1 \mathrm{E}$ & 829 & ${ }^{3} 0.877$ & ${ }^{4} 0.885$ & ${ }^{1} 0.788$ & ${ }^{7} 0.973$ & ${ }^{2} 0.838$ & ${ }^{5} 0.917$ & ${ }^{6} 0.971$ & 81.000 \\
\hline $1 \mathrm{~F}$ & 682 & ${ }^{3} 0.729$ & ${ }^{4} 0.745$ & ${ }^{1} 0.681$ & ${ }^{7} 0.939$ & ${ }^{2} 0.720$ & ${ }^{5} 0.797$ & ${ }^{6} 0.913$ & 81.000 \\
\hline $1 G$ & 978 & ${ }^{5} 0.990$ & ${ }^{2} 0.984$ & ${ }^{1} 0.981$ & ${ }^{7} 0.997$ & ${ }^{4} 0.988$ & ${ }^{3} 0.987$ & ${ }^{5} 0.990$ & 1.000 \\
\hline $1 \mathrm{H}$ & 0.892 & ${ }^{1} 0.868$ & ${ }^{3} 0.897$ & ${ }^{2} 0.879$ & ${ }^{7} 0.975$ & ${ }^{4} 0.898$ & ${ }^{5} 0.932$ & ${ }^{6} 0.972$ & 1.000 \\
\hline $2 \mathrm{~A}$ & 0.971 & ${ }^{1} 0.954$ & ${ }^{2} 0.963$ & ${ }^{2} 0.963$ & ${ }^{7} 0.997$ & ${ }^{4} 0.964$ & ${ }^{5} 0.976$ & ${ }^{6} 0.990$ & 1.000 \\
\hline $2 \mathrm{~B}$ & 0.973 & ${ }^{1} 0.969$ & ${ }^{2} 0.972$ & ${ }^{2} 0.972$ & ${ }^{7} 0.996$ & ${ }^{4} 0.974$ & ${ }^{5} 0.981$ & ${ }^{6} 0.995$ & 81.000 \\
\hline 3 & 0.984 & ${ }^{2} 0.982$ & ${ }^{2} 0.982$ & ${ }^{1} 0.977$ & ${ }^{6} 0.994$ & ${ }^{2} 0.982$ & ${ }^{5} 0.986$ & ${ }^{7} 0.999$ & ${ }^{8} 1.000$ \\
\hline $4 \mathrm{~A}$ & 0.974 & ${ }^{4} 0.977$ & ${ }^{3} 0.976$ & ${ }^{1} 0.970$ & ${ }^{7} 0.996$ & ${ }^{2} 0.971$ & ${ }^{5} 0.980$ & ${ }^{6} 0.994$ & ${ }^{8} 1.000$ \\
\hline $4 \mathrm{~B}$ & 0.958 & ${ }^{4} 0.962$ & ${ }^{1} 0.958$ & ${ }^{3} 0.960$ & ${ }^{6} 0.990$ & ${ }^{1} 0.958$ & ${ }^{5} 0.978$ & ${ }^{6} 0.990$ & 81.000 \\
\hline $4 C$ & 0.978 & ${ }^{4} 0.978$ & ${ }^{3} 0.976$ & ${ }^{1} 0.973$ & ${ }^{6} 0.994$ & ${ }^{1} 0.973$ & ${ }^{5} 0.982$ & ${ }^{7} 1.000$ & ${ }^{7} 1.000$ \\
\hline 4D & 0.970 & ${ }^{3} 0.975$ & ${ }^{3} 0.975$ & ${ }^{1} 0.966$ & ${ }^{6} 0.991$ & ${ }^{2} 0.971$ & ${ }^{5} 0.981$ & ${ }^{7} 0.996$ & ${ }^{8} 1.000$ \\
\hline $4 \mathrm{E}$ & 0.970 & ${ }^{3} 0.972$ & ${ }^{4} 0.975$ & ${ }^{2} 0.971$ & ${ }^{7} 0.993$ & ${ }^{1} 0.970$ & ${ }^{5} 0.984$ & ${ }^{6} 0.992$ & ${ }^{8} 1.000$ \\
\hline $4 \mathrm{~F}$ & 0.983 & ${ }^{2} 0.982$ & ${ }^{4} 0.989$ & ${ }^{1} 0.980$ & ${ }^{7} 0.998$ & ${ }^{3} 0.985$ & ${ }^{5} 0.991$ & ${ }^{6} 0.994$ & 81.000 \\
\hline $4 \mathrm{G}$ & 0.966 & ${ }^{2} 0.968$ & ${ }^{10} 0.965$ & & ${ }^{6} 0.992$ & ${ }^{4} 0.972$ & ${ }^{5} 0.977$ & ${ }^{7} 0.993$ & ${ }^{8} 1.000$ \\
\hline $5 \mathrm{~A}$ & 0.962 & ${ }^{1} 0.952$ & ${ }^{4} 0.962$ & ${ }^{2} 0.957$ & ${ }^{7} 0.993$ & ${ }^{3} 0.960$ & ${ }^{5} 0.968$ & ${ }^{6} 0.986$ & ${ }^{8} 1.000$ \\
\hline $5 B$ & 0.981 & ${ }^{4} 0.981$ & ${ }^{10} 0.978$ & ${ }^{2} 0.979$ & ${ }^{6} 0.997$ & ${ }^{3} 0.980$ & ${ }^{5} 0.989$ & ${ }^{7} 1.000$ & 71.000 \\
\hline $5 C$ & 0.992 & ${ }^{2} 0.981$ & ${ }^{10} 0.978$ & ${ }^{5} 0.989$ & ${ }^{6} 0.997$ & ${ }^{3} 0.986$ & ${ }^{3} 0.986$ & ${ }^{7} 1.000$ & 71.000 \\
\hline $6 \mathrm{~A}$ & 0.975 & ${ }^{2} 0.973$ & ${ }^{4} 0.976$ & ${ }^{1} 0.967$ & ${ }^{6} 0.994$ & ${ }^{3} 0.975$ & ${ }^{5} 0.990$ & ${ }^{6} 0.994$ & 81.000 \\
\hline $6 C$ & 0.897 & ${ }^{2} 0.905$ & ${ }^{4} 0.918$ & ${ }^{1} 0.893$ & ${ }^{7} 0.978$ & ${ }^{3} 0.906$ & ${ }^{5} 0.933$ & ${ }^{6} 0.970$ & ${ }^{8} 1.000$ \\
\hline $6 \mathrm{D}$ & 0.894 & ${ }^{2} 0.907$ & ${ }^{4} 0.911$ & ${ }^{1} 0.895$ & ${ }^{7} 0.977$ & ${ }^{3} 0.909$ & ${ }^{5} 0.920$ & ${ }^{6} 0.970$ & ${ }^{8} 1.000$ \\
\hline $6 \mathrm{E}$ & 0.890 & ${ }^{2} 0.898$ & ${ }^{4} 0.908$ & ${ }^{1} 0.889$ & ${ }^{6} 0.968$ & ${ }^{3} 0.900$ & ${ }^{5} 0.925$ & ${ }^{7} 0.974$ & ${ }^{8} 1.000$ \\
\hline $7 \mathrm{~A}$ & 1.000 & ${ }^{1} 1.000$ & ${ }^{1} 1.000$ & ${ }^{1} 1.000$ & ${ }^{1} 1.000$ & ${ }^{1} 1.000$ & ${ }^{1} 1.000$ & ${ }^{1} 1.000$ & ${ }^{1} 1.000$ \\
\hline $7 \mathrm{~B}$ & 0.957 & ${ }^{4} 0.965$ & ${ }^{1} 0.887$ & ${ }^{2} 0.915$ & ${ }^{71.000}$ & ${ }^{5} 0.979$ & ${ }^{5} 0.979$ & ${ }^{3} 0.922$ & 71.000 \\
\hline $7 C$ & 0.995 & ${ }^{2} 0.992$ & ${ }^{5} 0.996$ & ${ }^{1} 0.991$ & ${ }^{6} 0.998$ & ${ }^{2} 0.992$ & ${ }^{4} 0.994$ & ${ }^{6} 0.998$ & 81.000 \\
\hline 7D & 0.986 & ${ }^{3} 0.992$ & ${ }^{10} 0.990$ & ${ }^{10} 0.990$ & ${ }^{7} 0.998$ & ${ }^{3} 0.992$ & ${ }^{5} 0.995$ & ${ }^{6} 0.996$ & ${ }^{8} 1.000$ \\
\hline
\end{tabular}

Table 9. Values for FNIR at a fixed FPIR of $10^{-1}$ for latent identification, separated by latent activity. These values are extracted from those plotted on the vertical dashed lines in Fig. 19. Each row represents one latent activity. In each row, the Baseline Data is recorded in blue, the best non-baseline values are reported in green and the worst in red. Challenger values that meet or beat the baseline for each activity are shaded in blue. Superscript numbers preceding the FNIR value represent its ranking in each row.

\begin{tabular}{|c|c|c|c|c|c|c|c|c|c|}
\hline$\Omega$ & FBI Baseline & $\begin{array}{l}A \\
E\end{array}$ & $\begin{array}{l}\text { IDEMIA } \\
\text { Jenetric }\end{array}$ & $\begin{array}{l}B \\
F\end{array}$ & $\begin{array}{l}\text { Advanced Optical Systems } \\
\text { Touchless Biometric Systems }\end{array}$ & $\begin{array}{l}C \\
G\end{array}$ & $\begin{array}{l}\text { Green Bit } \\
\text { Crossmatch }\end{array}$ & $\begin{array}{l}\mathrm{D} \\
\mathrm{H}\end{array}$ & $\begin{array}{l}\text { Cornell University } \\
\text { Clarkson University }\end{array}$ \\
\hline $1 \mathrm{~A}$ & Peering Into Window & $1 \mathrm{~B}$ & Fist Banging on Glass & $1 \mathrm{C}$ & Fingertip Window Slide & $1 \mathrm{D}$ & Get-away Palm on Glass & $1 \mathrm{E}$ & "OK" Sign on Glass \\
\hline $1 \mathrm{~F}$ & Counter Vault on Glass & $1 \mathrm{G}$ & Cylinder Grab & $1 \mathrm{H}$ & Impatient Tapping on Glass & $2 \mathrm{~A}$ & Samsung Galaxy S5 & $2 B$ & Apple iPhone $5 \mathrm{~s}$ \\
\hline 3 & Check & $4 \mathrm{~A}$ & Lined Paper & 4B & Low-quality Copy Paper & $4 \mathrm{C}$ & High-quality Copy Paper & 4D & Yellow Lined Paper \\
\hline $4 \mathrm{E}$ & Low-quality White Envelope & $4 \mathrm{~F}$ & Greeting Card and Envelope & $4 G$ & Manila Envelope & $5 \mathrm{~A}$ & Photo Paper & $5 B$ & Glossy Magazine \\
\hline $5 c$ & U.S. Currency & $6 \mathrm{~A}$ & Stamp & $6 \mathrm{~B}$ & Address Label & $6 \mathrm{C}$ & Clear Packing Tape & $6 \mathrm{D}$ & Black Electrical Tape \\
\hline $6 \mathrm{E}$ & Duct Tape & $7 \mathrm{~A}$ & Circuit Board & $7 \mathrm{~B}$ & $\mathrm{CD} / \mathrm{DVD}$ & $7 \mathrm{C}$ & Clear Plastic Bag & $7 D$ & Black Plastic Bag \\
\hline
\end{tabular}


Detection Error Tradeoff: By Activity

All Challengers, Latent Identification
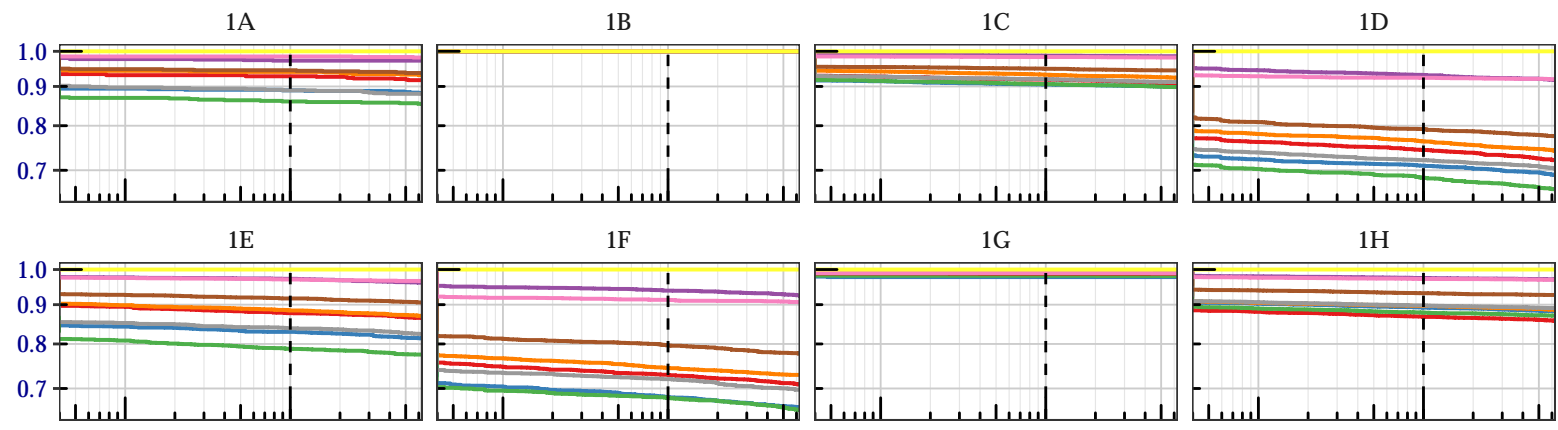

$2 \mathrm{~A}$

2B
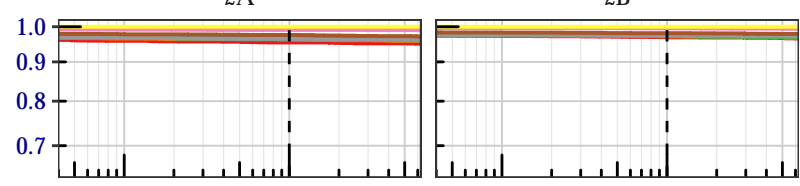

3

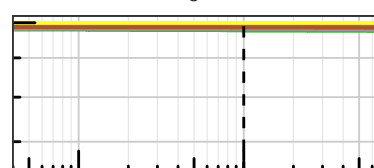

$4 \mathrm{~A}$

$4 \mathrm{~B}$

$4 C$

$4 \mathrm{D}$
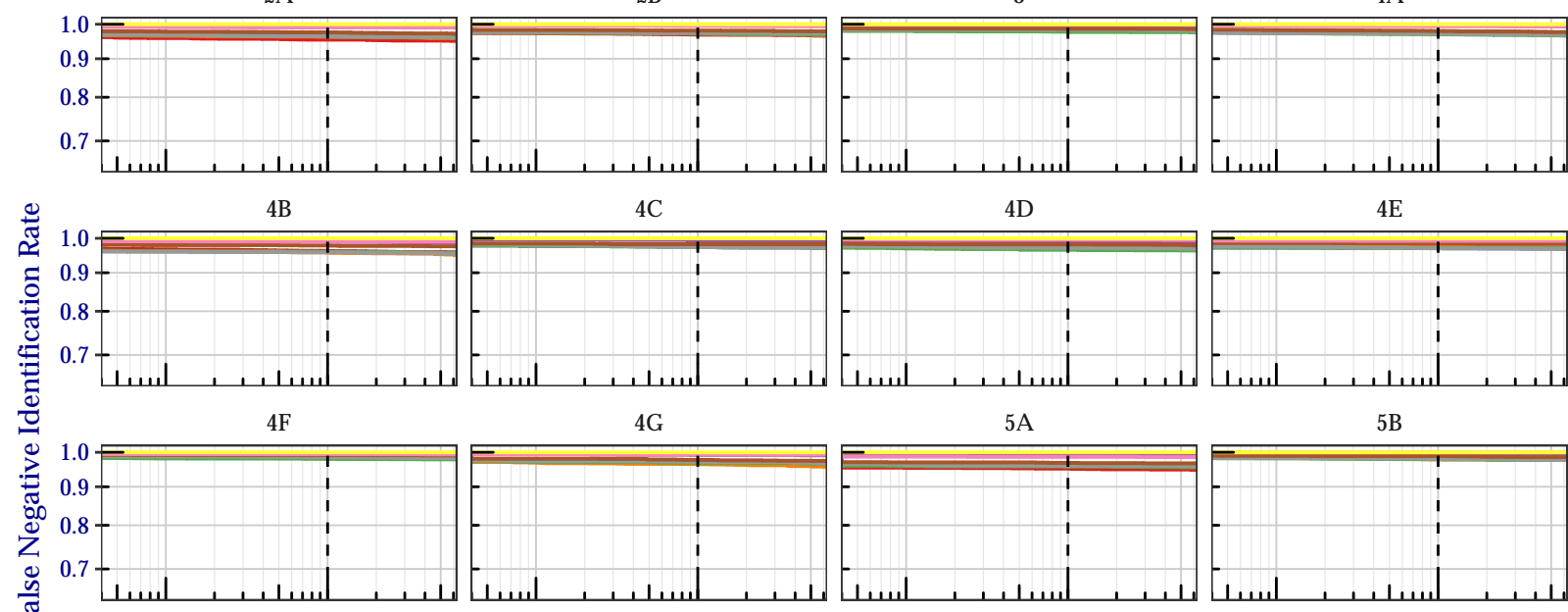

$4 \mathrm{G}$

$5 \mathrm{~A}$
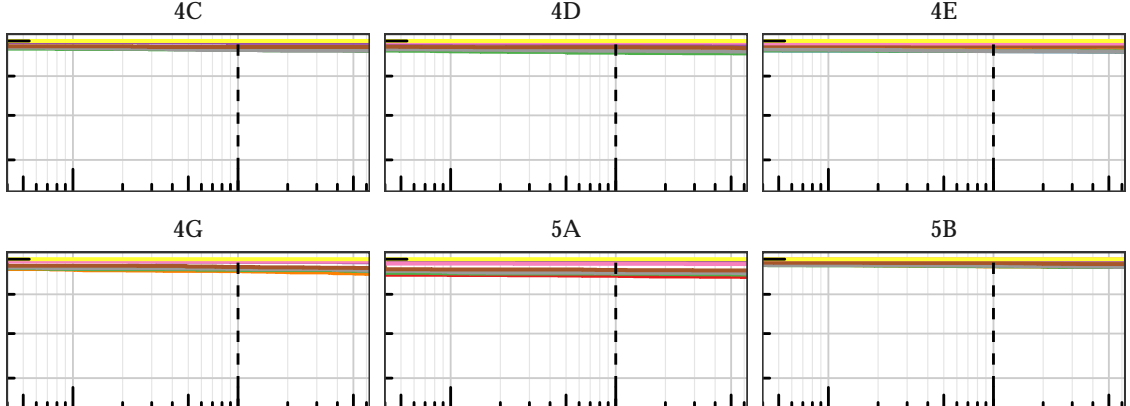

$5 B$

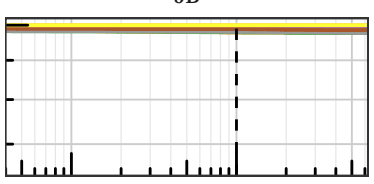

$5 \mathrm{C}$

$6 \mathrm{~A}$
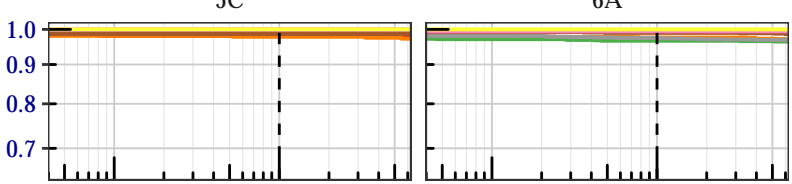

$6 \mathrm{C}$

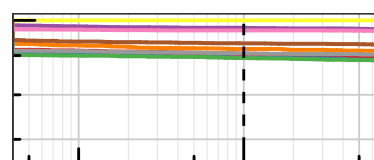

$6 \mathrm{D}$

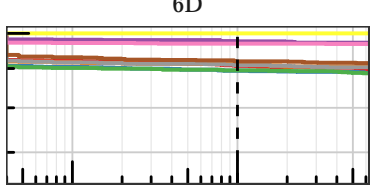

$6 \mathrm{E}$

7A

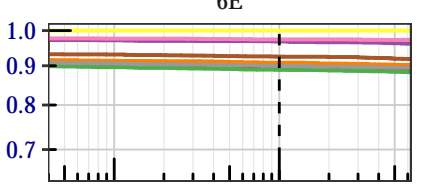

$7 \mathrm{D}$

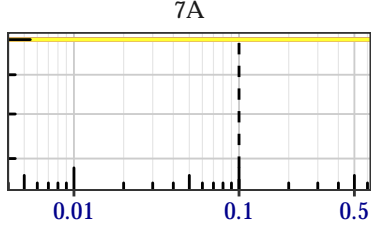

$7 \mathrm{~B}$
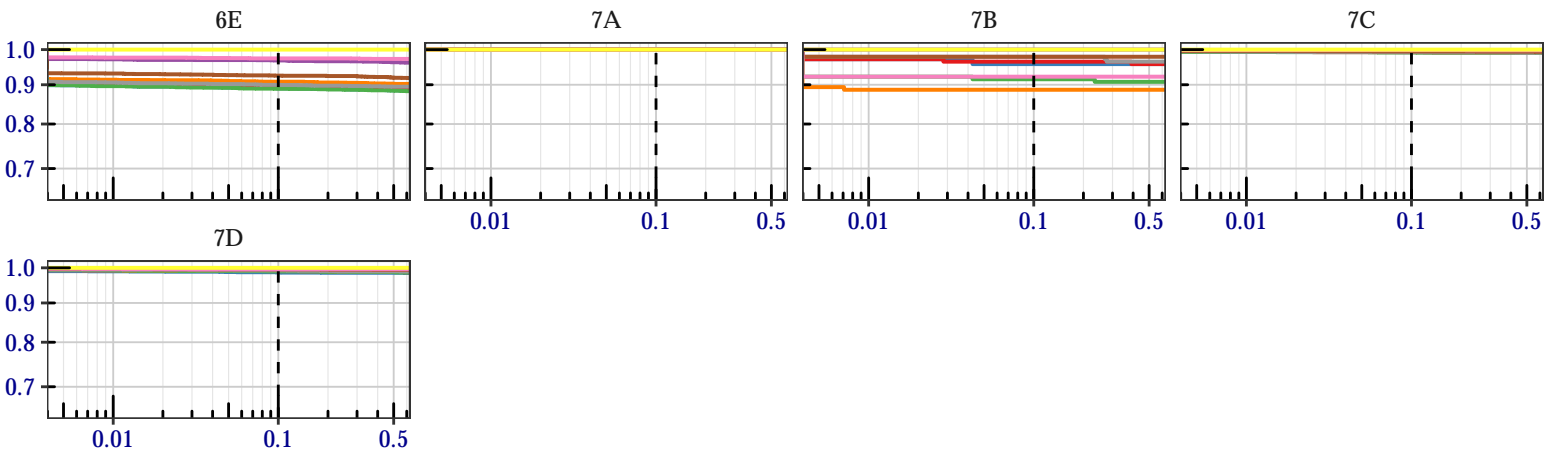

False Positive Identification Rate

$$
\text { Challenger }-\Omega-\mathrm{A}-\mathrm{B}-\mathrm{C}-\mathrm{D}-\mathrm{E}-\mathrm{F}-\mathrm{G}-\mathrm{H}
$$

Fig. 19. DET curves for each Challenger for latent identification, separated by latent activity. This plot shows the accuracy of the MATCHER when searching study participant latent fingerprint images against an enrollment set seeded with N2N images from each Challenger. The vertical dashed line indicates the FPIR at which a prize was to be awarded for the lowest overall FNIR, and the values lying on this line are reported in Table 9.

\begin{tabular}{|c|c|c|c|c|c|c|c|c|c|}
\hline$\Omega$ & FBI Baseline & $\begin{array}{l}A \\
E\end{array}$ & $\begin{array}{l}\text { IDEMIA } \\
\text { Jenetric }\end{array}$ & $\begin{array}{l}B \\
F\end{array}$ & $\begin{array}{l}\text { Advanced Optical Systems } \\
\text { Touchless Biometric Systems }\end{array}$ & $\begin{array}{l}C \\
G\end{array}$ & $\begin{array}{l}\text { Green Bit } \\
\text { Crossmatch }\end{array}$ & $\begin{array}{l}\mathrm{D} \\
\mathrm{H}\end{array}$ & $\begin{array}{l}\text { Cornell University } \\
\text { Clarkson University }\end{array}$ \\
\hline $1 \mathrm{~A}$ & Peering Into Window & $1 \mathrm{~B}$ & Fist Banging on Glass & $1 \mathrm{C}$ & Fingertip Window Slide & $1 \mathrm{D}$ & Get-away Palm on Glass & $1 \mathrm{E}$ & "OK" Sign on Glass \\
\hline $1 \mathrm{~F}$ & Counter Vault on Glass & $1 \mathrm{G}$ & Cylinder Grab & $1 \mathrm{H}$ & Impatient Tapping on Glass & $2 \mathrm{~A}$ & Samsung Galaxy S5 & $2 B$ & Apple iPhone $5 \mathrm{~s}$ \\
\hline 3 & Check & $4 \mathrm{~A}$ & Lined Paper & 4B & Low-quality Copy Paper & $4 \mathrm{C}$ & High-quality Copy Paper & 4D & Yellow Lined Paper \\
\hline $4 \mathrm{E}$ & Low-quality White Envelope & $4 \mathrm{~F}$ & Greeting Card and Envelope & $4 G$ & Manila Envelope & $5 \mathrm{~A}$ & Photo Paper & $5 B$ & Glossy Magazine \\
\hline $5 c$ & U.S. Currency & $6 \mathrm{~A}$ & Stamp & $6 \mathrm{~B}$ & Address Label & $6 \mathrm{C}$ & Clear Packing Tape & $6 \mathrm{D}$ & Black Electrical Tape \\
\hline $6 \mathrm{E}$ & Duct Tape & $7 \mathrm{~A}$ & Circuit Board & $7 \mathrm{~B}$ & $\mathrm{CD} / \mathrm{DVD}$ & $7 \mathrm{C}$ & Clear Plastic Bag & $7 D$ & Black Plastic Bag \\
\hline
\end{tabular}




\begin{tabular}{|c|c|c|c|c|c|c|c|c|c|}
\hline Activity & $\Omega$ & A & B & C & D & $\mathrm{E}$ & $\mathrm{F}$ & G & H \\
\hline $1 \mathrm{~A}$ & $11.2 \%$ & ${ }^{3} 8.0 \%$ & ${ }^{4} 6.4 \%$ & $114.1 \%$ & $62.8 \%$ & $211.5 \%$ & $56.1 \%$ & $71.5 \%$ & ${ }^{8} 0.0 \%$ \\
\hline $1 \mathrm{~B}$ & $0.0 \%$ & ${ }^{1} 0.0 \%$ & ${ }^{1} 0.0 \%$ & $10.0 \%$ & ${ }^{1} 0.0 \%$ & ${ }^{1} 0.0 \%$ & ${ }^{1} 0.0 \%$ & ${ }^{1} 0.0 \%$ & ${ }^{1} 0.0 \%$ \\
\hline $1 \mathrm{C}$ & $9.8 \%$ & $28.7 \%$ & $47.2 \%$ & $19.8 \%$ & $71.3 \%$ & $38.6 \%$ & $55.3 \%$ & ${ }^{6} 1.7 \%$ & ${ }^{8} 0.0 \%$ \\
\hline 1D & $30.0 \%$ & ${ }^{3} 26.9 \%$ & ${ }^{4} 25.0 \%$ & $133.0 \%$ & $77.6 \%$ & ${ }^{2} 28.7 \%$ & $521.8 \%$ & $67.9 \%$ & ${ }^{8} 0.0 \%$ \\
\hline $1 \mathrm{E}$ & $18.1 \%$ & ${ }^{3} 12.8 \%$ & ${ }^{4} 12.4 \%$ & $122.2 \%$ & $63.3 \%$ & ${ }^{2} 16.9 \%$ & $58.7 \%$ & $73.1 \%$ & ${ }^{8} 0.0 \%$ \\
\hline $1 \mathrm{~F}$ & $33.0 \%$ & ${ }^{3} 28.4 \%$ & ${ }^{4} 26.7 \%$ & $133.4 \%$ & $76.8 \%$ & $229.4 \%$ & $521.4 \%$ & $68.9 \%$ & ${ }^{8} 0.0 \%$ \\
\hline $1 G$ & $2.2 \%$ & ${ }^{6} 1.0 \%$ & $21.6 \%$ & $12.0 \%$ & $70.3 \%$ & ${ }^{4} 1.3 \%$ & ${ }^{3} 1.3 \%$ & ${ }^{5} 1.0 \%$ & $80.0 \%$ \\
\hline $1 \mathrm{H}$ & $11.4 \%$ & $113.6 \%$ & ${ }^{3} 10.8 \%$ & $212.6 \%$ & $72.7 \%$ & ${ }^{4} 10.7 \%$ & $57.1 \%$ & $62.9 \%$ & ${ }^{8} 0.0 \%$ \\
\hline $2 \mathrm{~A}$ & $3.3 \%$ & $14.8 \%$ & $24.0 \%$ & $33.8 \%$ & $70.4 \%$ & $43.7 \%$ & $52.7 \%$ & $61.0 \%$ & $80.0 \%$ \\
\hline $2 B$ & $2.9 \%$ & $13.2 \%$ & $33.0 \%$ & $23.1 \%$ & $70.4 \%$ & ${ }^{4} 2.7 \%$ & $52.1 \%$ & $60.5 \%$ & $80.0 \%$ \\
\hline 3 & $1.6 \%$ & ${ }^{4} 1.7 \%$ & $22.0 \%$ & $12.4 \%$ & $60.6 \%$ & $31.9 \%$ & $51.4 \%$ & ${ }^{7} 0.1 \%$ & $80.0 \%$ \\
\hline $4 \mathrm{~A}$ & $2.9 \%$ & $42.3 \%$ & $32.7 \%$ & $13.2 \%$ & ${ }^{7} 0.5 \%$ & $23.0 \%$ & $52.2 \%$ & ${ }^{6} 0.6 \%$ & $80.0 \%$ \\
\hline $4 \mathrm{~B}$ & $4.4 \%$ & ${ }^{4} 4.0 \%$ & $24.4 \%$ & $34.2 \%$ & $61.0 \%$ & $14.6 \%$ & $52.3 \%$ & $61.0 \%$ & $80.0 \%$ \\
\hline $4 C$ & $2.2 \%$ & $42.3 \%$ & $32.5 \%$ & $12.8 \%$ & $60.5 \%$ & $12.8 \%$ & $51.8 \%$ & $70.0 \%$ & $70.0 \%$ \\
\hline $4 \mathrm{D}$ & $3.2 \%$ & $32.6 \%$ & $32.6 \%$ & $13.6 \%$ & $61.0 \%$ & $22.9 \%$ & $52.1 \%$ & $70.5 \%$ & $80.0 \%$ \\
\hline $4 \mathrm{E}$ & $3.0 \%$ & $32.7 \%$ & ${ }^{4} 2.6 \%$ & $22.9 \%$ & & $13.0 \%$ & $51.6 \%$ & ${ }^{6} 0.8 \%$ & $80.0 \%$ \\
\hline $4 \mathrm{~F}$ & $1.7 \%$ & $21.9 \%$ & ${ }^{4} 1.1 \%$ & $12.0 \%$ & $70.2 \%$ & ${ }^{3} 1.7 \%$ & $50.9 \%$ & ${ }^{6} 0.6 \%$ & ${ }^{8} 0.0 \%$ \\
\hline $4 G$ & $3.7 \%$ & $23.4 \%$ & $14.1 \%$ & $33.3 \%$ & ${ }^{6} 0.8 \%$ & $43.2 \%$ & $52.6 \%$ & ${ }^{7} 0.7 \%$ & ${ }^{8} 0.0 \%$ \\
\hline $5 \mathrm{~A}$ & $3.8 \%$ & $15.1 \%$ & $43.9 \%$ & $24.6 \%$ & ${ }^{7} 0.7 \%$ & $34.0 \%$ & $53.3 \%$ & ${ }^{6} 1.4 \%$ & ${ }^{8} 0.0 \%$ \\
\hline $5 B$ & $1.9 \%$ & ${ }^{4} 1.9 \%$ & $12.2 \%$ & $12.2 \%$ & ${ }^{6} 0.3 \%$ & $12.2 \%$ & ${ }^{5} 1.4 \%$ & ${ }^{7} 0.0 \%$ & ${ }^{7} 0.0 \%$ \\
\hline $5 C$ & $0.8 \%$ & $21.9 \%$ & $12.7 \%$ & ${ }^{5} 1.1 \%$ & ${ }^{6} 0.3 \%$ & ${ }^{3} 1.4 \%$ & ${ }^{3} 1.4 \%$ & ${ }^{7} 0.0 \%$ & ${ }^{7} 0.0 \%$ \\
\hline $6 \mathrm{~A}$ & $2.8 \%$ & $23.1 \%$ & ${ }^{4} 2.8 \%$ & $13.6 \%$ & ${ }^{6} 0.7 \%$ & $32.9 \%$ & ${ }^{5} 1.3 \%$ & ${ }^{7} 0.6 \%$ & ${ }^{8} 0.0 \%$ \\
\hline $6 C$ & $10.6 \%$ & ${ }^{2} 10.0 \%$ & ${ }^{4} 8.6 \%$ & ${ }^{1} 11.1 \%$ & $72.4 \%$ & $39.6 \%$ & $56.9 \%$ & $63.0 \%$ & ${ }^{8} 0.0 \%$ \\
\hline $6 \mathrm{D}$ & $10.8 \%$ & $29.8 \%$ & $49.5 \%$ & $111.1 \%$ & $72.7 \%$ & $39.6 \%$ & ${ }^{5} 8.1 \%$ & $63.1 \%$ & ${ }^{8} 0.0 \%$ \\
\hline $6 \mathrm{E}$ & $11.4 \%$ & ${ }^{2} 10.7 \%$ & $49.7 \%$ & $111.5 \%$ & $63.5 \%$ & ${ }^{3} 10.3 \%$ & $57.9 \%$ & $72.7 \%$ & ${ }^{8} 0.0 \%$ \\
\hline $7 \mathrm{~A}$ & $0.0 \%$ & ${ }^{1} 0.0 \%$ & $10.0 \%$ & $10.0 \%$ & $10.0 \%$ & ${ }^{1} 0.0 \%$ & $10.0 \%$ & ${ }^{1} 0.0 \%$ & ${ }^{1} 0.0 \%$ \\
\hline $7 B$ & $4.3 \%$ & $43.5 \%$ & $111.3 \%$ & $28.5 \%$ & $70.0 \%$ & $52.8 \%$ & $62.1 \%$ & $37.8 \%$ & ${ }^{7} 0.0 \%$ \\
\hline $7 C$ & $0.5 \%$ & $20.9 \%$ & ${ }^{5} 0.5 \%$ & $10.9 \%$ & ${ }^{6} 0.3 \%$ & ${ }^{3} 0.8 \%$ & ${ }^{4} 0.6 \%$ & ${ }^{7} 0.2 \%$ & ${ }^{8} 0.0 \%$ \\
\hline $7 D$ & $1.3 \%$ & ${ }^{3} 0.9 \%$ & ${ }^{2} 1.1 \%$ & $11.3 \%$ & ${ }^{7} 0.1 \%$ & ${ }^{4} 0.9 \%$ & ${ }^{5} 0.6 \%$ & ${ }^{6} 0.4 \%$ & ${ }^{8} 0.0 \%$ \\
\hline
\end{tabular}

Table 10. Hit rate for Rank 1 for the MATCHER when searching study participant latent fingerprint images against an enrollment set of Challenger N2N images, separated by latent activity. Each row represents one latent activity. In each row, the Baseline Data is recorded in blue, the best non-baseline values are reported in green and the worst in red. Challenger values that meet or beat the baseline for each activity are shaded in blue. Superscript numbers preceding the FNIR value represent its ranking in each row. All ranks are depicted in Fig. 20.

\begin{tabular}{|c|c|c|c|c|c|c|c|c|c|}
\hline$\Omega$ & FBI Baseline & $\begin{array}{l}A \\
E\end{array}$ & $\begin{array}{l}\text { IDEMIA } \\
\text { Jenetric }\end{array}$ & $\begin{array}{l}\mathrm{B} \\
\mathrm{F}\end{array}$ & $\begin{array}{l}\text { Advanced Optical Systems } \\
\text { Touchless Biometric Systems }\end{array}$ & $\begin{array}{l}C \\
G\end{array}$ & $\begin{array}{l}\text { Green Bit } \\
\text { Crossmatch }\end{array}$ & $\begin{array}{l}\mathrm{D} \\
\mathrm{H}\end{array}$ & $\begin{array}{l}\text { Cornell University } \\
\text { Clarkson University }\end{array}$ \\
\hline $1 \mathrm{~A}$ & Peering Into Window & $1 \mathrm{~B}$ & Fist Banging on Glass & 1c & Fingertip Window Slide & $1 \mathrm{D}$ & Get-away Palm on Glass & $1 \mathrm{E}$ & “OK" Sign on Glass \\
\hline $1 \mathrm{~F}$ & Counter Vault on Glass & $1 \mathrm{G}$ & Cylinder Grab & $1 \mathrm{H}$ & Impatient Tapping on Glass & $2 \mathrm{~A}$ & Samsung Galaxy S5 & $2 \mathrm{~B}$ & Apple iPhone 5s \\
\hline 3 & Check & $4 \mathrm{~A}$ & Lined Paper & 4B & Low-quality Copy Paper & $4 \mathrm{C}$ & High-quality Copy Paper & $4 \mathrm{D}$ & Yellow Lined Paper \\
\hline $4 \mathrm{E}$ & Low-quality White Envelope & $4 \mathrm{~F}$ & Greeting Card and Envelope & $4 \mathrm{G}$ & Manila Envelope & $5 \mathrm{~A}$ & Photo Paper & $5 B$ & Glossy Magazine \\
\hline $5 \mathrm{C}$ & U.S. Currency & $6 \mathrm{~A}$ & Stamp & $6 \mathrm{~B}$ & Address Label & $6 \mathrm{C}$ & Clear Packing Tape & $6 \mathrm{D}$ & Black Electrical Tape \\
\hline $6 \mathrm{E}$ & Duct Tape & $7 \mathrm{~A}$ & Circuit Board & $7 \mathrm{~B}$ & $\mathrm{CD} / \mathrm{DVD}$ & $7 \mathrm{C}$ & Clear Plastic Bag & $7 \mathrm{D}$ & Black Plastic Bag \\
\hline
\end{tabular}




\section{Cumulative Match Characteristic: By Activity}

All Challengers, Latent Identification
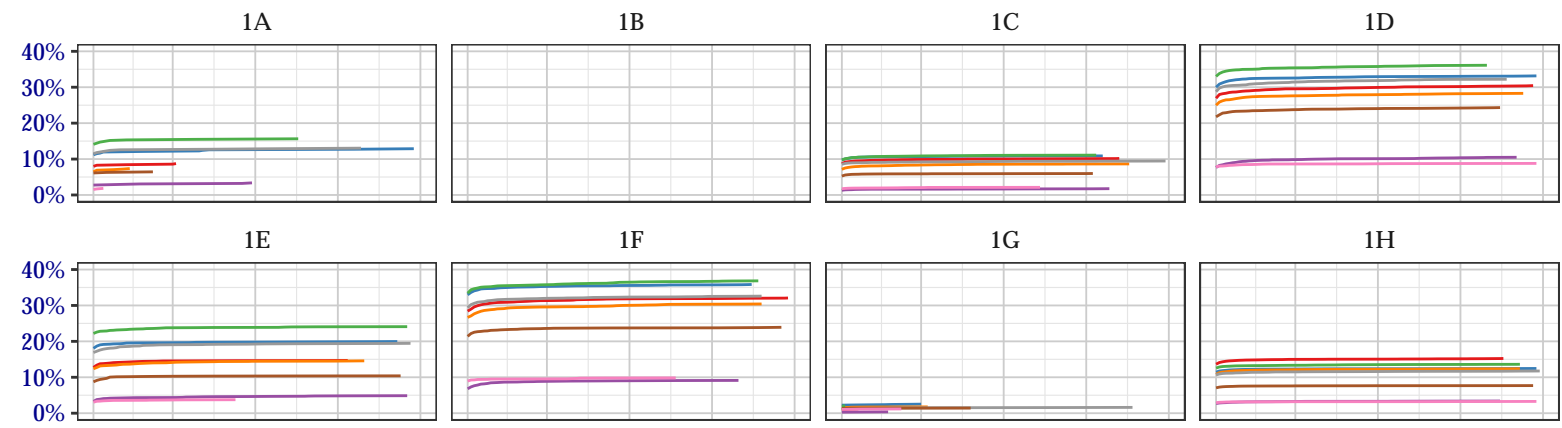

2B

3
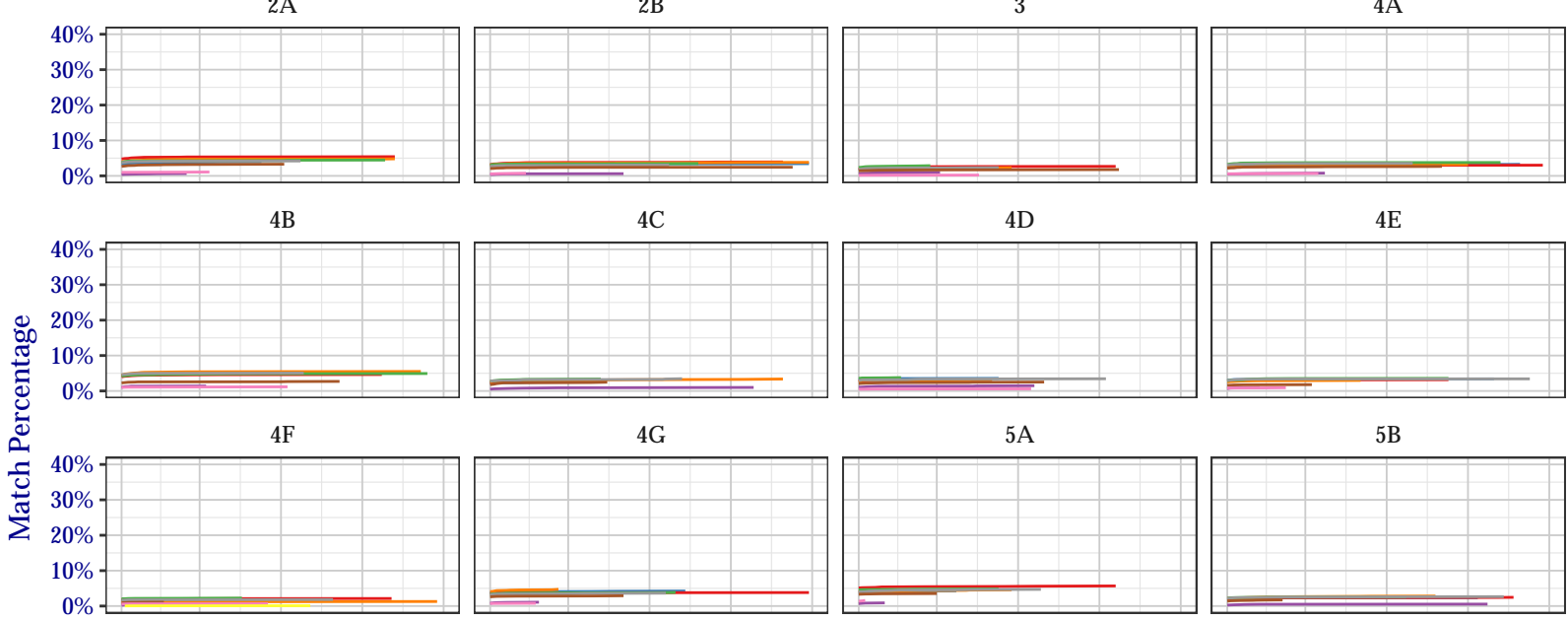

$4 \mathrm{C}$

$4 \mathrm{D}$

$4 \mathrm{E}$
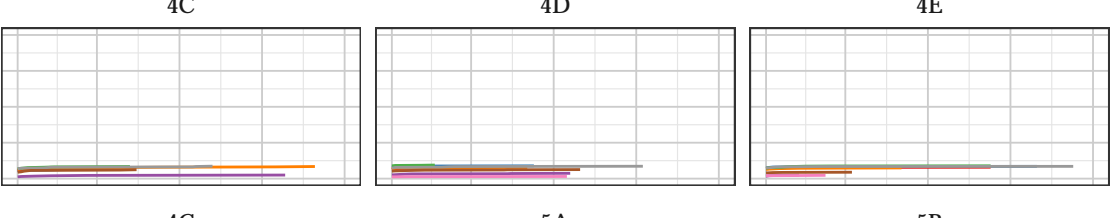

$5 \mathrm{~A}$
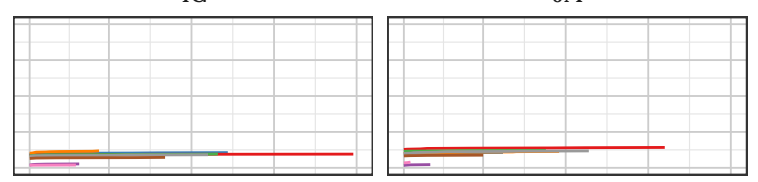

$6 \mathrm{C}$

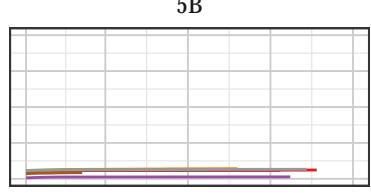

$5 \mathrm{C}$

$6 \mathrm{~A}$
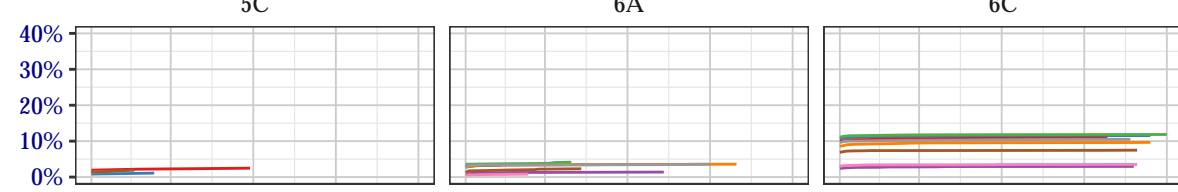

$6 \mathrm{D}$
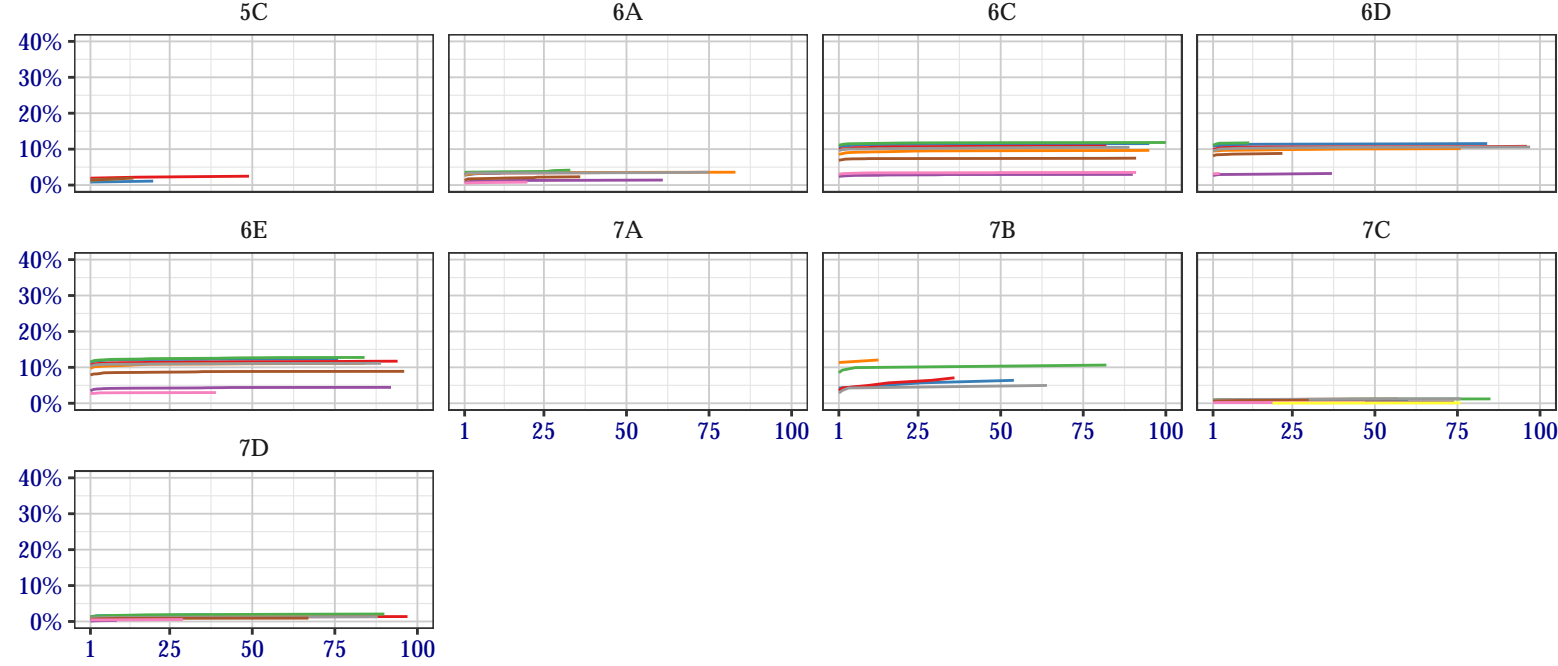

Rank

Challenger $-\Omega-\mathrm{A}-\mathrm{B}-\mathrm{C}-\mathrm{D}-\mathrm{E}-\mathrm{F}-\mathrm{G}-\mathrm{H}$

Fig. 20. CMC curves for each Challenger for latent identification, separated by latent activity. This plot shows the rate at which the MATCHER, when searching study participant latent fingerprint images against an enrollment set seeded with N2N images from each Challenger, found the correct mate, regardless of similarity score. The values for rank 1 are reported in Table 10. If a curve stops before reaching the far right of the plot, it indicates that a mate was never found past the last corresponding rank.

\begin{tabular}{|c|c|c|c|c|c|c|c|c|c|}
\hline$\Omega$ & FBI Baseline & $\begin{array}{l}A \\
E\end{array}$ & $\begin{array}{l}\text { IDEMIA } \\
\text { Jenetric }\end{array}$ & $\begin{array}{l}\mathrm{B} \\
\mathrm{F}\end{array}$ & $\begin{array}{l}\text { Advanced Optical Systems } \\
\text { Touchless Biometric Systems }\end{array}$ & $\begin{array}{l}c \\
G\end{array}$ & $\begin{array}{l}\text { Green Bit } \\
\text { Crossmatch }\end{array}$ & $\begin{array}{l}\mathrm{D} \\
\mathrm{H}\end{array}$ & $\begin{array}{l}\text { Cornell University } \\
\text { Clarkson University }\end{array}$ \\
\hline $1 \mathrm{~A}$ & Peering Into Window & $1 \mathrm{~B}$ & Fist Banging on Glass & $1 \mathrm{C}$ & Fingertip Window Slide & $1 \mathrm{D}$ & Get-away Palm on Glass & $1 \mathrm{E}$ & “OK" Sign on Glass \\
\hline $1 \mathrm{~F}$ & Counter Vault on Glass & $1 \mathrm{G}$ & Cylinder Grab & $1 \mathrm{H}$ & Impatient Tapping on Glass & $2 \mathrm{~A}$ & Samsung Galaxy S5 & $2 \mathrm{~B}$ & Apple iPhone 5s \\
\hline 3 & Check & $4 \mathrm{~A}$ & Lined Paper & $4 B$ & Low-quality Copy Paper & $4 \mathrm{C}$ & High-quality Copy Paper & $4 \mathrm{D}$ & Yellow Lined Paper \\
\hline $4 \mathrm{E}$ & Low-quality White Envelope & $4 \mathrm{~F}$ & Greeting Card and Envelope & $4 G$ & Manila Envelope & $5 \mathrm{~A}$ & Photo Paper & $5 B$ & Glossy Magazine \\
\hline $5 \mathrm{C}$ & U.S. Currency & $6 \mathrm{~A}$ & Stamp & $6 \mathrm{~B}$ & Address Label & $6 c$ & Clear Packing Tape & $6 \mathrm{D}$ & Black Electrical Tape \\
\hline $6 \mathrm{E}$ & Duct Tape & $7 \mathrm{~A}$ & Circuit Board & $7 \mathrm{~B}$ & $\mathrm{CD} / \mathrm{DVD}$ & 7C & Clear Plastic Bag & 70 & Black Plastic Bag \\
\hline
\end{tabular}




\begin{tabular}{lrrll}
\hline Activity & Searches & Study Participants & FNIR & Challenger \\
\hline 1A & 652 & 198 & 0.860 & $\mathrm{C}$ \\
1B & 31 & 15 & 1.000 & - \\
1C & 5468 & 272 & 0.905 & $\Omega$ \\
1D & 2877 & 253 & 0.684 & $\mathrm{C}$ \\
1E & 2586 & 272 & 0.788 & $\mathrm{C}$ \\
1F & 2706 & 214 & 0.681 & $\mathrm{C}$ \\
1G & 2102 & 222 & 0.978 & $\Omega$ \\
1H & 6194 & 217 & 0.868 & $\mathrm{~A}$ \\
2A & 2306 & 163 & 0.954 & $\mathrm{~A}$ \\
2B & 3278 & 158 & 0.969 & $\mathrm{~A}$ \\
3 & 2319 & 54 & 0.977 & $\mathrm{C}$ \\
4A & 4447 & 74 & 0.970 & $\mathrm{C}$ \\
4B & 2072 & 23 & 0.958 & $\Omega, \mathrm{B}, \mathrm{E}$ \\
4C & 1009 & 17 & 0.973 & $\mathrm{C}, \mathrm{E}$ \\
4D & 1827 & 26 & 0.966 & $\mathrm{C}$ \\
4E & 2078 & 62 & 0.970 & $\Omega, \mathrm{E}$ \\
4F & 3332 & 45 & 0.980 & $\mathrm{C}$ \\
4G & 1650 & 80 & 0.965 & $\mathrm{~B}$ \\
5A & 1444 & 84 & 0.952 & $\mathrm{~A}$ \\
5B & 2557 & 74 & 0.978 & $\mathrm{~B}$ \\
5C & 365 & 56 & 0.978 & $\mathrm{~B}$ \\
6A & 867 & 306 & 0.967 & $\mathrm{C}$ \\
6C & 2566 & 108 & 0.893 & $\mathrm{C}$ \\
6D & 1056 & 111 & 0.894 & $\Omega$ \\
6E & 2689 & 109 & 0.889 & $\mathrm{C}$ \\
7A & 296 & 34 & 1.000 & - \\
7B & 141 & 6 & 0.887 & $\mathrm{~B}$ \\
7C & 1977 & 71 & 0.991 & $\mathrm{C}$ \\
7D & 1829 & 82 & 0.986 & $\Omega$ \\
\hline & 62721 & & & \\
\hline & & & & \\
\hline & & & \\
\hline
\end{tabular}

Table 11. A breakdown of the data used in latent identification. Searches shows the number of searches for a given Activity. Study Participants shows the number of study participants represented in Searches. FNIR is the lowest FNIR for each activity from Fig. 19. Challenger contains the Challengers that achieved FNIR. Only those images that were successfully searched by the MATCHER are represented. Not all study participants left behind latent prints for all activities. Not all collected data was able to be developed and digitized prior to releasing results.

\begin{tabular}{|c|c|c|c|c|c|c|c|c|c|}
\hline$\Omega$ & FBI Baseline & $\begin{array}{l}A \\
E\end{array}$ & $\begin{array}{l}\text { IDEMIA } \\
\text { Jenetric }\end{array}$ & $\begin{array}{l}\mathrm{B} \\
\mathrm{F}\end{array}$ & $\begin{array}{l}\text { Advanced Optical Systems } \\
\text { Touchless Biometric Systems }\end{array}$ & $\begin{array}{l}\text { C } \\
G\end{array}$ & $\begin{array}{l}\text { Green Bit } \\
\text { Crossmatch }\end{array}$ & $\begin{array}{l}\mathrm{D} \\
\mathrm{H}\end{array}$ & $\begin{array}{l}\text { Cornell University } \\
\text { Clarkson University }\end{array}$ \\
\hline $1 \mathrm{~A}$ & Peering Into Window & $1 \mathrm{~B}$ & Fist Banging on Glass & $1 \mathrm{C}$ & Fingertip Window Slide & 1D & Get-away Palm on Glass & $1 \mathrm{E}$ & "OK" Sign on Glass \\
\hline $1 \mathrm{~F}$ & Counter Vault on Glass & 16 & Cylinder Grab & $1 \mathrm{H}$ & Impatient Tapping on Glass & $2 \mathrm{~A}$ & Samsung Galaxy S5 & $2 \mathrm{~B}$ & iPhone $5 \mathrm{~s}$ \\
\hline 3 & Check & $4 \mathrm{~A}$ & Lined Paper & $4 B$ & Low-quality Copy Paper & $4 \mathrm{C}$ & High-quality Copy Paper & $4 \mathrm{D}$ & Yellow Lined Paper \\
\hline $4 \mathrm{E}$ & Low-quality White Envelope & $4 \mathrm{~F}$ & Greeting Card and Envelope & $4 \mathrm{G}$ & Manila Envelope & $5 \mathrm{~A}$ & Photo Paper & $5 B$ & Glossy Magazine \\
\hline $5 c$ & U.S. Currency & $6 \mathrm{~A}$ & Stamp & $6 \mathrm{~B}$ & Address Label & $6 \mathrm{C}$ & Clear Packing Tape & $6 \mathrm{D}$ & Black Electrical Tape \\
\hline $6 \mathrm{E}$ & Duct Tape & $7 \mathrm{~A}$ & Circuit Board & $7 \mathrm{~B}$ & CD/DVD & $7 \mathrm{C}$ & Clear Plastic Bag & $7 \mathrm{D}$ & Black Plastic Bag \\
\hline
\end{tabular}




\section{B. Podium Finishers}

No Challenger was able to achieve an FNIR within $2 \%$ of $\Omega$ for N2N identification, and as such, there was no winner for the Nail to Nail Fingerprint Challenge's Grand Prize. The N2N Judging Committee opted to divide the funds that would have been awarded to the Grand Prize winner amongst the podium finishers for all other prizes.

\section{B.1 Speed Prize}

From the values presented in Table 4, second place for the Speed Prize should be awarded to A, and third place should be awarded to $F$.

\section{B.2 Gallery Accuracy}

From the values presented in Table 5, second place for the Gallery Accuracy Prize should be awarded to E, and third place should be awarded to A.

\section{B.3 Latent Accuracy}

The values presented in Table 7 show a tie within the confidence interval for second place for the Latent Accuracy Prize. Per the metrics in Section 7.1.5, NFIQ 2.0 values, presented in Table 12, are used to break the tie. As is required by NFIQ 2.0, all images were downsampled, if necessary, to 196.85 PPCM (500 PPI) before running the algorithm [2].

Following the Nail to Nail Fingerprint Challenge rules, starting with the NFIQ 2.0 column in Table 7, the tie is broken. Second place for the Latent Accuracy Prize should be awarded to E, and third place should be awarded to $A$.

It should be noted that the NFIQ 2.0 algorithm was trained on plain impression live scan images, which does not describe any of the images created by the Challengers. Because all Challenger images differ from the training data used in NFIQ 2.0, the values produced may seem peculiar. As a result, it is prudent to use the individual NFIQ 2.0 feature values to break the tie. Even then, standard deviations for ridge valley uniformity and frequency domain analysis amongst Challengers have nearly indistinguishable distributions. Additionally, not all Challengers acquired the same number of images, which skews these distributions (Section 9.2).

\begin{tabular}{lrrr}
\hline Challenger & NFIQ 2.0 & FDA $\sigma$ & RVU $\sigma$ \\
\hline$\Omega$ & 53 & 0.231 & 0.975 \\
A & ${ }^{8} 20$ & ${ }^{8} 0.313$ & ${ }^{6} 1.162$ \\
$B$ & 153 & ${ }^{1} 0.211$ & ${ }^{1} 0.876$ \\
$\mathrm{C}$ & ${ }^{4} 49$ & & ${ }^{4} 1.138$ \\
D & ${ }^{5} 40$ & ${ }^{2} 0.224$ & ${ }^{3} 1.044$ \\
E & 634 & ${ }^{6} 0.293$ & 81.291 \\
F & 350 & ${ }^{4} 0.267$ & ${ }^{2} 0.907$ \\
G & 731 & ${ }^{7} 0.294$ & ${ }^{7} 1.172$ \\
H & 251 & ${ }^{3} 0.267$ & ${ }^{5} 1.139$ \\
\hline
\end{tabular}

Table 12. Median values produced by NFIQ 2.0 computed for images acquired by all Challengers. In the event of a tie for any prize, the tie would be broken based on these values. The Baseline Data is recorded in blue. The best non-Baseline values in each column are reported in green and the worst are in red. Challenger values that meet or beat the Baseline are shaded in blue. Superscript numbers preceding values represent the ranking of the value in each column. FDA refers to Frequency Domain Analysis and RVU refers to Ridge Valley Uniformity, as defined in [12], with $\sigma$ indicating standard deviation. Refer to Appendix B.3 for NFIQ 2.0 caveats.

\begin{tabular}{|c|c|c|c|c|c|c|c|c|c|}
\hline$\Omega$ & FBI Baseline & $\begin{array}{l}A \\
E\end{array}$ & $\begin{array}{l}\text { IDEMIA } \\
\text { Jenetric }\end{array}$ & $\begin{array}{l}\text { B } \\
F\end{array}$ & $\begin{array}{l}\text { Advanced Optical Systems } \\
\text { Touchless Biometric Systems }\end{array}$ & $\begin{array}{l}\mathrm{C} \\
\mathrm{G}\end{array}$ & $\begin{array}{l}\text { Green Bit } \\
\text { Crossmatch }\end{array}$ & $\begin{array}{l}\mathrm{D} \\
\mathrm{H}\end{array}$ & $\begin{array}{l}\text { Cornell University } \\
\text { Clarkson University }\end{array}$ \\
\hline $1 \mathrm{~A}$ & Peering Into Window & $1 \mathrm{~B}$ & Fist Banging on Glass & 1C & Fingertip Window Slide & $1 \mathrm{D}$ & Get-away Palm on Glass & $1 \mathrm{E}$ & "OK" Sign on Glass \\
\hline $1 \mathrm{~F}$ & Counter Vault on Glass & 16 & Cylinder Grab & $1 \mathrm{H}$ & Impatient Tapping on Glass & $2 \mathrm{~A}$ & Samsung Galaxy S5 & $2 \mathrm{~B}$ & Apple iPhone $5 \mathrm{~s}$ \\
\hline 3 & Check & $4 \mathrm{~A}$ & Lined Paper & $4 \mathrm{~B}$ & Low-quality Copy Paper & $4 \mathrm{C}$ & High-quality Copy Paper & 4D & Yellow Lined Paper \\
\hline $4 \mathrm{E}$ & Low-quality White Envelope & $4 \mathrm{~F}$ & Greeting Card and Envelope & $4 G$ & Manila Envelope & $5 \mathrm{~A}$ & Photo Paper & $5 B$ & Glossy Magazine \\
\hline $5 \mathrm{C}$ & U.S. Currency & $6 \mathrm{~A}$ & Stamp & $6 \mathrm{~B}$ & Address Label & $6 \mathrm{C}$ & Clear Packing Tape & $6 \mathrm{D}$ & Black Electrical Tape \\
\hline $6 \mathrm{E}$ & Duct Tape & $7 \mathrm{~A}$ & Circuit Board & $7 \mathrm{~B}$ & CD/DVD & $7 \mathrm{C}$ & Clear Plastic Bag & $7 D$ & Black Plastic Bag \\
\hline
\end{tabular}




\section{Public Data}

Through the fingerprint data collection held at JHU APL, IARPA amassed a large and diverse set of friction ridge imagery. Much care was taken to ensure that informed consent documents and research protocols approved by the IRBs and agreed to by study participants allowed for the public distribution of the friction ridge data collected.

IARPA is pleased to announce that data collected as part of the Nail to Nail Fingerprint Challenge is being released to biometric researchers to aid in the advancement of friction ridge research. NIST will be handling the distribution of the data on behalf of IARPA.

To help support future NIST biometric technology evaluations and biometric research challenges, IARPA has agreed to allow NIST to hold back data from $30 \%$ of the study participants. NIST plans to announce opportunities for the research community to participate in studies that will make use of this data.

As of the publication date, the distribution is not yet ready. To be notified when the data is ready for release, visit NIST's website, https://nist.gov/programs-projects/n2n-fingerprint-capture-challenge. Once available, researches will be able to complete a web form and directly download the data.

\begin{tabular}{|c|c|c|c|c|c|c|c|c|c|}
\hline$\Omega$ & FBI Baseline & $\begin{array}{l}A \\
E\end{array}$ & $\begin{array}{l}\text { IDEMIA } \\
\text { Jenetric }\end{array}$ & $\begin{array}{l}\mathrm{B} \\
\mathrm{F}\end{array}$ & $\begin{array}{l}\text { Advanced Optical Systems } \\
\text { Touchless Biometric Systems }\end{array}$ & $\begin{array}{l}C \\
G\end{array}$ & $\begin{array}{l}\text { Green Bit } \\
\text { Crossmatch }\end{array}$ & $\begin{array}{l}\mathrm{D} \\
\mathrm{H}\end{array}$ & $\begin{array}{l}\text { Cornell University } \\
\text { Clarkson University }\end{array}$ \\
\hline $1 \mathrm{~A}$ & Peering Into Window & $1 \mathrm{~B}$ & Fist Banging on Glass & $1 \mathrm{C}$ & Fingertip Window Slide & 1D & Get-away Palm on Glass & $1 \mathrm{E}$ & “OK" Sign on Glass \\
\hline $1 \mathrm{~F}$ & Counter Vault on Glass & 16 & Cylinder Grab & $1 \mathrm{H}$ & Impatient Tapping on Glass & $2 \mathrm{~A}$ & Samsung Galaxy S5 & $2 \mathrm{~B}$ & Apple iPhone $5 \mathrm{~s}$ \\
\hline 3 & Check & $4 \mathrm{~A}$ & Lined Paper & $4 \mathrm{~B}$ & Low-quality Copy Paper & $4 \mathrm{C}$ & High-quality Copy Paper & $4 \mathrm{D}$ & Yellow Lined Paper \\
\hline $4 \mathrm{E}$ & Low-quality White Envelope & $4 \mathrm{~F}$ & Greeting Card and Envelope & $4 \mathrm{G}$ & Manila Envelope & $5 \mathrm{~A}$ & Photo Paper & $5 \mathrm{~B}$ & Glossy Magazine \\
\hline $5 c$ & U.S. Currency & $6 \mathrm{~A}$ & Stamp & $6 \mathrm{~B}$ & Address Label & $6 c$ & Clear Packing Tape & $6 \mathrm{D}$ & Black Electrical Tape \\
\hline $6 \mathrm{E}$ & Duct Tape & $7 \mathrm{~A}$ & Circuit Board & $7 \mathrm{~B}$ & CD/DVD & $7 \mathrm{c}$ & Clear Plastic Bag & 70 & Black Plastic Bag \\
\hline
\end{tabular}




\section{Glossary}

\section{Backend Server}

The computer network and database infrastructure used to collect fingerprint images from N2N devices.

\section{Baseline Data}

Fingerprint images rolled on a live scan device by a skilled operator during the Nail to Nail Fingerprint Challenge.

\section{Challenger}

A finalist in the Nail to Nail Fingerprint Challenge that brought a device to the fingerprint data collection.

\section{Extractor}

The fingerprint feature extraction and template generation algorithm provided by NIST. The algorithm extracts features from a fingerprint image and saves them into a template that can be inserted into an enrollment set or searched.

\section{Facility Application Programming Interface}

The programming interface by which Challengers submitted captured imagery to the $\mathrm{N} 2 \mathrm{~N}$ backend server.

\section{Judging Committee}

A three-person committee comprised of United States Government officials who determined the winners of the Nail to Nail Fingerprint Challenge and ruled on changes to the test plan.

\section{Matcher}

The fingerprint template matching algorithm provided by NIST for use in searching N2N and latent fingerprint images against a large enrollment set.

\section{Moderated Capture}

A method of capturing fingerprints without the physical touch of a skilled operator. An operator is still present, but can only provide feedback to the subject. The operator may request that the subject retry an acquisition. This capture type is somewhere between fully controlled and fully uncontrolled.

\section{Nail to Nail}

The surface area of a finger's distal phalanx from one edge of the fingernail to the other, ideally including the tip. This is often abbreviated as $\mathrm{N} 2 \mathrm{~N}$.

\section{Rolled}

A nail to nail capture, where the finger comes in contact with a flat surface, such as a ink fingerprint card or a live scan platen.

\section{Rolled-equivalent}

A nail to nail capture. This differs from rolled in that it does not imply that the finger comes in contact with a platen, only that the resulting image performs equivalently to one that does. It may be possible for a touch-free device to capture an image from one edge of the fingernail to the other without physically rolling the finger on a flat surface.

\begin{tabular}{|c|c|c|c|c|c|c|c|c|c|}
\hline$\Omega$ & FBI Baseline & $\begin{array}{l}A \\
E\end{array}$ & $\begin{array}{l}\text { IDEMIA } \\
\text { Jenetric }\end{array}$ & $\begin{array}{l}\mathrm{B} \\
\mathrm{F}\end{array}$ & $\begin{array}{l}\text { Advanced Optical Systems } \\
\text { Touchless Biometric Systems }\end{array}$ & $\begin{array}{l}c \\
G\end{array}$ & $\begin{array}{l}\text { Green Bit } \\
\text { Crossmatch }\end{array}$ & $\begin{array}{l}\mathrm{D} \\
\mathrm{H}\end{array}$ & $\begin{array}{l}\text { Cornell University } \\
\text { Clarkson University }\end{array}$ \\
\hline $1 \mathrm{~A}$ & Peering Into Window & $1 \mathrm{~B}$ & Fist Banging on Glass & 1C & Fingertip Window Slide & 10 & Get-away Palm on Glass & $1 \mathrm{E}$ & "OK" Sign on Glass \\
\hline $1 \mathrm{~F}$ & Counter Vault on Glass & $1 \mathrm{G}$ & Cylinder Grab & $1 \mathrm{H}$ & Impatient Tapping on Glass & $2 \mathrm{~A}$ & Samsung Galaxy S5 & $2 \mathrm{~B}$ & Apple iPhone $5 \mathrm{~s}$ \\
\hline 3 & Check & $4 \mathrm{~A}$ & Lined Paper & $4 \mathrm{~B}$ & Low-quality Copy Paper & $4 \mathrm{C}$ & High-quality Copy Paper & $4 \mathrm{D}$ & Yellow Lined Paper \\
\hline $4 \mathrm{E}$ & Low-quality White Envelope & $4 \mathrm{~F}$ & Greeting Card and Envelope & $4 \mathrm{G}$ & Manila Envelope & $5 \mathrm{~A}$ & Photo Paper & $5 \mathrm{~B}$ & Glossy Magazine \\
\hline $5 c$ & U.S. Currency & $6 \mathrm{~A}$ & Stamp & $6 \mathrm{~B}$ & Address Label & $6 \mathrm{C}$ & Clear Packing Tape & $6 \mathrm{D}$ & Black Electrical Tape \\
\hline $6 \mathrm{E}$ & Duct Tape & $7 \mathrm{~A}$ & Circuit Board & $7 \mathrm{~B}$ & $\mathrm{CD} / \mathrm{DVD}$ & $7 \mathrm{C}$ & Clear Plastic Bag & $7 \mathrm{D}$ & Black Plastic Bag \\
\hline
\end{tabular}




\section{Skilled Operator}

A individual with expert knowledge on fingerprint image quality that operates a fingerprint capture device. When capturing a rolled fingerprint, the individual holds the hand of the subject and physically performs the rolling action.

\section{Study Participant}

An individual recruited for the Nail to Nail Fingerprint Challenge who provided their fingerprints to all Challengers.

\begin{tabular}{|c|c|c|c|c|c|c|c|c|c|}
\hline$\Omega$ & FBI Baseline & $\begin{array}{l}A \\
E\end{array}$ & $\begin{array}{l}\text { IDEMIA } \\
\text { Jenetric }\end{array}$ & $\begin{array}{l}\mathrm{B} \\
\mathrm{F}\end{array}$ & $\begin{array}{l}\text { Advanced Optical Systems } \\
\text { Touchless Biometric Systems }\end{array}$ & $\begin{array}{l}C \\
G\end{array}$ & $\begin{array}{l}\text { Green Bit } \\
\text { Crossmatch }\end{array}$ & $\begin{array}{l}\mathrm{D} \\
\mathrm{H}\end{array}$ & $\begin{array}{l}\text { Cornell University } \\
\text { Clarkson University }\end{array}$ \\
\hline 1A & Peering Into Window & $1 \mathrm{~B}$ & Fist Banging on Glass & $1 \mathrm{C}$ & Fingertip Window Slide & 10 & Get-away Palm on Glass & $1 \mathrm{E}$ & “OK” Sign on Glass \\
\hline $1 \mathrm{~F}$ & Counter Vault on Glass & $1 \mathrm{G}$ & Cylinder Grab & $1 \mathrm{H}$ & Impatient Tapping on Glass & $2 \mathrm{~A}$ & Samsung Galaxy S5 & $2 \mathrm{~B}$ & Apple iPhone 5s \\
\hline 3 & Check & $4 \mathrm{~A}$ & Lined Paper & $4 \mathrm{~B}$ & Low-quality Copy Paper & $4 \mathrm{C}$ & High-quality Copy Paper & $4 \mathrm{D}$ & Yellow Lined Paper \\
\hline $4 \mathrm{E}$ & Low-quality White Envelope & $4 \mathrm{~F}$ & Greeting Card and Envelope & $4 \mathrm{G}$ & Manila Envelope & $5 \mathrm{~A}$ & Photo Paper & $5 B$ & Glossy Magazine \\
\hline $5 c$ & U.S. Currency & $6 \mathrm{~A}$ & Stamp & $6 \mathrm{~B}$ & Address Label & $6 \mathrm{C}$ & Clear Packing Tape & $6 \mathrm{D}$ & Black Electrical Tape \\
\hline $6 \mathrm{E}$ & Duct Tape & $7 \mathrm{~A}$ & Circuit Board & $7 \mathrm{~B}$ & $\mathrm{CD} / \mathrm{DVD}$ & $7 \mathrm{C}$ & Clear Plastic Bag & $7 D$ & Black Plastic Bag \\
\hline
\end{tabular}

